Percepciones de los profesionales y las autoridades competentes sobre el proceso de protección integral en el Sistema de Responsabilidad Penal para Adolescentes (SRPA)

Trabajo de grado para optar al título de Magister en Psicología Jurídica

\author{
Julián Contreras Cortés
}

Directora

Lizette Duque Cruz

Universidad Santo Tomás

División Ciencias de la Salud

Facultad de Psicología

Maestría en Psicología Jurídica

Bogotá, D.C. Noviembre de 2017 


\section{Tabla de Contenido}

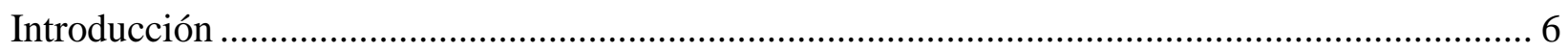

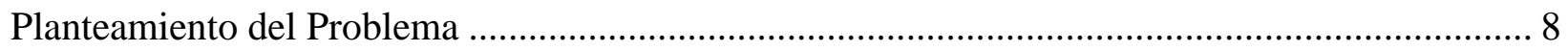

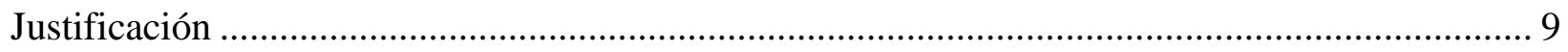

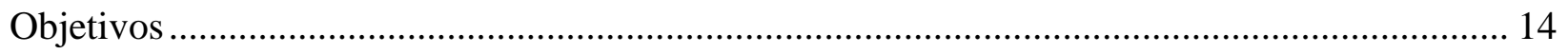

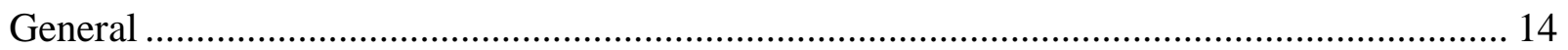

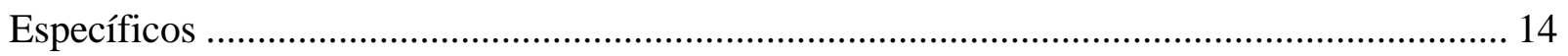

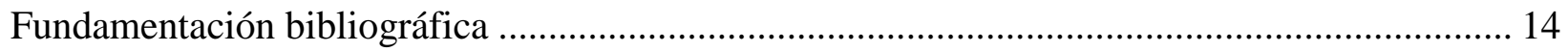

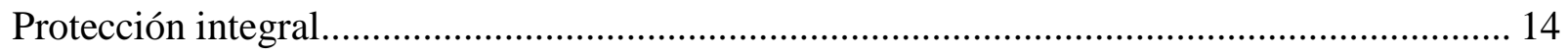

Proceso Administrativo de Restablecimiento de Derechos (PARD) .................................... 15

Obligación Del Restablecimiento De Los Derechos De Los Niños, Las Niñas Y Los

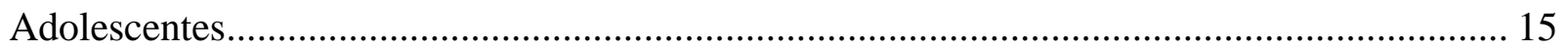

Conducta delictiva en adolescentes. ........................................................................... 16

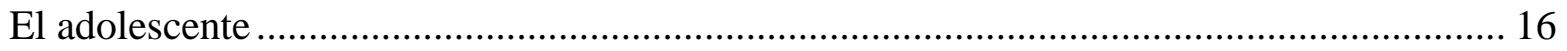

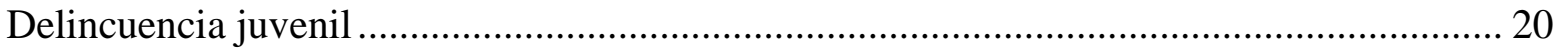

Teorías criminológicas sobre la delicuencia juvenil.................................................. 24

Modelo Integrado de la Conducta Delictiva ................................................................... 27

Sistema de Responsabilidad Penal para Adolescente SRPA ........................................... 39

Evolución del sistema penal para adolescentes .......................................................... 39

Estructura del Sistema de Responsabilidad Penal para Adolescentes .............................. 46

Las sanciones como medidas de Restablecimiento de Derechos en el SRPA..................... 50

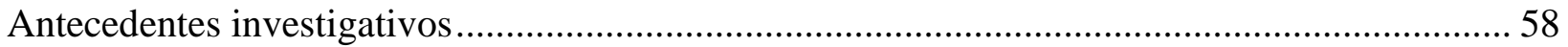




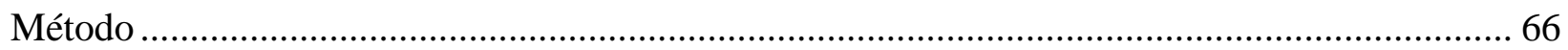

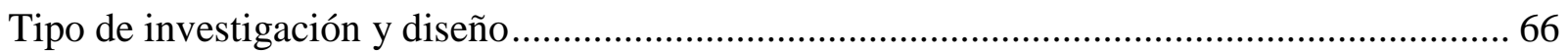

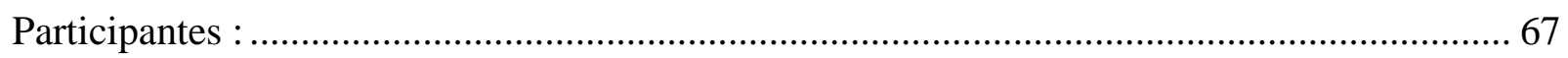

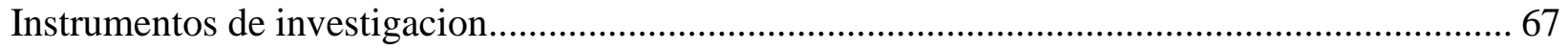

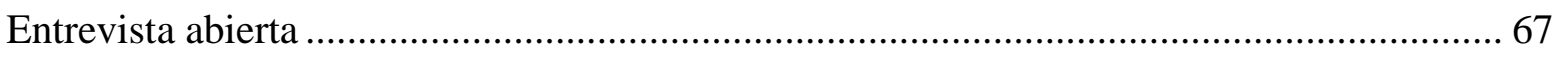

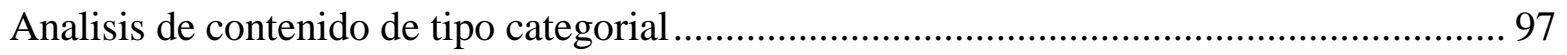

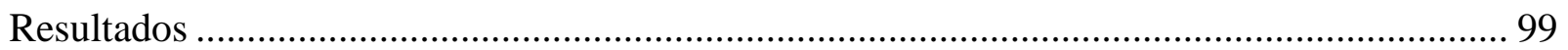

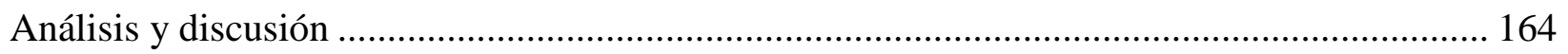

Principios de la Protección integral en el Sistema de Responsabilidad Penal para adolescentes

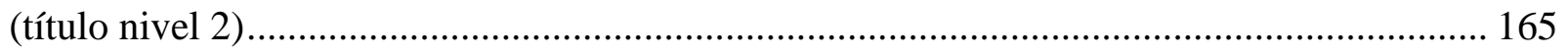

Proceso Administrativo de Restablecimiento de Derechos en el Sistema de Responsabilidad para

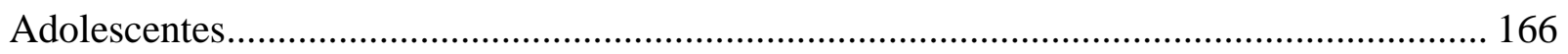

Garantías de derechos en el Sistema de Responsabilidad Penal para Adolescente ............... 169

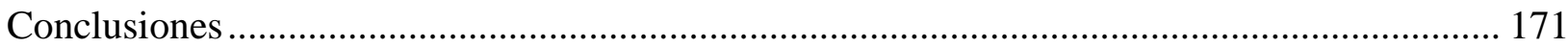

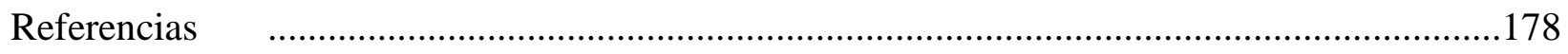


Lista de Tablas

Tabla 1. Sanciones en SRPA, las cuales vienen contempladas en la( Ley 1098 de 2006)... 53

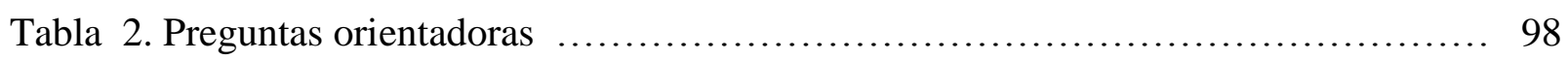

Tabla 3. Definición de categorías y subcategorías deductivas ....................... 102

Tabla 4. Matriz análisis categorial Principios de la Protección integral en el Sistema

de Responsabilidad Penal para adolescentes .................................. 103

Tabla 5. Matriz sobre el proceso administrativo de Restablecimiento de Derechos en

el Sistema de Responsabilidad para Adolescentes ............................... 131

Tabla 6. Matriz Garantías de derechos en el Sistema de Responsabilidad Penal para

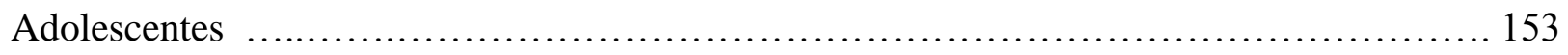




\section{Lista Figuras}

Figura 1. Componente conceptual del proceso de gestión de responsabilidad penal .... 46

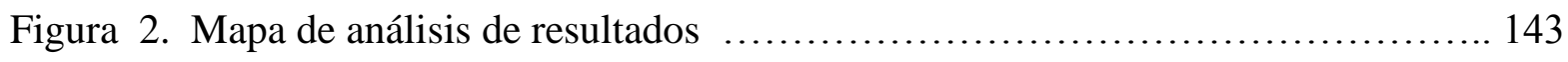




\section{Introducción}

El presente trabajo de grado tiene la intención de determinar en qué medida el Sistema de Responsabilidad Penal para Adolescentes SRPA resulta garante en la protección integral de derechos y restablecimiento de derechos en favor de los adolescentes para atender algunas problemáticas sociales.

Inicialmente, se identificará el contexto social del adolescente, lo cual permitirá vislumbrar, si este es predisponente a factores de riesgo, que lo avoquen a participar de eventos delictivos. Posteriormente se realizará una revisión de la norma existente, su enfoque restaurativo y de restablecimiento de derechos. Estos dos componentes permitirán determinar si realmente se cumple con las garantías de la protección integral y el restablecimiento de Derechos en favor de los adolescentes.

Históricamente la sociedad en representación del Estado ha venido soportando la carga en los eventos delictivos, protagonizados por adolescentes como participes o líderes de estas acciones. En cabeza del Estado y la Administración de Justicia, han propiciado la creación de instrumentos legales y políticas públicas, para abordar y contrarrestar esta situación de carácter social. Se han realizado diversos estudios e investigaciones en la búsqueda de las causas generadoras de esta problemática, encontrando factores como la globalización, el cambio de las dinámicas económicas, el bajo nivel educativo entre otros.

Con la instauración de la de la ley 1098 de 2006, se busca promover un sistema de normas basadas en la justicia restaurativa, el restablecimiento de derechos y la garantía de los mismos, por parte de los organismos estatales. Para obtener los resultados esperados en esta investigación, se 
considera que la consulta a expertos en este tema, y que son los encargados de garantizar la protección integral y el restablecimiento de derechos en favor de los Adolescentes, en representación del Estado, de sus relatorías y respuestas más acertada determinaran las causas reales que impiden una verdadera reinserción social del adolescente.

En el libro II del Código de Infancia y adolescencia, de la ley 1098 de 2006, se establecen las directrices para el tratamiento que la norma penal, debe imprimirles a los procesos en los cuales son participes los adolescentes. La misma norma señala, cuáles son las autoridades competentes para atender esta situación, la cual debe tener un carácter prevalente de derechos, teniendo encuentra el interés superior del niño, niña o adolescente. Se habla de justicia restaurativa, de garantía de derechos y de restablecimiento de los mismos en el caso de estar vulnerados. El solo hecho que un adolescente entre en conflicto con la ley penal, nos encamina a determinar, si las acciones tomadas en su momento están restableciendo sus derechos, para el presente trabajo se considera relevante, analizar las opiniones y conceptos del equipo interdisciplinario, encargado de garantizar estos derechos, en la medida que son los profesionales que están involucrados en este proceso y que son los llamados por la norma, la sociedad y la familia, para restablecer los derechos ya vulnerados. Por este motivo en el presente trabajo, pretenderemos resolver estas dudas realizando entrevistas a estos profesionales y autoridades competentes, expertos en temas de atención a los adolescentes que de una u otra manera se ven incursos en la norma penal para esta población.

Se procura con esta investigación, determinar, en qué medida el Estado es garante de derechos y en la protección integral y el restablecimiento de derechos dentro de las acciones implementadas en el proceso. Y en qué medida estas acciones han sido restrictivas o restaurativas 
como lo establecen los cánones legales nacionales e internacionales en temas de infancia y de adolescencia.

\section{Planteamiento del Problema}

La normatividad existente en materia de Delincuencia de adolescentes establece que debe ser pedagógica, específica y diferenciada, ajustadas a la protección integral. En Colombia, comenzó a implementarse el Sistema de Responsabilidad Penal para Adolescentes en el año 2007, pasando por tímidos procesos de revisión y ajustes. Llegando a la conclusión que las medidas a aplicarse deben ser desde la óptica de una justicia restaurativa y de restablecimiento de derechos; que involucren tanto al adolescente como a la víctima, otorgando a ambos la oportunidad de resarcir el daño causado, no solo a la víctima sino también al adolescente y a la sociedad. A la víctima por ser blanco directo del delito, al adolescente por estar incurso en situaciones delincuenciales a corta edad (Lo cual lleva intrínseco una vulneración de derechos) y a la sociedad, porque los adolescentes son el pilar en la construcción social de un país en vías de desarrollo como Colombia.

En el presente trabajo se pretende dilucidar si los principios restauradores y el carácter pedagógico, específico y diferenciado de esta norma en Colombia, están dando los resultados esperados y causando el impacto de minimizar o contrarrestar el acceso de adolescentes a la vida delictiva. Para lograr resolver este cuestionamiento se considera que los actores involucrados tienen la respuesta más acertada; en este caso, las personas que la ley inviste de figuras de autoridad para atender y articular las entidades que conforman el sistema penal de adolescentes.

Precisado lo anterior, se considera fundamental, identificar mediante este proceso investigativo: ¿Cuáles son las percepciones de los profesionales y las autoridades competentes 
sobre el proceso de protección integral en el Sistema de Responsabilidad Penal para Adolescentes (SRPA) en el delito?.

Estos actores, permitiran contextualizar la aplicabilidad que se esta imprimiendo a la normatividad y si la misma, esta dando respuestas estructurales que conlleven a desarticular la participacion de adolescentes en actos delictivos, de igual forma brindará los argumentos para determinar si el Estado está brindando las garantías al adolescente en conflicto con la ley penal, para un verdadero restablecimiento de derechos.

\section{Justificación}

De acuerdo a reportes del Observatorio del Bienestar a la Niñez y Adolescencia del Instituto Colombiano de Bienestar Familiar, los principales delitos que vinculan a los adolescentes al Sistema de Responsabilidad Penal son: Tráfico, fabricación o porte de estupefacientes; hurto, en todas sus modalidades; lesiones personales y fabricación, tráfico, porte o tenencia de armas de fuego, o municiones. (Observatorio de la niñez y de la adolescencia julio de 2017)

Sanabria y Uribe (2010), en su investigación titulada: Problemáticas en jóvenes infractores y no infractores en Colombia, encontraron que los adolescentes tienen una mayor propensión a la delincuencia ante la imposibilidad de alcanzar legalmente sus metas y objetivos en el ámbito escolar y social. Esta propensión se encuentra presente cuando los adolescentes perciben como pobre su desempeño académico, y además presentan inasistencia escolar generando mayor cantidad de tiempo libre que puede ser invertido en comportamientos problemáticos como la vinculación a pandillas. Ahora bien, Sanabria y Uribe (2009), agregan que la persistencia de algún tipo de comportamiento ya sea desviada o no durante un periodo de la adolescencia pueden ser 
altos predictores de problemáticas de ajuste psicológico individual y social, incluyendo el comportamiento delincuencial durante la edad adulta productiva.

Adicionalmente, Sanabria y Uribe (2010) mencionan que estos riesgos y la delincuencia en adolescentes genera en la sociedad un ambiente diario de impunidad, años de escolaridad y vida productiva desperdiciados, elevados costos económicos y demandas para la atención de las emergencias que brotan de la delincuencia, además de incapacidades y discapacidades prolongadas. Este tipo de comportamiento, según estas autoras, representa para la sociedad, de acuerdo a los estudios realizados en el área de la delincuencia juvenil, un alto costo, debido al impacto que posee la delincuencia en el núcleo familiar, relaciones interpersonales, proyecto de vida y pérdida de tiempo productivo.

La prevalencia del comportamiento delictivo en la juventud es uno de los indicadores para la planificación de programas orientados a la prevención y/o rehabilitación de este comportamiento. De esta forma, el conocimiento que puede generar su estudio es relevante ya que permite el conocimiento de las particularidades de la población juvenil respecto a la emisión de comportamientos delincuentes y así mismo plantear su prevención y/o rehabilitación. Condicionando la importancia en el estudio específicamente del tipo de acto delictivo, la edad y el sexo de las poblaciones juveniles que se encuentran manifestando esta conducta. Teniendo en cuenta las implicaciones individuales, sociales y económicas que se presentan, generando una alarma social, que involucra a instituciones privadas y no privadas, y en consecuencia su atención en el asunto (Sanabria y Uribe, 2010).

En Colombia el adolescente infractor ha sido objeto de tratamiento legal desde el siglo XIX, atendiendo la necesidad de reglamentar el procedimiento que debía seguirse frente a sus actos que comportaban infracciones a la ley y las buenas costumbres y por ello en 1837 fue expedido el 
llamado Código de Santander, en el cual se estableció que el menor de 7 años que transgredía la ley se entendía como absolutamente inimputable, quienes se encontraban entre los 7 y 10 años eran sometidos a medidas correctivas por parte de sus padres y amonestados por la autoridad, en tanto que aquellos que no fueran mayores de 17 años y atendiendo a su conducta anterior, se remitían a una casa de reclusión en un tiempo fijado por el Juez. (García y Carranza, 1990)

Posteriormente a través de la Ley 98 de 1920, se crearon los Jueces de Menores, cuya función principal era determinar la consecuencia específica que debían afrontar los menores con problemas de conducta, considerando inimputables a quienes se encontraban entre los 7 y 17 años, estas concepciones fueron incluidas dentro de la Ley 95 de 1936, Código de Procedimiento Penal. ( El Código del Menor -Decreto 2737 de 1989)

La Ley 83 de 1946 creó la jurisdicción de menores, los cuales siguiendo el modelo señalado se consideraron responsables frente a los actos que vulneraban los bienes jurídicos tutelados en la ley penal, tanto así que fueron instituidos establecimientos propios para su reeducación, contando con apoyo de grupos interdisciplinarios que aplicaban medidas de asistencia y protección.

En el año 1964 el legislador tuvo que entrar a definir el trato que debía adoptarse respecto de los menores de 12 años y de quienes se encontraban entre los 12 y 18 años de edad, advirtiendo que en cada caso debía ser atendido por una autoridad diferente, para el primer grupo se debía dar un trato eminentemente administrativo, en tanto que para los segundos la competencia radicaba en los Jueces de Menores.

En ese sentido se le otorgó la obligación de fijar este procedimiento al Instituto Colombiano de Bienestar Familiar, a través de los defensores de familia, creado mediante le Ley 75 de 1968; más adelante se expide el Decreto 2737 de 1989 conocido como Código del Menor, que básicamente retrotrae los avances frente a la responsabilidad penal que se le había conferido al 
menor infractor, para denominarlo nuevamente como inimputable, siendo uno de los aspectos a tener en cuenta para ubicarlo en una situación irregular, al considerarlo equivalente a un menor en condiciones de abandono o peligro, con insatisfacción de necesidades básicas o con deficiencia física, sensorial o mental, entre otros, por lo que el menor de 18 años debía acudir ante la Jurisdicción de Menores o ante el Juez Promiscuo de Familia, quienes decidían si debía recibir una sanción, siendo la mínima la amonestación

En lo que respecta a la aplicación del Sistema se advierte que la Corte Suprema de Justicia ha manifestado: "El Código de la Infancia y la Adolescencia contenido en la Ley 1098 de 2006, conforme lo dispuesto en el artículo $1^{\circ}$ (finalidades), tiene como marco armonizador, el garantizar a los niños, las niñas y a los adolescentes su pleno y armonioso desarrollo para que crezcan en el seno de la familia y de la comunidad rodeados de un ambiente de felicidad, amor y comprensión en el cual prevalezca el reconocimiento a la igualdad y la dignidad humana, sin discriminación de especie alguna" (Corte Suprema de Justicia, Proceso № 33702, M.P. Javier de Jesús Zapata, 09/12/2010).

Los casos que se atienden en los centro zonales especializados llevan a pensar que el ambiente en que se desarrollan los jóvenes de hoy en Bogotá carecen en gran parte de las posibilidades señaladas en la mencionada sentencia probablemente por las fallas o lagunas en que vienen incurriendo las familias por ser ajenos a su papel de corresponsabilidad frente a los jóvenes adolescentes asumiendo estilos familiares o patrones de conducta equívocos que son asumidos como correctos por los adolescentes. En ese contexto, debido a la percepción de inseguridad ciudadana originada en la comisión de delitos por parte de adolescentes es necesario mantener un código que establezca adecuadas correcciones como medidas regulatorias conforme a una ciudad como Bogotá. Hoy las dificultades respecto a la inseguridad generada por la delincuencia juvenil 
no son mayores que las de antes, actualmente se evidencian porque existen más posibilidades de socialización, lo que facilita que el joven se integre en pandillas o grupos organizados al margen de la ley; otro aspecto por tener en cuenta es el papel que desempeñan los medios de comunicación al destacar el accionar de las pandillas o los grupos delictivos, lo que en ocasiones sirve para magnificar al joven criminal.

La capital del país, continúa siendo la ciudad con más alto índices de aprehensiones realizadas, en lo que va corrido de la implementación del Sistema de Responsabilidad Penal de Adolescentes. Siendo Bogotá la capital de Colombia, de acuerdo a proyección realizada por la Secretaria de Planeación Distrital, cuenta para 2016 con 7.980.001 habitantes, según esta misma proyección por rangos de edades entre 10 y 14 años cuenta con 603.336 y entre 15 y 19 años 637.600 habitantes. La franja etaria de proyección no estipula específicamente el grupo de adolescentes entre 14 y 18 años de edad. Sin embargo, tomando como base el dato de la edad entre 15 y 19 años, y comparándolo con el número de aprehensiones por infringir la ley penal (55.209) el panorama resulta extremadamente preocupante. (Consejo Superior de la Judicatura, Sala Administrativa, Dimensión Psicológica y Pedagógica en el SRPA, Miguel Cote Menéndez, 2010, página 57)

Hay un alto índice de adolescentes que han ingresado al Sistema de Responsabilidad Peal, durante el periodo 2007 a mayo de 2016, está en distritos judiciales donde es más alta la densidad de población adolescente, la mayoría son hombres (47.259 casos), contra 7950 casos femeninos. El rango de edad con mayor índice de ingresos es 17 años, con 18.851 casos de aprehensiones en flagrancia, seguido de los adolescentes de 16 años con 15.980 ingresos. Son relevantes los ingresos de niños de 14 años cuyos datos indican 6769 ingresos. (Consejo Superior de la Judicatura, Sala 
Administrativa, Dimensión Psicológica y Pedagógica en el SRPA, Miguel Cote Menéndez, 2010, página 57)

\section{Objetivos}

\section{General}

Comprender las percepciones de los profesionales y las autoridades competentes sobre la protección integral en el Sistema de Responsabilidad Penal para Adolescentes (SRPA).

\section{Específicos}

- Identificar los principios fundamentales de la protección integral en Sistema de Responsabilidad Penal para Adolescentes, desde los profesionales y las autoridades competentes.

- Describir el Proceso Administrativo de Restablecimiento de Derechos (PARD) en el Sistema de Responsabilidad Penal parar Adolescentes desde las percepciones profesionales y autoridades competentes.

- Establecer las garantías que ofrece el SRPA para la protección integral del adolescente, desde las percepciones de los profesionales y autoridades competentes.

\section{Fundamentación bibliográfica}

\section{Protección integral}

En Colombia, los adolescentes tienen protección integral, lo cual significa satisfacción plena de sus derechos y la garantía de su cumplimiento por parte de la familia, la sociedad y el estado. Se debe garantizar además la prevención de su vulneración y su restablecimiento inmediato en caso de haber sido vulnerados. 
Se entiende por protección integral de los niños, niñas y adolescentes el reconocimiento como sujetos de derechos, la garantía y cumplimiento de los mismos, la prevención de su amenaza o vulneración y la seguridad de su restablecimiento inmediato en desarrollo del principio del interés superior.

La protección integral se materializa en el conjunto de políticas, planes, programas y acciones que se ejecuten en los ámbitos nacional, departamental, distrital y municipal con la correspondiente asignación de recursos financieros, físicos y humanos. (Código de Infancia y Adolescencia. Ley 1098 de 2006)

\section{Proceso Administrativo de Restablecimiento de Derechos (PARD)}

Se entiende por restablecimiento de los derechos de los niños, las niñas y los adolescentes, la restauración de su dignidad e integridad como sujetos y de la capacidad para hacer un ejercicio efectivo de los derechos que le han sido vulnerados. (Código de Infancia y Adolescencia. Ley 1098 de 2006)

\section{Obligación del restablecimiento de los derechos de los niños, las niñas y los} adolescentes.

El restablecimiento de los derechos de los niños, las niñas o los adolescentes es responsabilidad del Estado en su conjunto a través de las autoridades públicas, quienes tienen la obligación de informar, oficiar o conducir ante la policía, las defensorías de familia, las comisarías de familia o en su defecto, los inspectores de policía o las personerías municipales o distritales, a todos los niños, las niñas o los adolescentes que se encuentren en condiciones de riesgo o vulnerabilidad. Cuando esto ocurra, la autoridad competente deberá asegurarse de que el Sistema 
Nacional de Bienestar Familiar garantice su vinculación a los servicios sociales. (Art.50. Código de Infancia y Adolescencia. Ley 1098 de 2006).

\section{Conducta delictiva en adolescentes.}

A fin de tener un acercamiento a los procesos de incursión de un adolescente en situaciones delictivas, es pertinente conocer, diferentes conceptos teóricos de esta etapa del ciclo vital. Revisaremos diferentes definiciones y causales de conductas que conllevan a un adolescente a entrar en conflicto con la ley penal.

\section{El adolescente}

La adolescencia, es una etapa del ciclo vital que la sociedad occidental plantea como fase de transición en el desarrollo de la personalidad, en la que se produce un abandono del mundo de la infancia para dar paso a nivel psicológico y social al ciclo de la adultez (Alarcón, 2005). Una de las características descritas de este periodo por parte de Erikson (1969), es la constante búsqueda y limitación de la identidad. En el mismo sentido, Castillo (1992) plantea que la adolescencia por ser una fase transitoria puede ser dividida al menos en tres ciclos diferentes, tales como: (a) adolescencia inicial (11-13 años), que se caracteriza por el inicio del proceso que tendrá no menos de 10 años de duración, en la que un sujeto podrá experimentar variados cambios biológicos, sociales, cambios que conllevaran a la reorganización interna y externa del individuo y por consiguiente cierta inestabilidad emocional. (b) Alrededor de los 13 a 16 años, se da inicio a la adolescencia media con la capacidad de descubrir el sí mismo y un serio cuestionamiento a las acciones realizadas por la estructura social en la que se encuentra inmerso.

Los adolescentes, se encuentran en un momento evolutivo del desarrollo humano que tiene características particulares y que entran en interacción con el contexto. Según la Organización Mundial de la Salud (2000), la adolescencia es un periodo evolutivo del ser humano, comprendido 
entre los 10 a 19 años y caracterizada por un sinnúmero de cambios biológicos, psicológicos y sociales. Esta etapa ha sido considerada según Muñoz (2000), como una fase crítica en el desarrollo intermedio entre las etapas de la niñez y la adultez de un individuo, por los conflictos éticos, sociales y de autoridad que se presentan en ella.

Dicho proceso, se pone en marcha ya que el adolescente busca darle un sentido tanto a las acciones propias como las observadas externamente y es en este punto en donde se hace más evidente los niveles de agresividad y el sistema de valores entra en juego, por los niveles hipercríticos que se ponen en marcha ante diversas acciones. Por último, la tercera etapa comprendida entre los 17 y 21 años, se define como el momento en donde el mundo interior que ha Estado en caos, inicia un proceso del restablecimiento del orden, conllevando al establecimiento de su ética y la diferenciación del sí mismo en relación con su integración en la sociedad.

Asimismo, la Organización Mundial de la Salud (2000), precisa que la adolescencia es un periodo entre los 11 y 19 años, en las que se consideran que el individuo atraviesa dos etapas: adolescencia temprana 12 a 14 años y la adolescencia tardía 15 a 19 años. Cada etapa, se distingue por los cambios a nivel biológico, fisiológico, psicológico y social.

Hay que tener en cuenta que la cultura y la georreferenciación es un factor que cambia circunstancias en el curso o desarrollo de esta etapa de la vida, en el caso de Colombia, se vive un conflicto de guerra interna alzada en armas desde hace más de 50 años que se ha insertado en la cultura y el desarrollo de la sociedad colombiana con aspectos diferenciales en percepción de seguridad, formas alternativas de conflicto y otros aspectos que marcan una diferencia en el desarrollo de la adolescencia de los Colombianos. Sin embargo, existen algunas características inherentes de este periodo evolutivo, tales como: cambios físicos y psicológicos, inseguridad, 
inestabilidad emocional, crisis, conflictos con estructuras sociales, las cuales se producen dentro de un escenario de búsqueda de independencia, poder y autonomía (Gómez 2007).

En esta etapa del desarrollo los aspectos personales también cambian, por eso para Lozano, Torres y Olivas (2010) la pubertad y la adolescencia son etapas de crecimiento acelerado. En este periodo, los jóvenes desarrollan mayor autonomía y el aprendizaje de nuevos roles. De igual manera, someten a juicio los hábitos y estilos de vida aprendidos desde la infancia, exploran nuevas sensaciones, ponen a prueba los límites familiares, sociales, aumenta la impulsividad y adoptan conductas de riesgo entre las que se puedan encontrar los actos descriptivos y violentos, la comisión de infracciones y los actos delictivos.

Estas conductas que pueden convertirse en infracciones a la ley se relacionan con la agresividad, que para Peña (2010) durante la adolescencia los niveles de agresividad suelen elevarse y esta puede tener su etiología en factores tanto biológicos como sociales. La agresividad es una variable relacionada con los adolescentes infractores. Peña (2010) define la agresividad como una disposición persistente a ser agresivo en diversas situaciones, indica la actitud o inclinación que siente una persona o un colectivo humano a realizar un acto agresivo. La agresividad suele ser concebida como una respuesta adaptativa que forma parte de las estrategias de afrontamiento de los seres humanos a las amenazas externas.

Se encuentra entonces la agresividad como una estrategia de afrontamiento ante amenazas externas, que como se ha mencionado anteriormente, para los adolescentes las amenazas son muchas que provienen del medio exterior y de su parte interior, como lo son la toma de decisiones, asumir una identidad y ser independiente.

Para Lillo (2004) la adolescencia es una fase de transición entre un estadio, el infantil, para culminar en el adulto. En esta etapa se da una elaboración de la identidad de cada menor que se 
verá reflejada en la vida adulta, esto implica un camino lento y lleno de dificultades que hacen de la adolescencia un árbol lleno de esfuerzos por resolver los retos que generan el crecimiento y poder alcanzar la etapa adulta. En los cambios corporales se encuentra el crecimiento físico y endocrino que propicia unas modificaciones corporales que culminarán en la consolidación de un cuerpo adulto y facilitarán la aparición de los caracteres sexuales diferenciados en el varón y en la mujer. Aparecen por primera vez manifestaciones de la capacidad reproductiva del ciclo menstrual y la primera emisión seminal.

A nivel social, los cambios que se presentan continúan su relación con el cambio de la niñez a la adultez, los roles desempeñados están más definidos y de límites menos precisos y variables según el contexto cultural, adquiriendo así un nuevo status social, e incluye la mente, el cuerpo y las relaciones con su medio social en su estatus de ciudadano de la comunidad donde vive, se le pide que se comporte como un adulto, aunque aún no se le reconoce esa cualidad. Los procesos psicológicos tienen que ver con las dificultades para aceptarse que se proyectan en el cuerpo, en su apariencia y en acomodación sexual, afectando la autoestima y generando sentimientos intensos de frustración (Lillo, 2004).

Las relaciones también cambian, con los padres se pasa de una dependencia emocional infantil a uno de mayor independencia afectiva, en el que el adolescente adquiere conciencia de que sus pensamientos y sentimientos independientemente de que puedan pensar o hacer sus padres, por esto se adquiere conciencia de tener una vida íntima. Con el grupo de pares se nota que se amplía el grupo de amigos o se profundizan las relaciones en una búsqueda conjunta de identidad (Lillo, 2004). 


\section{Delincuencia juvenil}

Teniendo en cuenta las descripciones anteriores sobre adolescencia como etapa evolutiva de todos los seres humanos, pero que es vivida de forma particular por cada persona y está influenciada por factores externos e internos y las dificultades que se puedan presentar, a continuación, se hará un recorrido por la delincuencia juvenil y los adolescentes infractores.

La delincuencia juvenil, al igual que la delincuencia en la adultez, es fruto de diversas variables que interactúan entre sí. No se puede atribuir a una causa concreta ni se puede analizar de forma aislada. Por tanto, es un problema multidisciplinar y debe explicarse desde muchos puntos de vista (Defez, 2006).

Blanco y Varela (2011) mencionan también que la delincuencia juvenil se caracteriza también por la crisis de la adolescencia y en ocasiones se traduce en un acto iniciador, es decir, una forma en que los jóvenes reflejan que han crecido y son independientes de los adultos.

El fenómeno de la delincuencia juvenil ha tenido diversidad de definiciones sobre los adolescentes en conflicto con la ley. Sin embargo, para el caso de la legislación colombiana y el presente estudio, se adopta el planteado por Cruz y Cruz (2007) ya que diferencia el rango de edad a nivel sociológico y jurídico; el menor infractor es toda persona que no ha cumplido la mayoría de edad, que se caracteriza por realizar conductas tipificadas en la legislación penal, las cuales para el caso de los adolescentes no pueden llegarse aplicar desde la perspectiva de la pena, ya que el resultado del acto ilícito no puede justificarse como una conducta antijurídica, implicando que este sea sometido a un sistema de atención especial que garantice sus derechos.

Continuando con los aportes a la descripción de "menor infractor" se encuentra a Peña (2010), mencionando que un delincuente juvenil es un individuo que comete un hecho que está penalizado por las leyes y no posee la mayoría de edad penal. 
En el aspecto individual y psicológico de los adolescentes infractores de la ley, se encuentran aportes de Sanabria y Uribe (2009), quienes plantean que los adolescentes que muestran conductas antisociales, generalmente están caracterizados por presentar una transgresión de las leyes tanto en el colegio como en el hogar con comportamientos violentos repetitivas, que terminan en la comisión de delitos como hurto y se encuentra asociación con bandas criminales.

En síntesis las posturas de los autores mencionados anteriormente, tienen en cuenta un rango de edad para hablar de adolescente infractor como primer criterio de inclusión; además se encuentran características personales como bajo rendimiento escolar, agresividad y el grado de responsabilidad asumido por estos.

Los principales delitos que vinculan a los adolescentes al Sistema de Responsabilidad Penal para adolescentes son: Tráfico, fabricación o porte de estupefacientes; hurto, en todas sus modalidades; lesiones personales y fabricación, tráfico, porte o tenencia de armas de fuego, partes o municiones; a nivel nacional el porcentaje de reiteración del delito frente es de 19,96\%. (Policía Nacional Observatorio del delito, revista criminalidad volumen 54).

Lo anterior, aunque no es una situación nueva, se constituye como un fenómeno de alta relevancia social, judicial, económica y política, ya que se instala como una situación de gran importancia desde el siglo XIX debido al aumento en el número de casos y la reincidencia que ha generado cambios en las dinámicas de grupos delincuenciales que reclutan adolescentes y también el aumento en el número de pandillas juveniles. Esto envuelve a diferentes sectores e instituciones encargadas de abordar dicha situación por medio de políticas públicas que abarquen una intervención más allá de lo penal.

Sanabria y Uribe (2010), en su investigación titulada: Problemáticas en jóvenes infractores y no infractores en Colombia, encontraron que los adolescentes tienen una mayor propensión a la 
delincuencia ante la imposibilidad de alcanzar legalmente sus metas y objetivos en el ámbito escolar y social. Esta propensión se encuentra presente cuando los adolescentes perciben como pobre su desempeño académico, y además presentan inasistencia escolar generando mayor cantidad de tiempo libre que puede ser invertido en comportamientos problemáticos como la vinculación a pandillas. Ahora bien, Sanabria y Uribe (2009), agregan que la persistencia de algún tipo de comportamiento ya sea desviada o no durante un periodo de la adolescencia pueden ser altos predictores de problemáticas de ajuste psicológico individual y social, incluyendo el comportamiento delincuencial durante la edad adulta productiva.

Adicionalmente, Sanabria y Uribe (2010) mencionan que estos riesgos y la delincuencia en adolescentes genera en la sociedad un ambiente diario de impunidad, años de escolaridad y vida productiva desperdiciados, elevados costos económicos y demandas para la atención de las emergencias que brotan de la delincuencia, además de incapacidades y discapacidades prolongadas. Este tipo de comportamiento, según estas autoras, representa para la sociedad, de acuerdo con los estudios realizados en el área de la delincuencia juvenil, un alto costo, debido al impacto que posee la delincuencia en el núcleo familiar, relaciones interpersonales, proyecto de vida y pérdida de tiempo productivo.

La prevalencia del comportamiento delictivo en la juventud es uno de los indicadores para la planificación de programas orientados a la prevención y/o rehabilitación de este comportamiento. De esta forma, el conocimiento que puede generar su estudio es relevante ya que permite el conocimiento de las particularidades de la población juvenil respecto a la emisión de comportamientos delincuentes y así mismo plantear su prevención y/o rehabilitación. Condicionando la importancia en el estudio específicamente del tipo de acto delictivo, la edad y el sexo de las poblaciones juveniles que se encuentran manifestando esta conducta. Teniendo en 
cuenta las implicaciones individuales, sociales y económicas que se presentan, generando una alarma social, que involucra a instituciones privadas y no privadas, y en consecuencia su atención en el asunto (Sanabria y Uribe, 2010).

En Colombia el adolescente infractor ha sido objeto de tratamiento legal desde el siglo XIX, atendiendo la necesidad de reglamentar el procedimiento que debía seguirse frente a sus actos que comportaban infracciones a la ley y las buenas costumbres y por ello en 1837 fue expedido el llamado Código de Santander, en el cual se estableció que el menor de 7 años que trasgredía la ley se entendía como absolutamente inimputable, quienes se encontraban entre los 7 y 10 años eran sometidos a medidas correctivas por parte de sus padres y amonestados por la autoridad, en tanto que aquellos que no fueran mayores de 17 años y atendiendo a su conducta anterior, se remitían a una casa de reclusión por el tiempo determinado por el Juez.

Posteriormente a través de la Ley 98 de 1920, se crearon los Jueces de Menores, cuya función principal era determinar la consecuencia específica que debían afrontar los menores con problemas de conducta, considerando inimputables a quienes se encontraban entre los 7 y 17 años, estas concepciones fueron incluidas dentro de la Ley 95 de 1936, Código de Procedimiento Penal.

La Ley 83 de 1946 creó la jurisdicción de menores, los cuales siguiendo el modelo señalado se consideraron responsables frente a los actos que vulneraban los bienes jurídicos tutelados en la ley penal, tanto así que fueron instituidos establecimientos propios para su reeducación, contando con apoyo de grupos interdisciplinarios que aplicaban medidas de asistencia y protección.

En el año 1964 el legislador tuvo que entrar a definir el trato que debía adoptarse respecto de los menores de 12 años y de quienes se encontraban entre los 12 y 18 años de edad, advirtiendo que en cada caso debía ser atendido por una autoridad diferente, para el primer grupo se debía dar 
un trato eminentemente administrativo, en tanto que para los segundos la competencia radicaba en los Jueces de Menores.

En ese sentido se le otorgó la obligación de fijar este procedimiento al Instituto Colombiano de Bienestar Familiar, a través de los defensores de familia, creado mediante le Ley 75 de 1968; más adelante se expide el Decreto 2737 de 1989 conocido como Código del Menor, que básicamente retrotrae los avances frente a la responsabilidad penal que se le había conferido al menor infractor, para denominarlo nuevamente como inimputable, siendo uno de los aspectos a tener en cuenta para ubicarlo en una situación irregular, al considerarlo equivalente a un menor en condiciones de abandono o peligro, con insatisfacción de necesidades básicas o con deficiencia física, sensorial o mental, entre otros, por lo que el menor de 18 años debía acudir ante la Jurisdicción de Menores o ante el Juez Promiscuo de Familia, quienes decidían si debía recibir una sanción, siendo la mínima la amonestación.

\section{Teorías criminológicas sobre la delicuencia juvenil}

Garrido (1987, citado por Peña, 2010), define la conducta delictiva como una forma de desviación; un acto prohibido por las leyes penales de una sociedad. Teniendo en cuenta esto, debe existir una ley penal que prohíba dicha conducta. Se debe tener en cuenta que el delito es relativo, tanto en tiempo como en espacio, puesto que las leyes evolucionan, y lo que en in momento fue un delito, posteriormente puede que no lo sea, por ejemplo, el consumo o no de drogas ha cambiado en las legislaciones pasando de no admitir el consumo de sustancias psicoactivas de ninguna manera a reglamentar el uso de dosis mínimas como sucede con la marihuana.

Entonces, el delito y la conducta delictiva es un constructo jurídico legal, y se estructura a partir de un conjunto de acciones que están sancionadas en una ley penal, en congruencia, Redondo 
(2008) menciona que el comportamiento delictivo, es la materialización de un sinnúmero de actos lesivos y agresivos que buscan amenazar o atentar a otros individuos, bienes, para la obtención de algún tipo de beneficio o satisfacción.

Por su parte, Bartollas (2000), agrega que este tipo de comportamiento, se produce y mantiene en compañía de los vínculos sociales y las relaciones que se establecen de la misma, entendiendo que las relaciones establecidas con grupos de referencia como la familia, escuela y amigos, pueden ser influir de manera significativa en la estructuración de un futuro tipo de comportamiento delictivo.

El comportamiento delictivo y el trastorno antisocial son dos fenómenos diferentes que en ocasiones tienden a confundirse, Feldman (1989), plantearan diferencias entre el comportamiento delictivo y el antisocial, llegando a postular como el segundo podría llegar a determinar al primero, pues los comportamientos que son infracciones a las leyes pueden estar motivados por un grupo de factores internos y externos que se encuentren en el desarrollo del individuo y pueden terminar en un trastorno clínico antisocial.

Una vez realizada una aproximación al constructo de comportamiento delictivo, se realizará un acercamiento a las teorías criminológicas que describen la delincuencia.

Desde la criminología se presentan diversas concepciones y explicaciones que han surgido alrededor del delito y el comportamiento delictivo. La criminología surge en la academia como una disciplina que estudia el comportamiento delictivo, reacción social y los sistemas empleados para su control. Por ello, parte de la criminología se dedica al estudio y explicación de la delincuencia desde diversas teorías que intentan describir y definir este constructo (Garrido, Stangeland y Redondo, 2006). A continuación, se presentan diferentes posturas sobre el mismo. 
Existen varias teorías criminológicas que explican el comportamiento delictivo, para esta investigación se tendrá en cuenta la teoría integradora de la conducta puesto que es la que se ajusta a las acciones realizadas en este trabajo de investigación y la visión del adolescente infractor, pues tiene en cuenta los diferentes factores que intervienen en su comportamiento y de esta manera se puede realizar una intervención teniendo en cuenta los factores protectores y de riesgo.

La evolución de la Criminología, permitió establecer un conjunto de algunas modernas teorías integradoras que tiene como objeto el desarrollo de explicaciones de manera amplia y comprensiva sobre el fenómeno del delito. (Garrido, Stangeland y Redondo, 2006). De acuerdo a lo anterior, se plantean tres teorías que intentan dar una respuesta explicativa sobre la génesis de la delincuencia; teoría Multifactorial, teoría de rasgos latentes, teoría de las etapas vitales (Garrido, Stangeland y Redondo, 2006).

A continuación, se exponen desde cada teoría las premisas que explican la delincuencia: a) La teoría multifactorial, el origen de la delincuencia a la influencia de factores: personales, sociales y económicos; b) teoría de rasgos latentes, los individuos poseen ciertas características personales que los predispone frente a un mayor nivel de riesgo a llevar a cabo actos delictivos; c) teoría de las etapas vitales, al igual como el ser humano atraviesa por etapas evolutivas durante su vida y esto genera una serie cambios, paralelamente las variables que se asocian a la su conducta delictiva varían.

Andrews y Bonta (1994) afirman que, en el análisis del comportamiento delictivo, el ser humano no debe ser considerado como aislado, ya que vive, crece y se desarrolla dentro de un contexto interactivo y dinámico; es por esto que el ámbito académico, familiar, relación con el grupo de pares y la comunidad deban tenerse en cuenta como unidades que conforman el proceso de socialización. La teoría de la conducta delictiva planteada por parte de estos autores, se basa en 
el análisis de la acción con sus determinantes particulares desde el condicionamiento clásico y operante: recompensas, costos, antecedentes, y del aprendizaje socio cognitivo: control cognitivo de la conducta y significación clave de las creencias, actitudes y relaciones sociales.

A la hora de explicar, cómo el sujeto decide cometer un delito Andrews y Bonta, (1994) enuncian que el sujeto toma una decisión tendiente a la comisión de un delito cuando realiza una valoración de la situación y considera que es favorable y dentro de los caminos para involucrarse en la carrera delictiva se encuentran dos: las actitudes y las relaciones antisociales.

Una vez tenido en cuenta el proceso de toma de decisión para cometer un acto delictivo, las actitudes al delito también forman parte de ese proceso de decisión y son entendidas como valores y creencias pro criminales o anti criminales determinantes de la dirección que podría adoptar el control personal; representan la fuente de racionalizaciones y auto exculpaciones más importantes que la persona tiene disponible en cualquier situación. Las asociaciones antisociales con pares, familiares y significativos que modelan la situación de acción y gobernando las reglas por las que las recompensas y castigos son señalados y distribuidos (Andrews y Bonta, 1994).

\section{Modelo Integrado de la Conducta Delictiva}

Este modelo es el modelo explicativo que ha seleccionado esta investigación como estructura para comprender y describir el comportamiento de los adolescentes infractores de la ley, así como la manera de realizar intervenciones a nivel psicosocial. Se ha seleccionado este modelo ya que permite el reconocimiento del periodo evolutivo humano por el cual se encuentra atravesando la población objeto de estudio, además de entender desde diferentes perspectivas los comportamientos delictivos de los adolescentes y de esta manera se plantean las intervenciones psicosociales y las maneras de implementarlas. 
El comportamiento delictivo de un individuo, no puede ser entendido sin integrar y conocer de manera interrelacionada el contexto dinámico y estático en el que no sólo se ha desenvuelto el sujeto sino también en el que ha crecido y desarrollado, es decir, el fenómeno de la delincuencia no puede ser entendida sin tener en cuenta la persona, su ambiente y su conducta en un proceso de interacción en el que se evidencia una influencia recíproca (Andrews y Bonta, 2010).

La psicología de la conducta criminal es una teoría que plantean Andrews y Bonta (2010) con el objetivo de explicar la conducta criminal en los individuos, haciendo una búsqueda de una comprensión teórica, basada en la investigación y aplicación de la variación en el comportamiento criminal de los individuos.

La comprensión empírica de la conducta criminal no solo encuentra resultados observables sino también la naturaleza de la variación en la conducta criminal, esto tiene en cuenta las diferencias individuales en la historia criminal y los predictores de oportunidades o posibilidades futuras de emitir conducta criminal. Éstos predictores se llaman factores de riesgo ó necesidades criminógenas, además son dinámicos es decir cambian continuamente. Por el contrario, los factores protectores se relacionan con características de las personas y las circunstancias que las rodean que son asociadas con una menor probabilidad u oportunidad de ingresar en actividad criminal. En esta teoría se le da mucha atención al contexto como moderador de diferencias individuales (Andrews y Bonta, 2010).

En el aspecto familiar como factor de riesgo, un elemento que influye de manera significativa es la pobre vinculación afectiva, poca supervisión y bajo nivel de disciplina, se convierte en un riesgo no sólo a nivel psicológico sino social al aumentar las posibilidades del adolescente de asociarse con otras personas que hayan emitido conducta criminal. Otro aspecto de 
la familia es el modelo que representa para el niño, puede haber conductas antisociales aprendidas por el adolescente (Andrews y Bonta, 2010).

Las actitudes no son observables, pero son importantes para la conducta criminal y permiten ser predictor de oportunidad de incidir en conductas relacionadas con el crimen. Las actitudes antisociales son los pensamientos, sentimientos y creencias que apoyan la conducta criminal.

La evaluación de las actitudes antisociales se realiza por medio de afirmaciones ante las cuales la persona expresa acuerdo o desacuerdo, por ejemplo, indagar sobre si está de acuerdo con hacer trampa en la declaración de impuestos o indagar sobre lo que opina de si una persona merece ser golpeada solo porque otro está molesto. Otra forma de manifestar las actitudes antisociales es por medio de mecanismos como la naturalización, racionalización y excusas ante comportamientos antisociales, también se encuentra la evaluación favorable del comportamiento criminal (Andrews y Bonta, 2010).

Con esta teoría integradora de la conducta se han realizado estudios como el de Mulde, Brand., Bullen y Van (2010), quienes se enfocaron en realizar una clasificación de los infractores juveniles graves que se encontraban en un programa de tratamiento mediante el análisis de los factores de riesgo encontrando que la edad de inicio de la conducta criminal y persistencia en ella influye de gran manera para una reincidencia posterior. Adicionalmente se encuentra la conciencia de la infracción a la ley y empatía hacia el delito, los problemas familiares al momento de estar en el tratamiento. Asimismo, mencionan que los factores para la persistencia en la conducta delictiva en jóvenes infractores son: falta de pautas de crianza adecuadas, conducta antisocial en los padres, baja vinculación afectiva con padres, búsqueda de nuevas experiencias y sensaciones, rechazo por parte de los pares (Mulde et al, 2010). 
Otro hallazgo importante de los investigadores es sobre la reincidencia en adolescentes, afirman que se puede predecir la reincidencia a partir de la edad de inicio de la conducta criminal, entre menor sea esta, se aumenta el riesgo de persistencia en la conducta en la juventud y de reincidencia en la adultez (Mulde et al, 2010).

Para autores como Graña, Garrido y González (2008) y Blascos (2012) mencionan que las teorías criminológicas, permiten entrever cada una de las nociones de vulnerabilidad y exposición al riesgo en el que se puede llegar a encontrar inmerso cualquier individuo y por ende, tener cierta incidencia en la determinación de un tipo de comportamiento. Estas nociones de vulnerabilidad y de exposición han sido denominados factores, los cuales pueden llegar a constituirse como predisponentes para la aparición, mantenimiento o extinción de cierta conducta que puede ser aceptada o no a nivel socio-jurídico.

\section{Sobre los justificantes criminógenos y su relación con la intervención psicosocial, el}

\section{delito y su etiología}

Este concepto es el que junto a las teorías integradoras de la conducta se encuentran de forma trasversal en la investigación y guían el actuar metodológico y analítico para este trabajo puesto que guarda congruencia con la visión del adolescente infractor que no está determinado por factores externos e internos inmodificables que lo condenen a ser un delincuente sino que por el contrario se entiende como un ser humano que de manera particular tiene un conjunto de factores que interactúan entre si y se relacionan con la conducta delictiva pero también con la intervención psicosocial y comportamientos pro sociales. 
Los justificantes criminógenos son el conjunto de interacciones de vulnerabilidades y factores de protección que dan como resultado el proceso personal y particular de cada individuo, en adelante se mencionarán los diferentes factores que hacen parte de la descripción de la situación del adolescente infractor de la ley, se debe tener en cuenta que es la interacción de vulnerabilidades contextuales y personales las que resultan como justificantes criminógenas que serán la clave de la intervención psicosocial.

Los estudios realizados por Andrews y Bonta (2006) plantean que las necesidades criminógenas son todos aquellos predictores de oportunidades o posibilidades futuras de emitir conducta criminal que no son deterministas, pues son probabilidades de incidencia en la conducta infractora de la ley o no.

Es necesario aclarar que la valoración de cualquiera de los factores puede ser positiva o negativa, así un mismo factor podría hacer las veces de protección o de riesgo, esto depende no sólo de las diferencias individuales, sino también de las condiciones del entorno de cada individuo. Los factores no son entes que actúen por aparte o de forma individual, determinando la protección o el daño sufrido por las personas, es preciso que exista entre ellos una interrelación (Lozano, Torres y Olivas 2010).

Berkowitz (1996, citado por Peña, 2010), afirma que un factor de riesgo es una condición que aumenta la probabilidad de la ocurrencia de acciones agresivas, aunque no de forma invariable. También se entiende que son eventos que ocurren con anterioridad al inicio del problema y que aumentan la probabilidad de obtener el resultado posterior. Es importante aclarar que el que un individuo presente factores de riesgo no implica un determinismo para que vaya a desarrollar conductas problemáticas; significa exclusivamente que, se compara con un individuo sin la 
presencia de esos factores, tendrá una mayor probabilidad de llegar a implicarse en esas conductas. Por tanto, los factores de riesgo no son causas.

Por su parte, Lozano, Torres y Olivas (2010) refieren que los factores de riesgo proceden cuando las características individuales y las condiciones en que se realizan las actividades diarias incrementan la posibilidad de daño o probabilidad de aparición o permanencia de una conducta.

Un factor de protección es una característica individual que inhibe, reduce o atenúa la probabilidad del ejercicio y mantenimiento de las conductas antisociales. Los factores de riesgo y de protección son los extremos de un continuo, un mismo factor será protector o de riesgo según el extremo de la escala en que esté situado, sin embargo, la presencia o ausencia de los mismos no es una garantía de la presencia o ausencia de conductas antisociales, a mayor número de factores de riesgo habrá mayor probabilidad de aparición de conductas antisociales (Peña, 2010). Para Lozano, Torres y Olivas (2010) los factores de protección son actividades de un individuo que ayudan a fortalecer o mantener su seguridad además de inhibir, reducir o atenuar la probabilidad del ejercicio y mantenimiento de conductas peligrosas.

La persona, su ambiente y su conducta interactúan generando influencia recíproca, sin dejar de lado factores determinantes como los ambientales y sociales, estos factores guardan relación y es por ello que hace difícil establecer de manera independiente su influencia como factor de riesgo, para ello se generan diferentes variables que permitan describir mejor el fenómeno (Andrews y Bonta, 1994; citado por Graña, Garrido y González ,2008).

La presencia de diversos factores de riesgo puede producir un incremento de la frecuencia, intensidad y gravedad de las conductas antisociales, pudiendo así provocar en el mantenimiento persistente en estadios evolutivos más avanzados, apareciendo entonces, un patrón de comportamiento que va infringir o transgredir las leyes siendo denominados como crimen, delito 
o delincuencia como por ejemplo el robo, tráfico de drogas y homicidio. Los comportamientos antisociales sólo pueden ser entendidos desde una perspectiva multicausal, en la que confluyen factores de riesgo de diversa índole. Además, dichos factores no son estáticos, sino que están en continua interacción, afectándose mutuamente y, afianzando y realimentando (Peña, 2010)

Los factores de riesgo se dividen en: contextuales, individuales, biológicos, psicológicos, de socialización, escolares y de relación con los pares. En los contextuales se encuentran los siguientes: (a) el contacto con los medios de comunicación masiva y el aprendizaje vicario del uso de la violencia, además de su legitimación; (b) la zona o lugar de vivienda del joven; (c) el desempleo como situación en la que el individuo pierde contacto con la sociedad y sus valores además del uso del tiempo libre; (d) Variaciones culturales y étnicas por el cambio de leyes que rigen el comportamiento. En los factores individuales se encuentran las siguientes variables: (a) Hormonas, neurotransmisores y toxinas como niveles de testosterona; (b) funcionamiento del sistema nervioso y estudios neurofisiológicos; (c) Anomalías cromosómicas (d) La transmisión genética familiar de conductas agresivas. En los factores biológico-evolutivos se encuentra: (a) Diferencias asociadas al género, los varones tienen mayor propensión que las mujeres a cometer delitos violentos; (b) Diferencias asociadas a la edad, aparición temprana de comportamiento delictivo (Peña, 2010).

Los factores psicológicos son: (a) Hiperactividad, déficit de atención, impulsividad y toma de riesgos ya que desde temprana edad empiezan a influir en la toma de decisiones y el control de impulsos; (b) Desórdenes internalizan tés: nerviosismo / ansiedad y depresión por la co-morbilidad con trastornos de ansiedad y depresión.(c) Asociación con trastornos mentales, consumo de drogas, (d) Iniciación temprana en la violencia y delincuencia (e) Variables de personalidad, impulsividad, búsqueda de sensaciones, empatía, autoestima y agresividad (f) Actitudes y 
creencias (g) Recursos personales y valores ético-morales. Dentro de los factores de socialización se encuentra: (a) Criminalidad de los padres como factor familiar que genera modelos comportamentales (b) Maltrato infantil como riesgo para la comisión de conductas violentas y antisociales (c) Pautas educativas inadecuadas (d) Interacción padres-hijos (e) Apego familiar, el apego seguro se convierte en protección (f) Conflictos maritales (g) Actitud parental favorable hacia la violencia (h) Eventos familiares estresantes como transiciones y procesos vitales (i) Separación de los padres (j) Padres Adolescentes (k) el gran tamaño de la familia. Los factores escolares son los siguientes: (a) Fracaso académico (b) Apego escolar (c) ausentismo escolar (d) Elevada delincuencia y vandalismo en la escuela (e) Traslados del colegio (f) Aspiraciones o preferencias ocupacionales (Peña, 2010).

El factor en la relación con el grupo de iguales se observa: (a) Hermanos infractores (b) Compañeros infractores (c) Pertenencia a una banda o grupo organizado delictivo (Peña, 2010).

Otra de las clasificaciones de los factores es presentada por Lozano, Torres y Olivas (2010), quienes ubican los factores en cuatro categorías iniciales: factores individuales, familiares, de socialización y finalmente los ambientales o contextuales. Primero se encuentra los individuales dentro de los cuales se encuentra el género que se determina al interior de la familia cuando el niño es formado en valores, creencias y actitudes permitiendo la posterior identificación como hombre o mujer.

Adicionalmente se encuentra la edad, ya que la adolescencia ubica a los jóvenes en situaciones de riesgo por su desarrollo y sus necesidades individuales. Los mediadores biológicos con aspectos como presencia de Trastorno de atención e hiperactividad (TDAH), dificultades de aprendizaje y de comportamiento, de autocontrol, hasta baja tolerancia a la frustración. El último 
factor de los individuales es el psicológico y de socialización que se forma a partir de las pautas de crianza, rasgos de personalidad y pautas de afrontamiento.

Como segundo, se encuentran los factores familiares, conformados por el ciclo vital o fase evolutiva de la familia, la constitución familiar que puede ser nuclear, monoparental, adoptiva, reconstruida. En estos tipos de familia pueden surgir factores de riesgo o de protección dependiendo de la capacidad que tengan sus miembros para adaptarse a las normas de convivencia y asumir los roles que corresponden a cada cual. Siguiendo con los factores familiares el de las pautas de crianza cobra gran relevancia ya que puede ser autoritaria en donde no haya desarrollo de opiniones y libertades del niño, permisiva con ausencia de normas y límites, también se encuentra el indiferente en donde los cuidadores no se hacen cargo o se ocupan de la crianza del niño. La comunicación de la familia y el manejo de la economía también cobran importancia aquí.

El tercer factor que se encuentra en la clasificación es la socialización; aquí se encuentran descritas las relaciones sostenidas entre grupos como el escolar, lugar en donde se desarrolla no sólo el aspecto académico del adolescente sino también de relaciones sociales con figuras de autoridad y pares.

Finalmente, se encuentran los factores ambientales o contextuales, son los que cierran el listado de factores que se relacionan con los tipos de comportamientos que ejecutan los adolescentes, toda vez que el entorno en el que se desenvuelven también ejerce presión sobre el comportamiento y es un factor de riesgo que debe considerarse para prevenir conductas infractoras. En este ambiente se puede encontrar desorganización en el barrio, pobreza extrema, injusticia, alto grado de desempleo.

En relación con lo grupal, se observa que los centros educativos como primeras instituciones en las que se generan procesos de socialización de los adolescentes pueden 
convertirse en origen del comportamiento antisocial de los alumnos. Un ambiente escolar positivo permite relaciones pro sociales entre los diferentes miembros de la comunidad educativa. Lo anterior, debido a que es el colegio en donde los adolescentes aprenden, pero también es el escenario en donde se enfrentan al manejo de las relaciones sociales viéndose expuestos constantemente a variadas normas, reglas y costumbres del contexto escolar. Allí, se adquieren y se pueden mantener patrones de aprendizaje de comportamientos, que pueden terminar en conductas antisociales y delictivas (Sanabria y Uribe, 2010).

Ante la panorámica expuesta Lozano, Torres y Olivas (2010), postulan que uno de los detonantes de la conducta delictiva se circunscribe en las fallas que se originan en el proceso de socialización durante la etapa de la adolescencia, constituyendo un factor de riesgo que predispone el origen de la delincuencia, debido a la influencia determinante sobre las relaciones. Por tanto, una socialización inadecuada del adolescente debilita sus relaciones y la de los futuros jóvenes hacia grupos como la familia, la sociedad y el colegio. Por consiguiente, si se presentan fallas en este proceso el adolescente puede compensar esa falta de vínculos creándolos con otros grupos como pandillas que refuerzan las conductas delictivas.

Rodríguez (2009), agrega que otro posible detonante que puede constituirse como un factor de riesgo y de predisposición a la conducta delictiva, es el menor tiempo que se comparte entre padres e hijos, producto de los efectos que trae consigo la globalización en los estilos de vida. Esta situación, ha hecho que las personas adquieran ciertas rutinas en su diario vivir que dificultan la crianza de los hijos y la atención a los mismos.

Por otro parte, Redondo (2008), Andrews y Bonta (2003) al igual que Garrido, López, Silva, López y Molina (2006), comparten que la etiología de la conducta criminal sólo puede ser entendida desde la perspectiva de los factores de riesgo desde sus dos dimensiones; dinámicos y 
estáticos, ya que finalmente son estos los que permiten dimensionar e identificar los factores de riesgo que predisponen a la comisión de los actos delictivos. Sin embargo, Andrews y Bonta (2006, citado por Redondo, 2008), proponen un tercer factor denominado parcialmente modificable, el cual hace referencia a la posibilidad que tiene el individuo de modificar la conducta a través del tratamiento.

Los factores estáticos, son todas aquellas variables que le son inherentes a la persona, como lo es su historia de vida y son poco probables de modificar, mientras que los dinámicos, hacen alusión a factores individuales y ambientales. Pueden modificarse a través de las pertinentes intervenciones.

El factor denominado parcialmente modificable, hace referencia a la potenciación de las habilidades, estilo de aprendizaje, relaciones interpersonales del sujeto.

Para Redondo (2008) y Garrido, López, Silva, López y Molina (2006), los factores de riesgo pueden ser considerados de manera individual poco alarmantes en la etiología del delito, debido a que la acumulación de múltiples factores es lo que constituye el efecto exponencial y colateral. Por ello, para dichos autores el factor de riesgo puede ser de dos tipos: Lejano, el cual hace referencia a los niveles económicos y tipo de familia y el próximo, que hace referencia al estilo de crianza y tipos de relaciones sociales. Adicionalmente, plantean que los factores de riesgo ya sean de tipo personal, familiar o social, son elevados si se encuentran asociados a niveles altos de impulsividad, fracaso de las pautas de crianza o contextos caracterizados por niveles altos de delincuencia.

Los factores de protección son todas aquellas variables que al momento de entrar en interacción con el individuo cumplen la función de protección, es decir, es una variable que disminuye los efectos patológicos de riesgos concretos, son una contención que regula la 
reciprocidad existente entre los factores de riesgo y conductas problemas, (Garrido, López, Silva, López y Molina, 2006). Asimismo, Redondo (2008), agrega que los factores de protección ya sean de tipo personal, familiar o social, se asocian a un menor riesgo delictivo si se encuentran asociados a niveles altos de autocontrol, pauta de crianzas consistentes o contextos caracterizados por niveles bajos de delincuencia.

Lo anteriormente expuesto, plantea los pilares que se asocian con la conducta delictiva al igual que establece la ruta para, identificar las necesidades criminógenas y los factores de protección de los adolescentes con medida de responsabilidad penal, buscando con ello, establecer tratamientos que busquen la disminución de la reincidencia. A través del modelo de tratamiento: riesgo-necesidad-responsabilidad propuesto por Andrews y Bonta; Redondo (2008), argumenta que el principio de riesgo no es más que la administración de un proceso de intervención acorde a las particularidades del individuo, el cual se establece a partir de un proceso de evaluación que permite identificar la posibilidad de reincidencia. Es de resaltar, que a partir de este principio se funda una diferencia entre factores estáticos, los cuales hacen referencia al pasado del sujeto, lo inmodificable y los factores dinámicos o necesidades criminógenas, que pueden ser modificables, como lo es la cognición. Estos últimos, se encuentran altamente relacionados con la conducta criminal.

En cuanto al principio de necesidad, se argumenta que el foco de intervención prioritariamente son las necesidades criminógenas (Polaschek y Reynolds, 2001, citado por Redondo, 2008). Es decir, los factores dinámicos tales como: abuso de sustancias psicoactivas, relaciones interpersonales poco favorables, entre otras.

Por último, el principio de responsabilidad representa los factores que pueden obstaculizar el éxito de la intervención. Estos factores pueden ser externos (contexto, programa, rapport) o 
internos (interés, procesos de aprendizaje, entre otros). Es de resaltar, que este principio se encuentra relacionado con el factor denominado parcialmente modificable.

\section{Sistema de Responsabilidad Penal para Adolescente SRPA}

\section{Evolución del sistema penal para adolescentes}

En el caso de Colombia, los adolescentes se encuentran bajo una legislación que según Arboleda, Baquero y Domínguez (2010) ha cambiado; para el derecho penal colombiano en el tratamiento de los adolescentes, el sistema sigue teniendo como base la falta de capacidad penal de éste, solamente se ha variado la utilización de terminología, en la ley 1098 de 2006 se habla de la responsabilidad penal atenuada y no de presunción de su inimputabilidad. Según el código de infancia vigente, las personas menores de 14 años no serán juzgadas ni declaradas responsables penalmente sin perjuicio de la responsabilidad civil de los padres o representantes legales, sin embargo, existirá responsabilidad penal para adolescentes.

Entre los principales cambios, respecto al antiguo código del menor, la Ley 1098 de 2006 cita tres: el primero, es que la responsabilidad penal para adolescentes se acoge el Sistema Penal acusatorio para adultos, en donde tienen jueces especializados y audiencias; segundo, los jóvenes menores de 14 años no pueden ser juzgados, pero entre los 14 y los 18 años, pueden ser privados de la libertad para ciertos delitos; entre los 14 y los 16 años sólo podrán ser privados de la libertad máximo 8 años por secuestro, extorsión y homicidio; entre los 16 y los 18 años, por tráfico de estupefacientes, hurto calificado, porte de armas, homicidio culposo, tortura y secuestro, máximo cinco años, y tercero, la Fiscalía General de la Nación y la Policía de Infancia y Adolescencia tendrán como función investigar estos casos. En Colombia, lo anterior compete a los jueces de 
Responsabilidad Penal para Adolescentes, que tienen como función conocer las acciones y omisiones de los menores que no hayan cumplido los 18 años y que el código penal u otras leyes califiquen como delitos o faltas.

Ahora bien, este cambio de la ley hacia la adjudicación de responsabilidad al adolescente cambia el manejo que se da directamente con el infractor y este debe responder por los actos cometidos. Arboleda, Baquero y Domínguez (2010), mencionan su desacuerdo con el nuevo sistema, ya que para ellos un adolescente que comete un delito y sólo recibe una amonestación o un programa especializado de reeducación por un tiempo delimitado tiene mayores probabilidades de reincidir en la conducta delictiva, argumentando que estas amonestaciones no son castigos que generen una pérdida para los adolescentes. Para la presente investigación se considera importante la intervención psicosocial de los adolescentes que permita mejorar sus condiciones fortaleciendo los factores protectores y dando respuesta a sus necesidades.

En Colombia la ley de infancia y adolescencia en su libro II, referente al Sistema de Responsabilidad Penal para Adolescentes, comenzó a implementarse paulatinamente desde 2007. El Sistema de Responsabilidad Penal para Adolescentes establece un conjunto de procesos y define las autoridades que deben asumir la implementación de la ley. Esta misma ley establece y resalta la obligatoriedad de garantía de la justicia restaurativa. La cual tiene como herramienta principal el proceso pedagógico y el resarcimiento del daño. Esta ley establece las características diferenciales del sistema penal de adultos (Ley 1098 de 2006).

La evolución histórica del derecho penal frente al tema de la judicialización de los adolescentes que trasgreden las normas ha permitido la implementación de herramientas legislativas que limitan el "Ius Puniendi" ejercido por el Estado por estrategias que apuntan a reeducar o resocializar al adolescente para insertarlo nuevamente a la sociedad. Es de resaltar, que 
los avances obtenidos a nivel internacional en esta área ha conllevado a formar un Corpus Juris, es decir, un grupo de normas rectoras y básicas que se encuentran interrelacionadas entre sí con el objeto de garantizar los derechos humanos tanto de niñas y niños como de adolescentes. (Comisión Interamericana de Derechos, 2011)

Es de resaltar, que a nivel mundial de la misma forma que existe la Carta Internacional de Derechos Humanos, la Convención de los Derechos del Niño de 1989 se instituye como un pilar fundamental que pretende lograr la protección de infantes y adolescentes. Asimismo, a nivel internacional se han aprobado desde la dimensión del Sistema de las Naciones Unidas, “instrumentos no convencionales" que buscan mejorar la efectividad de la aplicación de los Derechos del Niño. Lo anterior, coadyuvó a que el sistema universal de protección de la niñez diera origen a un conjunto de reglas mínimas para la administración de la justicia de adolescentes llamadas Reglas de Beijing. Posteriormente, surgen las reglas de protección de adolescentes privados de la libertad denominadas de Tokio, las cuales buscan desde las Naciones Unidas evitar como medida de protección la privación de la libertad (Comité de Derechos del Niño, 2007).

Normalmente se relaciona el origen de la justicia penal juvenil con la Convención de los Derechos de los Niños del año 1989, puesto que dicho documento exige a los Estados firmantes crear un conjunto de leyes y programas especiales para los jóvenes menores de 18 años que hayan cometido algún tipo de delito contra la ley penal.

Sin embargo, no fue desde ese momento que se habló de justicia penal juvenil, sino que su alcance viene de mucho más atrás, el origen de la justicia para menores se origina a partir del siglo XVII, período conocido como la ilustración en donde grandes pensadores como el italiano Cesar Beccaria marcó un cambio ideológico en cuanto al actuar del Estado frente al derecho penal en la edad media. 
Beccaria fue crítico de las penas desproporcionadas y el excesivo uso de la pena de muerte en esta época. En otras palabras, debido a las corrientes ideológicas que surgieron en este período de la historia, se planteó la humanización del derecho penal, por lo que se propuso que las penas impuestas fueran proporcionales al daño cometido, así como diferenciar entre las edades de los infractores y su sexo.

Otros autores como Voltaire y Manuel Lardizábal, quienes afirman que frente a la desproporcionalidad de las penas y la crueldad con las que eran impuestas era preciso optar por la educación como medio para prevenir el delito más que castigar al infractor de la ley. [...] en lugar del dolor de castigar para corregir, prefieren educar previamente a la necesidad de castigar, y cuando se castiga al menor piden que la pena sea proporcional a su edad y no equivalente a la de una persona que ha alcanzado la mayoría de edad.

Los aportes de estos pensadores son de bastante importancia para el nacimiento de una justicia especial para los más jóvenes, puesto que se incorpora al derecho penal la necesidad de diferenciar entre personas menores de edad que no hayan llegado a su vida adulta, esto con el fin de imponer sanciones distintas y proporcionales. Así mismo, también es importante mencionar el nacimiento de la infancia como categoría social para hacer posible un tratamiento penal diferencial tanto adultos como de menores de edad.

En el siglo XVII nace el concepto de infancia como tal, se hace referencia en la importancia de que el niño tenga la esperanza de un futuro mejor. Posteriormente en el siglo XVIII, las razones por las cuales tener un niño por mantener la estirpe familiar son reemplazadas por las de concebirlo por amor, es en este contexto cuando Jean Jacques Rousseau introduce el concepto "dignidad del niño" que repercutiría en el tratamiento digno de los niños y niñas años más tarde 
Para el siglo XIX, el pensamiento sobre la responsabilidad del Estado para con la protección de los niños, niñas y adolescentes pasa a ser una idea constante. De igual forma, se hace más común el rechazo a la opción del castigo corporal como herramienta para corregir a los menores de edad, así entonces el bienestar del niño se convierte en interés prioritario del Estado. (Lopez Amora, 2012)

Finalmente, en el siglo $\mathrm{XX}$ es cuando se ratifican los derechos de los niños con la Convención, de tal suerte que todo este nuevo ordenamiento sobre la visión que se tenía de los niños, niñas y adolescentes cambia totalmente, se les otorga entonces un nuevo posicionamiento dentro de la sociedad, esto desemboca en que en la actualidad se destinen un número importante de políticas públicas y proyectos para la protección de esta población, todo lo anterior en concordancia con la Convención Internacional de los Derechos del Niño (CIDN) 1989.

Así entonces, la Convención como tratado internacional, reconoce a los niños, niñas y adolescentes como sujetos de derechos, describe sus derechos y agrupa todas las directrices para promover el bienestar y la protección especial de la deben ser sujetos la población infante y adolescente por parte de los Estados firmantes, también se establecen criterios sobre la administración de justicia para los menores de edad, introduciendo un nuevo paradigma de justicia juvenil diferenciado de los adultos, pero reconociendo la responsabilidad penal que les asiste como sujetos de derechos.

De igual manera se hace énfasis en que durante el proceso penal que se lleve a cabo con dicho menor se respete el interés superior del niño, niña o adolescente, este concebido como un principio rector o general del derecho, pues teniendo en cuenta la Convención este debe primar sobre cualquier actuación del Estado. Es así como el interés superior del niño se podría definir 
como "el conjunto de bienes necesarios para el desarrollo integral y la protección de la persona del menor de edad y, en general, de sus derechos, que buscan su mayor bienestar."

Por lo tanto, los procesos relacionados con la situación de los niños, niñas y adolescentes que lleven a cabo los Estados firmantes de la Convención deben estar encaminados a asegurar el mayor bienestar posible de la niñez y respetar el pleno cumplimiento de sus derechos, así lo establece el primer inciso del artículo 3 de la citada norma que en palabras textuales afirma: En todas las medidas concernientes a los niños que tomen las instituciones públicas o privadas de bienestar social, los tribunales, las autoridades administrativas o los órganos legislativos, una consideración primordial a que se atenderá será el interés superior del niño. (CIDN 1989, pág. 10)

Las directrices establecidas abarcan diferentes dimensiones de la justicia penal para adolescentes, establece disposiciones sobre la pena privativa de la libertad, la cual debe ser utilizada como último recurso y como del desarrollo del proceso penal que se lleve a cabo con el que haya quebrantado las leyes. Es decir, un correcto proceso en donde se asegure el bienestar del adolescente, así como reconocimiento pleno de sus derechos.

Basándonos en dichos preceptos no se puede establecer una definición exacta de justicia penal para adolescentes, sin embargo, El Fondo para la Infancia de las Naciones Unidas (UNICEF) brinda la siguiente definición:

La justicia penal juvenil se basa en un principio de reconocimiento de derechos y protección de menores de edad que han cometido alguna infracción a la ley penal. El elemento diferencial son las sanciones penales, puesto que éstas deben poseer unas finalidades educativas y de reintegración social, encaminadas a que el adolescente repare el daño que cometió. Así mismo, se debe hacer uso de la pena privativa de la libertad como 
último recurso y en caso de hacerlo se debe condenar por el menor tiempo posible. También es importante mencionar, que tratándose de adolescentes este paradigma de justicia debe diferenciarse de la implementada para los adultos (Unicef 2012, p. 1)

De igual forma, según esta organización (UNICEF) la finalidad de la justicia penal adolescente se puede agrupar en cuatro objetivos

Que durante todo el proceso penal que se adelante con el adolescente se asegure el debido proceso.

1. Impulsar la responsabilidad, del joven en conflicto con la ley penal, en el sentido que éste debe ser consciente de las consecuencias de sus actos y de su conflicto con la norma penal.

2. Suscitar su integración social.

3. Fomentar programas que permitan la integración social mediante medidas socioeducativas, así como incorporar a la comunidad en el proceso de inserción.

Así entonces la justicia penal juvenil a partir de la CIDN, se establece como un modelo de justicia para adolescentes en conflicto con la ley penal, en donde se reconocen sus derechos, pero también su responsabilidad sobre sus acciones.

Este paradigma va encaminado a fomentar que el adolescente, que se encuentra en una edad en donde se encuentra en pleno desarrollo tanto físico como mental y que no ha alcanzado la etapa adulta, se integre a la sociedad a través de medidas y sanciones que permitan la integración social del adolescente. 


\section{Estructura del Sistema de Responsabilidad Penal para Adolescentes}

En el año 2006 con la ley 1098, nace el Sistema de Responsabilidad Penal para Adolescentes (SRPA), la cual crea el Código de Infancia y Adolescencia. Este sistema está compuesto por un conjunto de normas las cuales tienen por objetivo regular la situación de los adolescentes en conflicto con la ley penal en todo el territorio nacional.

El artículo 139 de dicha normativa define al sistema de responsabilidad penal adolescente como: [...] el conjunto de principios, normas, procedimientos, autoridades judiciales especializadas y entes administrativos que rigen o intervienen en la investigación y juzgamiento de delitos cometidos por personas que tengan entre catorce (14) y dieciocho (18) años al momento de cometer el hecho punible Código de Infancia y Adolescencia [CIA] 2006, pág. 82).

Así mismo, el artículo 140, establece que la finalidad del programa de responsabilidad penal es: [...] en materia de responsabilidad penal para adolescentes tanto el proceso como las medidas que se tomen son de carácter pedagógico, específico y diferenciado respecto del sistema de adultos, conforme a la protección integral el proceso deberá garantizar la justicia restaurativa, la verdad y la reparación del daño. Código de Infancia y Adolescencia, 2006 pág. 97

En otras palabras el Sistema de Responsabilidad Penal para Adolescentes se basa en un conjunto de procesos y autoridades quienes tienen por objetivo desarrollar el proceso penal de adolescentes entre los rangos de edades descritos anteriormente que se encuentren en conflicto con la ley penal, de igual forma establecen los elementos principales que integran el Sistema de Responsabilidad Penal para Adolescentes, así como del rango de edades de los adolescentes que son objeto del sistema y resalta la obligación de garantizar la justicia restaurativa en todo el proceso, enfocado tanto en el proceso pedagógico como en el resarcimiento del daño. Así mismo, se identifica el carácter del sistema diferenciado del de los adultos. 


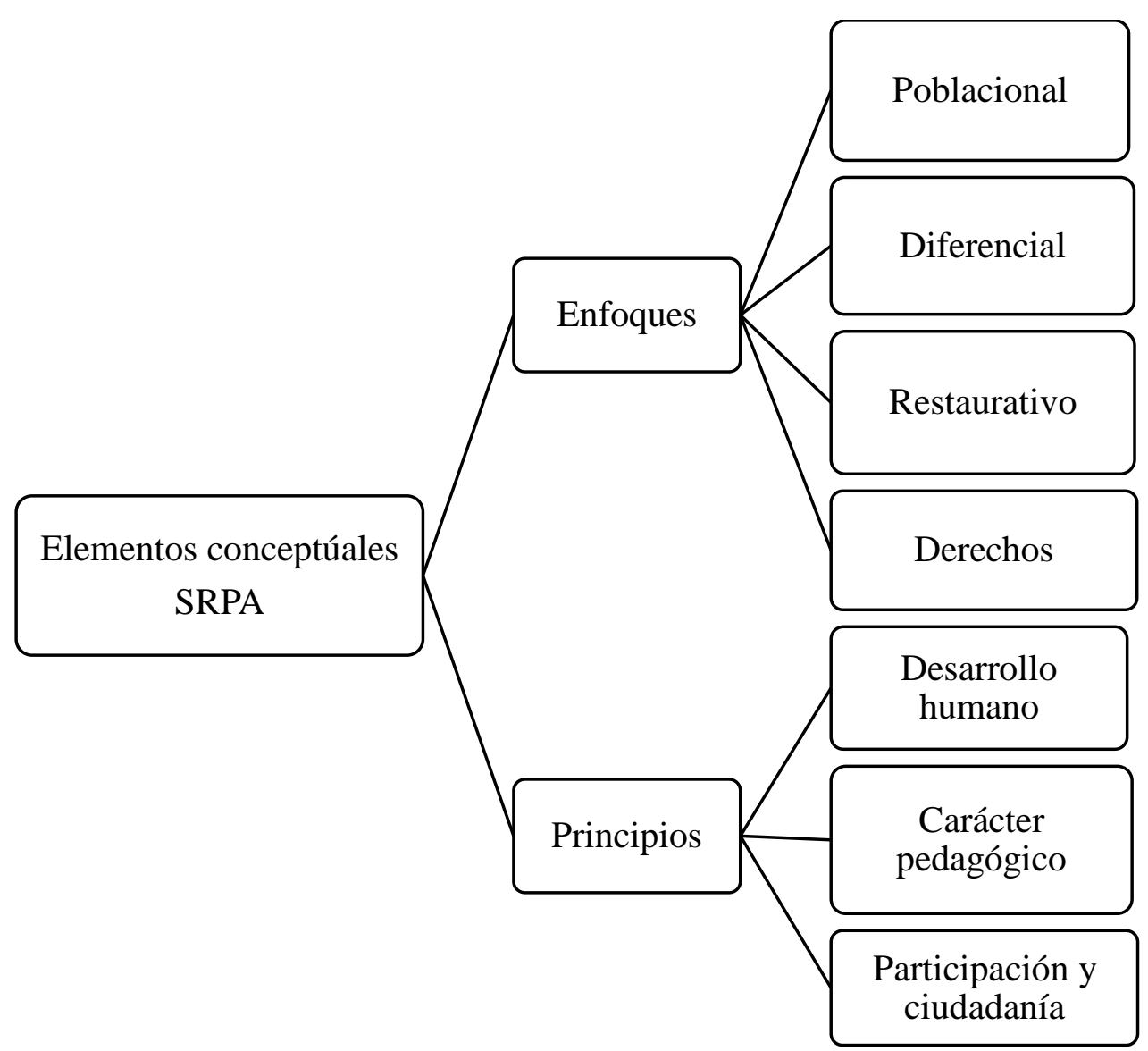

Figura 1. Componente conceptual del proceso de gestión de responsabilidad penal Fuente: Lineamiento ICBF 


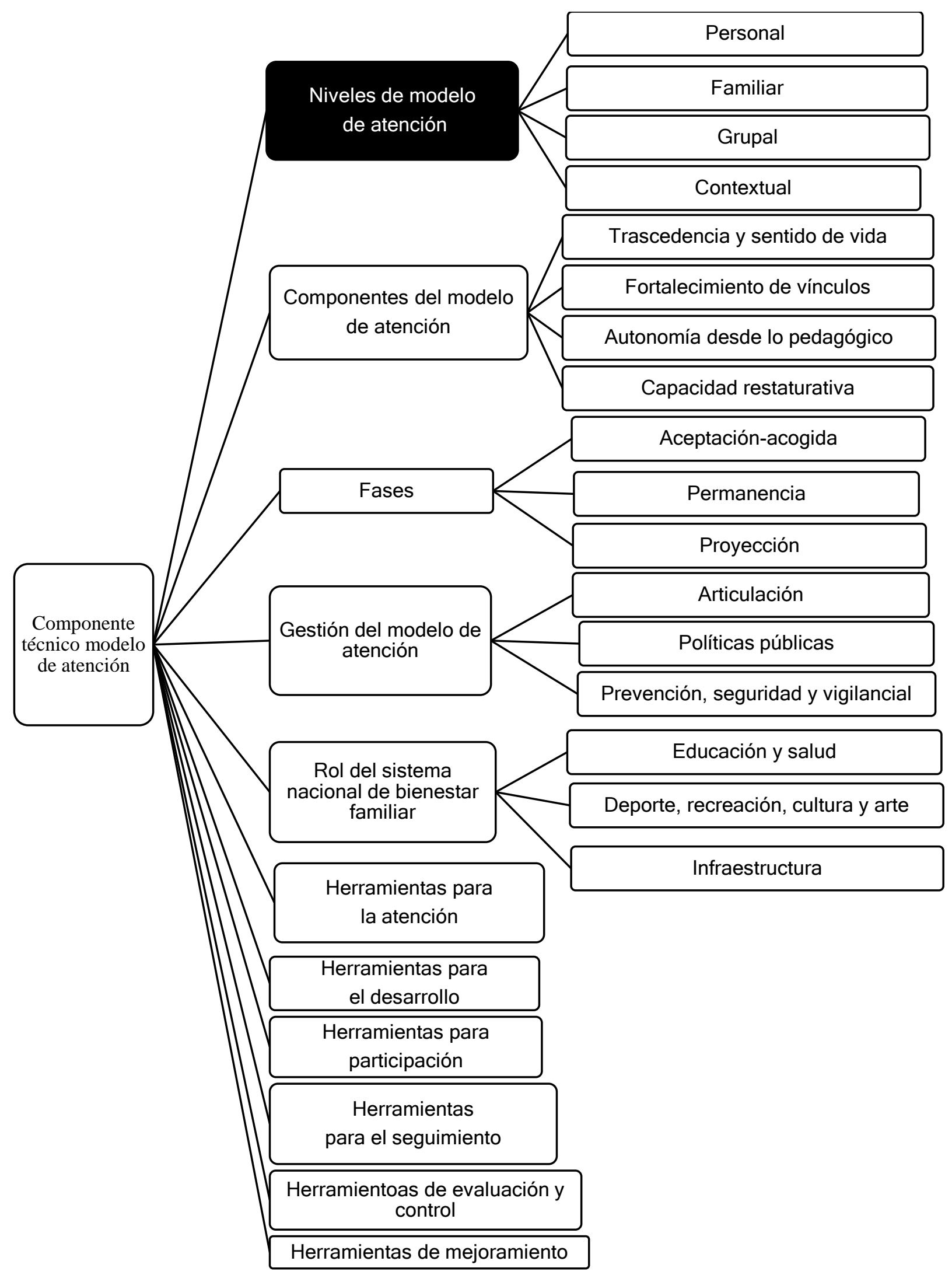


Dando cumplimiento a lo establecido en los artículos 11, 163, y 177 de la Ley 1098 de 2006, el Instituto Colombiano de Bienestar Familiar, construyó los lineamientos de atención a adolescentes que ingresan por presunta comisión de un delito. Estos lineamientos están compuestos por tres documentos:

1. Lineamiento Modelo de Atención a adolescentes y jóvenes en conflicto con la ley-SRPA

2. Lineamiento de servicios para medidas y sanciones del proceso judicial SRPA.

3. Lineamientos Medidas Complementarias y/o de Restablecimiento en Administración de Justicia.

Continua los lineamientos planteando: El presente documento, del modelo de atención, es la base técnica y pedagógica para la organización de la atención de los adolescentes, que, en cumplimiento de una sanción o medida, son ubicados en los servicios operados en el marco del Sistema de Responsabilidad para Adolescentes, y/o que cumplen una medida complementaria y/o de restablecimiento en administración de justicia.

Este primer documento contiene cinco capítulos: el primero, presenta el marco conceptual y normativo, los conceptos básicos de los enfoques que caracterizan la atención y los principios que garantizan el cumplimiento de las finalidades SRPA; el segundo, desarrolla el componente técnico, incluye una propuesta de niveles, componentes y fases del modelo de atención y da cuenta del concepto y propósitos del proceso de atención general; el tercero, contempla aspectos de carácter administrativo; el cuarto, da cuenta de aspectos financieros que se tendrán en cuenta en la contratación y en el funcionamiento de las entidades y programas; y el quinto, señala aspectos legales que deben cumplir las entidades en el proceso contractual. (Lineamientos técnico administrativos SRPA - ICBF 2017). 


\section{Las sanciones como medidas de Restablecimiento de Derechos en el SRPA}

Además del Código de Infancia y Adolescencia (ley 1098 de 2006), también se creó el documento Conpes 3629 de 2009, el cual hace precisiones sobre la política de atención para adolescentes, así como describe referentes internacionales y nacionales en lo que respecta a documentos de protección de adolescentes, presentación de un diagnóstico, marco conceptual, es decir la justicia restaurativa, planes de financiación y objetivos centrales, a largo y corto plazo.

El Conpes 3629 de 2009 establece que el Sistema de Responsabilidad Penal para Adolescentes desarrolla dos procesos; un proceso judicial y otro de restablecimiento de derechos, lo cual implica que además de ser un sistema en el cual los adolescentes son responsables por conductas punitivas, también debe ser garantizado el pleno ejercicio de sus derechos.

Con la implementacion del sistema de responsabilidad penal para las y los adolescentes, se establecieron sanciones en evento que el adolescente sea responsable, y en efecto la misma ley 1098 de 2006, dejo de manera clara y expresa que la sanciones tienen una finalidad protectora, educativa y restaurativa, y se aplicarán con el apoyo de la familia y de especialistas. En consecuencia el articulo 177 (modificado por el articulo 89 de la ley 1453 de 2011) se encuentran definidas 6 clases de sanciones como se muestra en la tabla a continuación: 
Percepcion Profesional y de Autoridades en el proceso S.R.P.A

Tabla 1

Sanciones en SRPA, las cuales vienen contempladas en la( Ley 1098 de 2006)

\begin{tabular}{|c|c|}
\hline Sanciones & Definición \\
\hline La amonestación & $\begin{array}{l}\text { "Es la recriminación que la autoridad judicial le hace al adolescente sobre las consecuencias del hecho } \\
\text { delictivo y la exigencia de la reparación del daño. En todos los casos deberá asistir a un curso } \\
\text { educativo sobre respeto a los derechos humanos y convivencia ciudadana que estará a cargo del } \\
\text { Instituto de Estudios del Ministerio Público" }\end{array}$ \\
\hline Las reglas de conducta. & $\begin{array}{l}\text { Es la imposición por la autoridad judicial al adolescente de obligaciones o prohibiciones para regular } \\
\text { su modo de vida, así como promover y asegurar su formación. Esta sanción no podrá exceder los dos } \\
\text { (2) años. }\end{array}$ \\
\hline $\begin{array}{l}\text { La prestación de servicios } \\
\text { sociales a la comunidad }\end{array}$ & $\begin{array}{l}\text { Es la realización de tareas de interés general que el adolescente debe realizar, en forma gratuita, por } \\
\text { un período que no exceda de } 6 \text { meses, durante una jornada máxima de ocho horas semanales } \\
\text { preferentemente los fines de semana y festivos o en días hábiles, pero sin afectar su jornada escolar. }\end{array}$ \\
\hline La libertad asistida & $\begin{array}{l}\text { Es la concesión de la libertad que da la autoridad judicial al adolescente con la condición obligatoria } \\
\text { de someterse a la supervisión, la asistencia y la orientación de un programa de atención especializada. } \\
\text { Esta medida no podrá durar más de dos años. }\end{array}$ \\
\hline $\begin{array}{l}\text { La internación en medio semi- } \\
\text { cerrado }\end{array}$ & $\begin{array}{l}\text { Es la vinculación del adolescente a un programa de atención especializado al cual deberán asistir } \\
\text { obligatoriamente durante horario no escolar o en los fines de semana. Esta sanción no podrá ser } \\
\text { superior a tres años. Artículo 183. Define: Las reglas de conducta. Es la imposición por la autoridad }\end{array}$ \\
\hline
\end{tabular}


judicial al adolescente de obligaciones o prohibiciones para regular su modo de vida, así como promover y asegurar su formación. Esta sanción no podrá exceder los dos (2) años.

\begin{tabular}{lll}
\hline La privación de la libertad en & La privación de la libertad en centro de atención especializada se aplicará a los adolescentes mayores \\
centro de atención & de dieciséis (16) y menores de dieciocho (18) años que sean hallados responsables de la comisión de \\
especializado & delitos cuya pena mínima establecida en el Código Penal sea o exceda de (6) años de prisión. En estos \\
& casos, la privación de libertad en centro de atención especializada tendrá una duración de uno (1) hasta \\
& cinco (5) años. \\
\hline
\end{tabular}


Artículo 181. (Ley 1098 de 2006) Internamiento preventivo. En cualquier momento del proceso y antes de la audiencia de juicio, el juez de control de garantías, como último recurso, podrá decretar la detención preventiva cuando exista:

1. Riesgo razonable de que el adolescente evadirá el proceso.

2. Temor fundado de destrucción u obstaculización de pruebas.

3. Peligro grave para la víctima, el denunciante, el testigo o la comunidad.

Parágrafo $1^{\circ}$. El internamiento preventivo no procederá sino en los casos en que, conforme a la gravedad del delito sería admisible la privación de libertad como medida. Se ejecutará en centros de internamiento especializados donde los adolescentes procesados deben estar separados de los ya sentenciados. (Ley 1098 de 2006)

Parágrafo $2^{\circ}$. El internamiento preventivo no podrá exceder de cuatro meses, prorrogable con motivación, por un mes más. Si cumplido este término el juicio no ha concluido por sentencia condenatoria, el Juez que conozca del mismo lo hará cesar, sustituyéndola por otra medida como la asignación a una familia, el traslado a un hogar o a una institución educativa.

Mientras se encuentren bajo custodia, los adolescentes recibirán cuidados, protección y toda la asistencia social, educacional, profesional, sicológica, médica y física que requieran.

Artículo 181. Internamiento preventivo. En cualquier momento del proceso y antes de la audiencia de juicio, el juez de control de garantías, como último recurso, podrá decretar la detención preventiva cuando exista:

Artículo 182. (Ley 1098 de 2006) La amonestación. Es la recriminación que la autoridad judicial le hace al adolescente sobre las consecuencias del hecho delictivo y la exigencia de la reparación del daño. En todos los casos deberá asistir a un curso educativo sobre respeto a los 
derechos humanos y convivencia ciudadana que estará a cargo del Instituto de Estudios del Ministerio Público. (Ley 1098 de 2006).

Artículo 183. (Ley 1098 de 2006) Define: Las reglas de conducta. Es la imposición por la autoridad judicial al adolescente de obligaciones o prohibiciones para regular su modo de vida, así como promover y asegurar su formación. Esta sanción no podrá exceder los dos (2) años.

De acuerdo a los datos estadísticos suministrados por ICBF, hasta la fecha, las autoridades judiciales han colocado esta medida a 14.638 adolescentes, lo cual corresponde al $19 \%$ de la población atendida en procesos penales. Eta medida debe ser supervisada y controlada por los padres y los organismos que articulan el SRPA, sin olvidar el fin pedagógico de la norma. (Ley 1098 de 2006)

Artículo 184. (Ley 1098 de 2006). La prestación de servicios sociales a la comunidad. Es la realización de tareas de interés general que el adolescente debe realizar, en forma gratuita, por un período que no exceda de 6 meses, durante una jornada máxima de ocho horas semanales preferentemente los fines de semana y festivos o en días hábiles, pero sin afectar su jornada escolar. Esta sanción ha sido impuesta a 3.052 adolescentes, lo cual corresponde al $4 \%$ del total.

Artículo 185. (Ley 1098 de 2006) La libertad vigilada. Es la concesión de la libertad que da la autoridad judicial al adolescente con la condición obligatoria de someterse a la supervisión, la asistencia y la orientación de un programa de atención especializada. Esta medida no podrá durar más de dos años. De acuerdo a las estadísticas de ICBF (abril 2016) este tipo de sanción ha sido implementada por los jueces de conocimientos a 17.441 adolescentes, lo cual corresponde al $22 \%$ del total de adolecentes ingresados al SRPA, registrándose así las cifras más altas en cuanto a sanciones. 
Artículo 186. (Ley 1098 de 2006) Medio semi-cerrado. Es la vinculación del adolescente a un programa de atención especializado al cual deberán asistir obligatoriamente durante horario no escolar o en los fines de semana. Esta sanción no podrá ser superior a tres años. Esta sanción ha sido aplicada por los ju7eces de conocimiento en 10.431 ocasiones, lo cual corresponde al 13 $\%$ de adolescentes aprehendidos en la comisión de delitos.

Artículo 187. (Ley 1098 de 2006) La privación de la libertad. Modificado por el art. 90, Ley 1453 de 2011. La privación de la libertad en centro de atención especializada se aplicará a los adolescentes mayores de dieciséis (16) y menores de dieciocho (18) años que sean hallados responsables de la comisión de delitos cuya pena mínima establecida en el Código Penal sea o exceda de (6) años de prisión. En estos casos, la privación de libertad en centro de atención especializada tendrá una duración de uno (1) hasta cinco (5) años.

En los casos en que los adolescentes mayores de catorce (14) y menores de dieciocho (18) años sean hallados responsables de homicidio doloso, secuestro o extorsión, en todas sus modalidades, la privación de la libertad en centro de atención especializada tendrá una duración de dos (2) hasta ocho (8) años. (Ley 1098 de 2006)

Parte de la sanción impuesta podrá ser sustituida por el establecimiento de presentaciones periódicas, servicios a la comunidad, el compromiso de no volver a delinquir y guardar buen comportamiento, por el tiempo que fije el juez. El incumplimiento de estos compromisos acarreará la pérdida de estos beneficios y el cumplimiento del resto de la sanción inicialmente impuesta bajo privación de libertad. (Ley 1098 de 2006)

Artículo. 188. (Ley 1098 de 2006) Derechos de los adolescentes privados de libertad. Además de los derechos consagrados en la Constitución Política y en la presente ley, el adolescente privado de libertad tiene los siguientes derechos: 
1. Permanecer internado en la misma localidad, municipio o distrito o en la más próxima al domicilio de sus padres, representantes o responsables.

2. Que el lugar de internamiento satisfaga las exigencias de higiene, seguridad y salubridad, cuente con acceso a los servicios públicos esenciales y sea adecuado para lograr su formación integral. (Ley 1098 de 2006)

3. Ser examinado por un médico inmediatamente después de su ingreso al programa de atención especializada, con el objeto de comprobar anteriores vulneraciones a su integridad personal y verificar el Estado físico o mental que requiera tratamiento. (Ley 1098 de 2006)

4. Continuar su proceso educativo de acuerdo con su edad y grado académico.

5. Que se le mantenga en cualquier caso separado de los adultos

6. Derecho a participar en la elaboración del plan individual para la ejecución de la sanción.

7. Derecho a recibir información sobre el régimen interno de la institución, especialmente sobre las sanciones disciplinarias que puedan serle aplicables y sobre los procedimientos para imponerlas y ejecutarlas

8. No ser trasladado arbitrariamente del programa donde cumple la sanción. El traslado sólo podrá realizarse por una orden escrita de la autoridad judicial.

9. No ser sometido a ningún tipo de aislamiento.

10. Mantener correspondencia y comunicación con sus familiares y amigos, y recibir visitas por lo menos una vez a la semana.

11. Tener acceso a la información de los medios de comunicación. (Ley 1098 de 2006)

Respecto a la medida de privación de libertad, la Comisión Interamericana de Derechos observa: La Comisión también ha identificado como una problemática generalizada en la región (Caribe) la limitada disponibilidad de medidas de derivación que supongan alternativas a la 
privación de la libertad así como de medidas de justicia restaurativa para los adolescentes en conflicto con la ley penal, que estén orientadas a la restitución de derechos y a la efectiva rehabilitación y reintegración social de los adolescentes. Esta situación, en la práctica, supone que los adolescentes en conflicto con la ley penal ingresen en centros de privación de libertad, cuando ésta debería ser una medida excepcional, de último recurso y por el menor tiempo necesario según se desprende del derecho internacional de los derechos humanos. (Comisión Interamericana de Derechos, noviembre 2015)

Esta medida de privación de la libertad, siendo el último recurso instaurado por la ley penal de Adolescentes, ha sido impuesta por los jueces de conocimiento a 14.032 adolescentes, correspondiente al $18 \%$ del total de aprehendidos. Esta cifra obliga a detenerse a analizar esta situación, toda vez que los fines pedagógicos y el compromiso de la familia tienden a desvanecerse en el momento en que la ley se torna restrictiva y represiva.

De acuerdo al informe de la Defensoría del Pueblo de Colombia Violaciones a los Derechos Humanos de adolescentes privados de la libertad pag. 85 (marzo 2015): A partir de las visitas de inspección realizadas se hallaron evidencias de casos de adolescentes privados de su libertad por delitos como el hurto, respecto de los cuales existe aplicación del principio de oportunidad, según lo establece el artículo 175 del Código de Infancia y Adolescencia, lo que hace evidente que el sistema en la actualidad se sigue aplicando con criterios de "situación irregular" que se entienden como superados por la Convención de los derechos del niño. (Hurtado Zaens, Diaz Soto, 2015)

La ley 1453 de 2011, por medio de la cual se reformó, entre otras, la Ley de Infancia y Adolescencia, llevó a que se incrementara la aplicación dela sanción de privación de libertad que, recordemos, aplica solo frente a delitos de alto impacto o gravedad como el homicidio doloso, el 
secuestro y la extorsión, en cualquiera de sus modalidades, haciendo que el número de adolescentes

privados de libertad entre 2010 y 2011 se incrementara en un 11,3\% y que entre el 2011 y el 2012 tal incremento fuera del 16,5\%. Si bien la privación de libertad es la tercera forma de sanción que con mayor frecuencia se aplica, es innegable su aumento en los últimos años. Otro importante dato, se establece respecto de la utilización de internamiento preventivo como medida de aseguramiento en adolescentes en conflicto con la ley. Dicha medida, aunque no constituye una sanción de privación de libertad, pone de manifiesto que las medidas intra murales siguen siendo las de mayor recurrencia por parte de los jueces de garantías encargado de tomar este tipo de decisiones.

\section{Antecedentes investigativos}

Los antecedentes investigativos planteados en este apartado surgen a partir del interés de conocer investigaciones relacionadas con el Sistema de Responsabilidad Penal para Adolescentes (SRPA). A partir de lo anterior se encontró que la manera de abordar este objeto de estudio se ha transformado debido a los mecanismos por los cuales se ha asumido la responsabilidad penal de los adolescentes en los distintos países y en el mundo en general a partir del contexto histórico en el cual se estudien (Sandoval y Tirado, 2013).

Por lo enunciado, a continuación se presentan algunas de las ideas y los planteamientos encontrados frente al objeto de estudio, para ello en un inicio se citan algunas de las investigaciones que dan cuenta de la forma en la que se ha estudiado la comprensión del fenómeno, teniendo en cuenta como se asume éste en algunos países, concluyendo con investigaciones acerca de los mecanismos por los cuales en Colombia se asume y se aborda la responsabilidad penal adolescente, esto a partir de investigaciones teóricas y empíricas las cuales permiten reconocer a partir de 
análisis documentales, entrevistas, pruebas y experiencias participativas comprender tanto el funcionamiento del SRPA, como la concepción de la delincuencia juvenil que da paso a este.

Lo anterior basado en los resultados de búsqueda de bases de datos como: Dialnet, Ebsco Host, Google Académico, Redalyc y Scielo; para la selección de los mismos, se tuvieron algunos criterios de búsqueda como el hecho de ser publicaciones realizadas durante el periodo entre el 2012 y el 2017, al igual que tener como tema central la responsabilidad penal adolescente.

En primer lugar se logró reconocer como Martínez y Pozo (2016), plantean en su investigación el hecho de que la delincuencia infantil y juvenil son una situación y una problemática actual que atañe al término de interacción social, los cuales dan paso a procesos de análisis socio jurídicos los cuales requieren la modificación de leyes que conozcan y estudien las problemáticas sociales que son causantes de la misma, puesto que aunque no existe una causa puntual de la delincuencia, se requiere seguir estudiando los factores que puedan disminuir las actividades delictivas, para así buscar mecanismos de reinserción a la sociedad. A partir de lo anterior se retoma la investigación llevada a cabo por Mettifogo, Arévalo, Gómez, Montedónico y Silva (2015), debido a que la misma consiste en un estudio narrativo, el cual contó con la participación de 22 jóvenes que a través de una entrevista estructurada narraron como ellos experimentaron el proceso de condena y los factores transicionales y personales que permitieron que estos desistieran de actividades delictivas, a partir de lo mencionado los autores lograron encontrar algunos de los factores principales como la necesidad de conocer los vínculos con grupos y familiares que sirvieran como redes de apoyo de los niños, niñas y adolescentes, junto con el trabajo en el reconocimiento de las habilidades de los mismos.

Lo mencionado en el párrafo anterior, ha dado paso al hecho de que dentro del derecho penal tome gran relevancia un área específicamente dirigida a la delincuencia juvenil, esto debido 
a la necesidad de dar una respuesta asertiva para intervenir y trabajar esta problemática como lo menciona Vásquez (2005, citado por Martínez y Pozo, 2016). Un ejemplo de ello es la investigación realizada por Jordán, Behar, Buitrago y Castillo (2017) en la cual se evidencia cómo a través de una investigación de tipo IAP, se genera contacto con un grupo de estudiantes del centro del Buen Pastor con el fin de diseñar y aplicar una estrategia comunicativa dentro del mismo centro, dando paso a estrategias de ayuda las cuales tienen como fin que los adolescentes logren construir una nueva forma de vida más allá del acto de violencia que hayan cometido.

En este sentido por lo planteado por Sandoval y Tirado (2013) se estudia el hecho de que las directrices en torno a la infracción penal de niños, niñas y adolescentes, han sido una problemática relativamente joven, ya que ésta ha sido analizada a partir del S. XIX con la revolución industrial, donde se empieza a ver al joven infractor, el cual dio paso en ese momento a la consideración del niño/a o joven como inimputable debido a su falta de responsabilidad y consciencia y por lo tanto un sujeto sin derechos ni obligaciones, lo cual, al pasar del tiempo se modificó al comprender al menor como un sujeto de derechos.

Lo antes señalado da paso a la necesidad de entender los cambios que se han tenido que llevar a cabo en la forma de asumir los derechos de los niños, niñas y adolescentes, pasando desde un modelo de la situación irregular, a uno de derechos y deberes sociales (Erazo, 2016). Lo anterior sustentado en la afirmación de Ramírez y Arroyo (2014), la cual menciona que: “En los últimos años en Colombia y gran parte de Latinoamérica, la delincuencia infantil es un fenómeno cada vez más evidente y con notorio crecimiento entre la población juvenil” (p. 422).

A partir de lo anterior se da paso al análisis de las causas por las cuales este fenómeno aumenta, puesto que como se evidencia en el estudio generado a partir del trabajo con 20 adolescentes institucionalizados llevado a cabo por Ramírez y Arroyo (2014), la necesidad de 
estudiar las variables neuropsicológicas y sociodemográficas relacionadas con el acto delictivo, puesto que estas son entendidas como la manifestación de los posibles problemas dados en el contexto social y familiar relacionados con el desarrollo de los niños.

En este orden de ideas se retoman algunos de los análisis de cómo países como Chile, España y Colombia han generado sus propios mecanismos de respuesta y leyes que dan cuenta de la necesidad de cada país para asumir la delincuencia juvenil, destacando en primer lugar que dentro de los hallazgos se destaca la relación presente entre las leyes y los principios internacionales planteados por la Convención de los Derechos del Niño (1989), esto frente a los mecanismos por los cuales se asume la responsabilidad penal de los menores de edad. Dentro de estos se encuentran hallazgos frente a la justicia restaurativa, el debido proceso, al igual que modelos para asumir la discriminación, la des judicialización y la diversificación, que tienen como fin generar políticas juveniles basadas en el marco de la sanción y la educación, para así lograr asumir la mediación entre las víctimas y los infractores (Rodríguez, 2012).

Así mismo, a partir de los resultados de las investigaciones se destaca la importancia de dichos principios internacionales, y de las leyes y deberes planteados por los Derechos humanos retomados por autores como Langer y Lillo (2014). Los cuales dieron paso a la comprensión de que los jóvenes son responsables de sus actos, y que estos cuentan con condiciones diferenciadas de penalización las cuales varían a su vez entre los países mencionados.

Ahora bien, se encontraron algunos ejemplos en torno a los mecanismos por los cuales dichos países asumen la responsabilidad penal juvenil; dentro de estos se evidencia como en Chile se asumen los procesos judiciales de los niños/as y adolescentes infractores, partiendo del hecho de que se requiere de medidas dirigidas a la rehabilitación como lo menciona Carrasco (2015); adicionalmente se evidencia que en dicho país se genera un enfoque de derechos basado en las 
características de la población a partir de la Ley $\mathrm{N}^{\circ} 20.084$ y el Servicio Nacional de menores (Maldonado, 2014). Por otra parte, se encuentran estudios que plantean como en España se tiene como principio fundamental la responsabilidad y la educación de los menores, puesto que se reconoce la necesidad de generar una medida basada en la educación de los infractores para la resolución del motivo por el cual se haya infringido la ley, al igual que el trabajo en las posibles variables que puedan generar alguna reincidencia del acto delictivo (Ortega-Campos, 2014; Colás, 2015).

De este modo dentro de los factores en común en las investigaciones se encuentra que dichas medidas dentro del Sistema de Responsabilidad Penal para Adolescentes, deben tener en cuenta la edad en la que se encuentren los actores del delito, puesto que como se ha mencionado, la responsabilidad penal juvenil, se toma como una sub-categoría de la responsabilidad penal general, debido a que éste respalda a los menores de 18 años, y tiene que tener en cuenta otras condiciones, como el hecho de reconocer aspectos como la maduración de los mismos, el rol social que se les adjudica y las leyes dirigidas a esta población. En este orden de ideas se retoman los hallazgos de autores como Vega (2015) y Tendlarz (2015), puesto que plantean que en el caso colombiano dichas medidas se enmarcan en primer lugar en el Código de infancia y adolescencia, el cual plantea que el trato penal y la responsabilidad de los niños y adolescentes será diferente según su edad, su capacidad psíquica y su grupo étnico.

De igual forma aunque la responsabilidad penal cumpla lineamientos a nivel del Código de Infancia y Adolescencia, es importante no dejar de lado los contextos en los que estos lineamientos se tengan en cuenta, puesto que como lo plantean López (2014), Méndez (2015) y Sandoval y Tirado (2013), no se han generado mecanismos que asuman todas las condiciones de infracción ya que además de los ya mencionados es necesario conocer y tener en cuenta otros aspectos como el 
género y la maternidad o paternidad, al igual que la participación en contextos de combate, los contextos de desarrollo y la satisfacción de las necesidades básicas de los niños, niñas y adolescentes implicados, ya que estas cumplen condiciones distintas las cuales se deben tener en cuenta para buscar el manejo adecuado de este tipo de situaciones.

Por consiguiente investigaciones como la llevado a cabo por Mojica y Moreno (2014), toman importancia puesto que permiten conocer la experiencia de los adolescentes dentro del SRPA, puesto que a partir del trabajo con 40 adolescentes y la aplicación de un Test de adaptación infantil se reconoce la importancia de tener en cuenta factores como la adaptación personal, escolar, familiar y social al igual que del funcionamiento de los mismos dentro de los centros de atención, puesto que el trabajo para la rehabilitación de estos se debe dar por medio de un trabajo en conjunto entre la familia, la sociedad y el estado con el fin de que estas permitan la adaptación del adolescente al contexto.

En este orden de ideas, en Colombia se deben tener en cuenta las reglas y normas diferenciadores, esto a partir de lo planteado por Bravo (2015) y Huertas y Morales (2013), puesto que al estudiar la Ley 1098 del 2006, se entiende como establece la normatividad del sistema de responsabilidad de los adolescentes basándose para ello en los principios de educación y diferenciación de este grupo de menores, planteando que los mayores de 14 años y menores de 18, se cobijan por el sistema penal acusatorio, con reglas diferenciadas para esta población; dando paso a otros hallazgos como lo son la finalidad de estas reglas, lo cual da paso a análisis como los planteados en el texto de Huertas y Morales (2013) ya que se reconoce la necesidad de contar con un defensor o comisario de familia que proteja los derechos del menor, al igual que con otro tipo de sanciones que no estén entorno a la privación de la libertad a menos que cumpla con unos 
mínimos para esto, y finalmente la prohibición de generar juicios sin el joven presente a menos que este interrumpa el proceso.

Así mismo y para la comprensión de las mecanismos por los cuales en Colombia se asume la responsabilidad penal Erazo (2016) y Sanz, Moreno y Pérez (2015), estudian como la mencionada Ley, da paso al SRPA (Sistema de Responsabilidad Adolescente) el cual establece la normatividad frente a los mecanismos judiciales de las infracciones y delitos de los adolescentes entre los 14 y 18 años, al igual que al establecimiento del ICBF como el regulador de los programas e instituciones que se relacionen con el SRPA. Con relación a lo anterior Sánchez (2016), plantea como en Colombia se reconoce el hecho de que el SRPA, sigue un proceso de modificación con el cual busca lograr estar en el marco de la justicia restaurativa, esto sin dejar de lado los derechos propios de los menores de edad, para lo cual los sistemas penales buscan tener un equilibrio frente a la protección de la sociedad ante las agresiones frente a la ley, rescatando la responsabilidad social y la necesidad de que agentes como la familia y la sociedad en general promuevan la restauración de los derechos

Con el fin de sustentar lo citado en el párrafo anterior se retoma la idea de la Ley Orgánica citada por Llanos y Marrero (2016), la cual consiste en que al generar una ley en torno a la responsabilidad penal de los menores de edad, se requiere conocer el objetivo de la misma, con el fin de prevenir mecanismos represivos durante los procesos penales con menores infractores, buscando promover la reinserción del joven por medio de mecanismos educativos que se basen en la responsabilidad, el conocimiento de los intereses del menor, la resocialización del mismo, todo esto sin dejar de lado los procesos de mediación y conciliación con la víctima de la infracción cometida por el menor. 
A partir de lo mencionado cabe resaltar que más allá del lugar y el cómo asume cada país la reinserción y los procesos penales de los niños, niñas y adolescentes, las investigaciones, procesos y mecanismos de acción se basan en el estudio de una serie de leyes y consignas que determinan las condiciones necesarias de tener en cuenta para el debido proceso; por lo cual se reconocen análisis como los planteados en el texto de Llanos y Marrero (2016), en torno a las implicaciones, el funcionamiento y la aplicaciones de normatividades como la declaración de los Derechos Humanos, la Convención de los Derechos del Niño, las reglas de las Naciones Unidas para la administración de la justicia a menores y las reglas para la protección de los menores privados de la libertad, entre otros lineamientos.

Para concluir, teniendo en cuenta que el objetivo de la investigación es comprender las percepciones de los profesionales y las autoridades competentes sobre la protección integral en el Sistema de Responsabilidad Penal para Adolescentes (SRPA), se considera interesante el hecho de que las investigaciones previas realizadas en torno al tema del SRPA consisten principalmente en investigaciones teóricas, análisis documentales o estudios que buscan comprender los factores o las experiencias de los jóvenes infractores, dejando de lado la importancia de generar investigaciones que reconozcan la perspectiva de los profesionales y autoridades que se encuentran dentro de este sistema. 


\section{Método}

\section{Tipo de investigación y diseño}

Para la realización de este estudio se hizo uso de técnicas de investigación cualitativa a través de la aplicabilidad de elementos de hermenéutica como fundamento útil para la interpretación de los fenómenos humanos, en la mirada de Wilhelm Dilthey (2015). Ello facilitará una revisión documental conceptual, teórica y legal de las materias a tratar realizando una interpretación en su aplicabilidad a casos específicos de la realidad.

De otra parte, para enriquecer el estudio, se tomará como base la aplicabilidad de la semiótica en tanto además de realizarse una revisión documental se aplicarán entrevistas abiertas, grupos de discusión o técnicas de observación y observación participante (narrativas) de acuerdo con Jesús Ibáñez (1985), es decir, que se analizarán impresiones de algunos sujetos implicados en los fenómenos de estudio estableciendo relaciones de significado que se producen en determinada cultura o ideología usando un método de representatividad estructural, es decir tratando de incluir en el análisis documentos existentes, hechos o personas en torno al fenómeno de estudio (Ibañez, 1985).

En específico se habla de aplicar la semiótica por cuanto constituye el estudio de los signos, de la producción de sentido de lo social, lo que ha adquirido relevancia. Habrá aquí un espacio para las representaciones, los discursos, las significaciones, los valores, todo ello entendido como lo simbólico tratando de encontrar signos, articulaciones y combinaciones actuales y posibles, las consecuencias de ello y los modos en que esto tiene lugar en la medida que crece, se consolida y confirma un lugar propio. 
Mediante la aplicabilidad de esta metodología se pretende contribuir al abordaje de una problemática relacionada con la población de adolescentes en conflicto con la ley, desde el campo psico jurídico, identificando los justificantes criminógenos y la intervención psicosocial en el SRPA en Bogotá. Asimismo, se pretende que los resultados de la investigación puedan ser una fuente de consulta para la estructuración y reestructuración de planes de intervención, a nivel nacional a la luz de la ley 1098 de 2006 que conlleven a disminuir los índices de criminalidad y reincidencia en adolescentes.

\section{Participantes}

En la presente investigación, se realizaron 7 (siete) entrevistas directas a los diferentes actores del proceso, dentro del sistema de responsabilidad penal para adolescentes, siendo estos, de acuerdo a la ley 1098 de 2006: Jueces penales para adolescentes, procurador delegado de Infancia, adolescencia y familia, defensores públicos del Sistema Nacional de Defensoría Pública de la Defensoría del Pueblo, Fiscales delegados ante jueces penales de adolescentes, Defensores de Familia del Instituto Colombiano de Bienestar Familiar, teniendo en cuenta que son estos las autoridades especializadas dentro del sistema de responsabilidad penal para adolescentes. Se incluirán entrevistas a Trabajadores Sociales, Psicólogos, del ICBF, quienes hacen el abordaje personal, familiar y social, participando como peritos y profesionales expertos dentro del proceso.

\section{Instrumentos de investigacion:}

\section{Entrevista Semiestructurada}

Se implementó como instrumento de investigación la Entrevista semiestructurada, según Taylor y Bogan (1986), el investigador previamente a la entrevista lleva a cabo un trabajo de 
planificación de la misma elaborando un guion que determine, aquella información temática que quiere obtener.

\section{Anexos}

\section{Entrevista 1}

Entrevistado: Autoridad Competente SRPA: Fiscal Delegado en Asuntos Penales de Adolescentes (Se identificará en el desarrollo de la investigación como Profesional 1)

Resumen Hoja de Vida: Abogado, especialista en Derecho de Penal. Magister en Derecho Penal. Máster en Derechos Humanos, ex fiscal delegado en asuntos penales. Ex Defensor del Pueblo Regional. Docente Universitario. 4 años en el ejercicio como Fiscal en el Sistema de Responsabilidad Penal para Adolescentes.

Se le informa los fines de la entrevista: Realizar una investigación acerca de la percepción de las autoridades y profesionales actores del SRPA, para presentar trabajo de grado, a fin de obtener el título de Magister en Psicología Jurídica de la Universidad Santo Tomas de Bogotá. Después de haber firmado el consentimiento informado, se procede a realizar entrevista. Se advierte que se guardará toda reserva sobre el contenido de la misma y será utilizada exclusivamente para los fines pertinentes ya explicados al inicio

¿Cree Ud. que el estado colombiano está respondiendo a las necesidades del país, en términos de justicia penal para adolescentes?

R/A. Si. Actualmente se realiza un comité interinstitucional a fin de corregir las pocas falencias que existen con respecto al tema. De ofrecer además una buena oferta a los jóvenes que tienen investigaciones pendientes y que se encuentran cumpliendo medidas, ya que tienen derecho a la rehabilitación y a la resocialización mediante planes y programas que sean garantizados por el estado y que deben ser implementados por las instituciones que integran el sistema. Para ello se 
busca que el joven que ha infringido la ley penal sea responsable de sus actos y que corrijan sus errores con las personas que los han cometido cambiando su manera de pensar y de actuar.

¿Cuales son los tipos de sanciones mas recurrentes?

R/A. La amonestacion, prestacion de servicios sociales a la comunidad, libertad vigilada, internamiento en medio semi cerrado.

¿Cuáles son las medidas preventivas más recurrentes?

R/A. Medidas de internamiento preventivo y de libertad vigilada son las mas utilizads or los jueces dependiendo del tipo de delito que se haya cometido por el adolescente.

¿Considera que la ubicación en medio familiar, es una medida de restablecimiento de derechos adecuada?

R/T. Si puesto que la familia hace parte de la rehabilitación del joven y solo con ellos se hace el restablecimiento de derechos de los jóvenes. De igual forma es importante el acompañamiento de la misma durante todo el proceso porque es allí en el medio en el que el joven se desenvuelve y son ellos los responsables de su crianza y de su evolución dentro del medio.

¿Considera que las medidas de internamiento preventivo, dan resultados pedagógicos?

$\mathrm{R} / \mathrm{T}$. Si en la medida que el tiempo que permanezca el joven dentro del centro ocupe su tiempo y realice actividades que le sirvan para su futuro. Que aproveche las oportunidades que el mismo sistema le ofrece.

¿Una medida privativa de la libertad, da resultados que controlen la participación de los adolescentes en futuros delitos?

R/T. Si, aunque también se debe tomar como una oportunidad de que el joven que cometió la infracción recapacite y mire las cosas desde otra óptica y trate de mejorar su estilo de vida y corrija el error que cometió. No se trata de imponer castigos con la medida en lo que tiene que ver 
con el sistema, sino de presentar su falla desde otra perspectiva y que mire otra forma de actuar y pensar.

¿Cuáles Considera son las causas más relevantes de la reincidencia en la comisión de delitos?

R/A. La educación, Falta de apoyo de la familia, la falta de oportunidades dentro de la sociedad, regresar al mismo grupo o ambiente social de barrios, grupo o pandilla.

¿Qué cree que se debe hacer para eliminar la reincidencia en la comisión de delitos por parte de los adolescentes?

R/T. Brindar oportunidades de estudio y trabajo a los jóvenes. Facilidad en el acceso a carreras profesionales y técnicas, a actividades culturales, así como música, danzas talleres que le permitan al joven estar ocupado y sr útil a la sociedad.

\section{Entrevista 2}

Entrevistado: Profesional Competente SRPA: Psicólogo Trabajadora Social Especializado grado 17. (Se identificará en el desarrollo de la investigación como Profesional 2)

Resumen Hoja de Vida: Trabajadora Social, Especialista Terapista Familiar, Magister en Protección Social, Investigadora Social. Docente Universitaria. 7 años en el ejercicio como Trabajadora Social en el Instituto Colombiano de Bienestar Familiar en el Sistema de Responsabilidad Penal para Adolescentes.

Se le informa los fines de la entrevista: Realizar una investigación acerca de la percepción de las autoridades y profesionales actores del SRPA, para presentar trabajo de grado, a fin de obtener el título de Magister en Psicología Jurídica de la Universidad Santo Tomas de Bogotá. 
Después de haber firmado el consentimiento informado, se procede a realizar entrevista. Se advierte que se guardará toda reserva sobre el contenido de la misma y será utilizada exclusivamente para los fines pertinentes ya explicados al inicio.

¿Cree Ud. que el estado colombiano está respondiendo a las necesidades del país, en términos de justicia penal para adolescentes?

R/T. El principio y fin último del sistema de responsabilidad penal para adolescentes es pedagógico, preventivo y restaurativo. Sin embargo, si pensamos en los datos estadísticos de incursión de adolescentes al área penal, por motivos de comisión de delitos, podemos considerar que esto no se está cumpliendo a cabalidad. Toda vez que un adolescente debería recibir por parte de lo estado, un blindaje que no permitiera su reincidencia en la delincuencia. Los estudios de entidades como la Defensoría del Pueblo, nos indican que si el adolescente está cumpliendo una sanción en medio cerrado o semicerrado, la labor pedagógica, no se está dando como tal, se resumen a simples esfuerzos por poner al adolescente a tono con la parte básica académica, o sea, se limitan a vincularlos a un grado educativo de acuerdo a sus competencias o conocimientos en las asignaturas regulares. Lo cual dista mucho de la labor de formación personal, repensada en reeducar o resocializar a este adolescente. Ahora bien, en el mismo orden de ideas, cuando se habla de preventiva, se supone que deberían lograrse en el adolescente profundos cambios trascendentales en su actitud hacia la vida misma, o una variación en el comportamiento y su conducta. Sin embargo, observamos que un mismo adolescente reincide en muchísimas oportunidades en la comisión de un mismo delito o en otros aún más graves. Como por ejemplo aquellos adolescentes que han sido judicializados por porte ilegal de armas en tres o cuatro oportunidades, generalmente es sancionado posteriormente por el delito de hurto calificado y agravado, tentativa de homicidio y en muchos casos por el delito de homicidio. En 
este sentido si el SRPA, cumpliese en un fin preventivo, desde el primer delito, por el cual ingreso, ya no debería incursionar jamás en conflicto con la ley penal. Ahora cumple un fin restaurativo. ¿Nos preguntamos a quien se restaura, al adolescente, a la víctima? A mi modo de ver el adolescente en cada delito cae en un abismo y generalmente, la victima tiene un deseo encarnizado de castigo, de tal forma que ni siquiera accede a acuerdos que permitan restaurar el daño ocasionado.

¿Cómo realizan acciones restaurativas con los adolescentes?

R/A. Las acciones que se implementan en la realidad son para estricto cumplimiento de las funciones del servidor público.

El adolescente, se sanciona en primera instancia con una amonestación, la cual impica un compromiso por parte de la familia y del mismo adolescente.

Otro tipo de sanción es la libertad asistida con servicio social comunitario.

De acuerdo a la carga laboral del servidor público, al adolescente se le hace un seguimiento cada seis meses, o se actualiza informacion basica en caso de tener audiencias en el juzgado. Caso contrario los seguimientos con fines restaurativos son minimos, ya que el tiempo y la carga laboral, medida en la cantidad deprocesos que se manejan, no permiten tener un control ni conoocimiento de la situacion actual de cada adolescente. En no pocas ocasiones se pierde el contacto con el adolesente y su familia, ya que al incumplir la sancion, optan por trasladarse de lugar de residencia, sin informar a las autoridades competentes. En estos casos el juez toma medidas para ubicarloo a traves de los organismos competentes.

¿Qué opina sobre las medidas de protección para adolescentes?

$\mathrm{R} / \mathrm{T}$. Las medidas son más restrictivas que restablecedoras o restaurativas. 
Una verdadera medida de protección debería estar plagada de elementos y componentes integrales, como trata de establecerlo la norma. Sin embargo, solo se brindan garantías a medias. Debido a que el estado no tiene la capacidad para adelantar acciones eficaces en temas de oportunidades educativas o laborales reales y coherentes a la realidad. Si a un adolescente se otorga libertad asistida, el estado no se encarga de su verdadera reinserción social, consistente en acciones validas educativas, lúdicas, laborales, familiares, económicas que le permitan desviarse del camino delictivo. De esta forma el adolescente continuo una vida de incursión en hurtos, consumo de spa, aunándose a pares inadecuados que lo conducen a continuar delinquiendo.

¿Qué se debe hacer para prevenir la delincuencia juvenil?

R/A. Para prevención de la delincuencia juvenil, debe trabajarse dese la primera infancia, haciendo inversión social en educación, en fortalecimiento de programas productivos familiares, que garanticen el sostenimiento de todos los miembros de la familia. Deben además fortalecerse el tema de prevención del consumo de spa. Y debe contrarrestarse a nivel general la delincuencia organizada, ya que, desde las organizaciones delictivas de adultos, se crean estrategias para cautivar niños y adolescentes frágiles o vulnerables, que permean un fácil convencimiento para el ingreso al accionar delincuencial.

¿La familia asume su rol con suficiente responsabilidad dentro del proceso pedagógico del adolescente?

R/A. Los adolescentes que ingresan al SRPA, proceden de diferentes tipos de familia, en general son familias monoparentales por línea materna, con un subsistema fraterno de varios hijos. En condiciones económicas muy precarias, con niveles educativos muy bajos, con muchas necesidades mínimas no satisfechas. De tal forma que cuando un adolescente ingresa al SRPA, 
la familia "prefiere" que este quede con medida de privación de libertad, considerando que de esta forma aprenderá la lección y es una forma de liberarse del problema.

¿Cómo se involucra la familia en el proceso de los adolescentes?

R/A. En realidad, la vinculación de la familia es mínima, esta no responde a los requerimientos de las autoridades y en la mayoría de los casos asume una posición periférica, sin involucrarse directamente en el proceso. Considera que el estado debe asumir el proceso sin participación de estos.

¿Qué acciones se toman con la familia?

R/T. Ninguna. Las medidas de amonestación no son funcionales. La familia recibe al adolescente a través del mecanismo de reintegro al medio familiar y no ejercen el control y la supervisión estipulada por el Defensor de Familia y lo estipulado en la medida de libertad otorgada por la autoridad competente.

¿Cuáles son los problemas más recurrentes de estos adolescentes? y ¿Qué hacen para tratarlos?

R/T. El principal problema es la reincidencia y el otro problema es la evasión del medio familiar y/o de las instituciones donde es ubicado.

¿Qué cree que se debe hacer para eliminar la reincidencia en la comisión de delitos por parte de los adolescentes?

R/T. Crear programas sociales a fin de lograr la incursión y permanencia en las aulas escolares y programas de fortalecimiento familiar, en temas de proyectos productivos, temas de formación y fortalecimiento de valores, ejercicio de pautas de crianza y modelos de crianza. ¿Qué aportes considera pueden hacerse desde el rol del trabajador social y los psicólogos para que un adolescente no reincida en la comisión de delitos? 
$\mathrm{R} / \mathrm{T}$. Implementación de pedagogía reeducativa, para lo cual se requiere compromiso y disponibilidad de tiempo, sin embargo, la alta cantidad de procesos no lo permiten. Se requiere ampliación de funcionarios en las instituciones de protección y ampliación de planta de personal e las entidades estatales, que permita brindar una atención más eficaz y pertinente.

\section{Entrevista 3}

Entrevistado: Autoridad Competente SRPA: Juez Penal de Adolescentes. (Se identificará en el desarrollo de la investigación como Profesional 3)

Resumen Hoja de Vida: Abogado, especialista en Derecho de Procesal Civil, especialista en Derecho de Familia, Magister en Derecho Penal. Exfiscal delegado en asuntos penales. Exfiscal delegada en Infancia y Adolescencia. Docente Universitario. 6 años en el ejercicio como Juez de Garantías en el Sistema de Responsabilidad Penal para Adolescentes.

Se le informa los fines de la entrevista: Realizar una investigación acerca de la percepción de los autoridades y profesionales actores del SRPA, para presentar trabajo de grado, a fin de obtener el título de Magister en Psicología Jurídica de la Universidad Santo Tomas de Bogotá.

Después de haber firmado el consentimiento informado, se procede a realizar entrevista. Se advierte que se guardará toda reserva sobre el contenido de la misma y será utilizada exclusivamente para los fines pertinentes ya explicados al inicio.

¿Cree Ud. que el estado colombiano está respondiendo a las necesidades del país, en términos de justicia penal para adolescentes?

R/A. Frente a la pregunta es importante tener en cuenta que atreves de la Ley 1098 de 2006, se realizaron esfuerzos bastante grande, para reformular las nuevas sanciones establecidas, atreves de un carácter pedagógico y restaurativo, sin embargo la dinámica social, nos han llevado 
a replantear muchas de las sanciones que hoy en día están establecida de carácter pedagógico y judicial para los Adolescentes, las cuales cada vez se están haciendo más corta frente al proceso de acompañamiento de los jóvenes que las hacen insuficiente, en su efectividad, por cuanto que los Adolescente conocen más ley, con el fin de evitar que les sean ; lo cual hace que el nivel de evasión sea grande y vienen superando las medidas a la que son sometidos. Son insuficientes y muchas veces los traslados por privación de la libertad no se cumple por cuanto que se evaden, estos traslados no se cumplen por la carencia de espacios para ubicarlos, esto hace hacen que el sistema no opere como debe ser y para el cual está diseñado, se necesita un sistema más eficiente para cumplir con las sanciones y realizar el acompañamiento correspondiente y el procedimiento judicial ajustado fallado a la ley.

¿Cuáles son los tipos de sanciones más recurrentes?

R/A. Bueno los tipos de Sanciones más recurren que se le impone a los Adolescente que entran en choque con la Norma Penal son: El Internamiento Preventivo, la cual consiste que en cualquier momento del proceso y antes de la audiencia de juicio, el juez de control de garantía, como último recurso la decreta, por cuanto que en la mayoría de los casos el Adolescente o los Adolescentes sobre ellos existe riesgo razonable de que se evadirá del proceso, existe temor fundado que destruirá u obstaculizara las pruebas o existe peligro grave para la víctima, el denunciante, el testigo o la comunidad en la cual se generó la exteriorización de su conducta criminal.

Este tipo de sanción recurrente es el Internamiento preventivo, este tipo de sanción opera en los casos en que, conforme a la gravedad del delito sería admisible la privación de la libertad. Esta se ejecuta en Centros de Internamientos Especializados cerrados, en los cuales los Adolescentes procesados están separados de los ya condenados. Este internamiento no podrá 
exceder de cuatro meses los cuales podrán prorrogarse con motivación, por un mes más, si realizado lo anterior el juicio no ha terminado por sentencia condenatoria, el Juez del caso lo hará cesar, sustituyendo dicha medida por otra como la asignación a una familia, el traslado a un hogar o a una institución educativa.

Otro tipo de sanción muy concurrente es la Amonestación, en la cual la autoridad judicial y competente recrimina al adolescente sobre las consecuencias del hecho en tuvo participación y por el cual se encuentra vinculado al proceso y por lo cual debe reparar el daño causado, en todo el caso deberá asistir a un curso educativo sobre respeto a los derechos humanos y convivencia ciudadana el cual estará a cargo del Instituto de Estudio del Ministerio Público.

Las reglas de conductas, que también es muy frecuente es la imposición de la Autoridad Judicial al adolescente de obligaciones para regular su modo vida y así como la de promover su y asegurar su formación. Esta sanción no podrá exceder de dos años.

¿Cuáles son las medidas preventivas más recurrentes?

R/A. La Amonestación, la prestación Servicios Sociales a la comunidad y la Libertad Vigilada la cual no podrá ser superior a dos años.

¿Considera que la ubicación en medio familiar, es una medida de restablecimiento de derechos adecuada?

R/A. Bueno la verdad que, en algunos casos, puede que resulte como en otros no resulta en lo absoluto que esta medida brinde las garantías necesarias en que el Adolescente no recaiga de inmediato en volver a la comisión de delitos en su comunidad y con más fuerza y decisión para su comisión. Aquí la Familia como garante del principio de corresponsabilidad debe aportar su efectividad en el control del adolescente que se le ha dado este tipo de ubicación familiar. ¿Considera que las medidas de internamiento preventivo, dan resultados pedagógicos? 
R/T. Esta clase de medidas deben ser revaluadas por el Sistema por cuanto que la pedagogía empleada en esos lugares no despierta la menor atracción y convencimiento como expectativa de vida al adolescente, se debe incentivar a través de nuevos métodos pedagógicos mucho más efectivos y productivos con los adolescentes como escuelas, universidades y programas que le brinden atracción a sus intereses re socializadores y que lo pongan en paz con su familia y comunidad.

¿Una medida privativa de la libertad, da resultados que controlen la participación de los adolescentes en futuros delitos?

R/T. Esta Medida no responde a la prevención, ni garantiza en que el Adolescente puede nuevamente reincidir en la comisión de un nuevo delito o en la repetición del mismo. La experiencia indica que en su mayoría los adolescentes que entran y son sancionados vuelven con mucha más furia a la calle y caen nuevamente en el delito, pero con más audacia en la comisión del mismo.

¿Las sanciones en medio cerrado, son eficaces?

R/T. No son eficaces, por el contrario, sirve como medio de protección al Adolescente para escudarse de sus adversarios o victimas de sus despliegues criminales y al pasar el tiempo y considerar que hay olvido de sus adversarios y victimas sale con confianza y nuevamente acomete la misma conducta criminal.

¿El adolescente cumple e proceso pedagógico dentro del SRPA?

$\mathrm{R} / \mathrm{T}$. Generalmente no lo cumple por cuanto que no le es atractivo y no llena sus expectativas de vida.

¿Con qué frecuencia los adolescentes reinciden en la comisión de delitos? 
R/T. Tal como lo anote arriba son muchas las posibilidades de su reincidencia por cuanto que no se realiza una verdadera prevención y garantía a la no repetición de sus conductas delictivas.

¿Cuáles Considera son las causas más relevantes de la reincidencia en la comisión de delitos?

R/T. La falta de una verdadera política pública que en verdad resulte atractiva, convincente y garantista para los Adolescentes.

\section{Entrevista 4}

Entrevistado: Autoridad Competente SRPA: Juez Penal de Adolescentes.( Se identificará en el desarrollo de la investigación como Profesional 4)

Resumen Hoja de Vida: Abogada, especialista en Derecho de Familia. Magister en Derecho Penal. Ex fiscal delegado en asuntos penales. Ex fiscal delegada en Infancia y Adolescencia. Docente Universitaria. 4 años en el ejercicio como Juez de Conocimiento en el Sistema de Responsabilidad Penal para Adolescentes.

Se le informa los fines de la entrevista: Realizar una investigación acerca de la percepción de las autoridades y profesionales actores del SRPA, para presentar trabajo de grado, a fin de obtener el título de Magister en Psicología Jurídica de la Universidad Santo Tomas de Bogotá. Después de haber firmado el consentimiento informado, se procede a realizar entrevista. Se advierte que se guardará toda reserva sobre el contenido de la misma y será utilizada exclusivamente para los fines pertinentes ya explicados al inicio. 
¿Cree Ud. que el estado colombiano está respondiendo a las necesidades del país, en términos de justicia penal para adolescentes?

R/A. Bueno en los últimos tiempos se están creando algunos mecanismos a fin de corregir las grandes lagunas que existen con respecto a esta Política Pública. La cual está encaminada de ofrecer una inmensa garantía en favor de estos jóvenes que tienen investigaciones aplazadas y que se encuentran cumpliendo medidas, ya que tienen derecho a su rehabilitación y a la resocialización mediante planes y programas que sean garantizados por el estado y que deben ser implementados por la institución que integra el sistema. Es por ello cuando un Adolescente ha entrado en choque con la norma penal debe garantizársele por medio del sistema el entendimiento del daño causado por su conducta y se haga responsable de sus actos y que pueda corregir, respondiéndole al ofendido repararan do el daño causado y garantizar una mejor convivencia con sus asociados.

¿Cuáles son los tipos de sanciones mas recurrentes?

R/A. La amonestación, prestación de servicios sociales a la comunidad, libertad vigilada, internamiento en medio semi cerrado.

¿Cuáles son las medidas preventivas más recurrentes?

R/A. La verdad que las Medidas mas recurrentes son la de internamiento preventivo y de libertad vigilada, en las cuales los jueces acuden a ellas teniendo en cuenta el tipo de delito en que se encuentre involucrado el Adolescente.

¿Considera que la ubicación en medio familiar, es una medida de restablecimiento de derechos adecuada?

R/T. La Familia como estamento indispensable, efectivo y responsable de la corresponsabilidad, viene fallando gravemente en realizar los correctivos necesarios a tiempo, constituyéndose esto en una gran falla y que amerita realizar un reestudio y actualizar o revisar 
esta responsabilidad que debe tener toda familia con relación al comportamiento de los adolescentes. Cada día se observa como la familia deja de lado la toma de decisión y participación en mecanismos prácticos, seguros y en tiempos favorables a sus hijos e hijas y por el contrario lo dejan al Estado para que realice lo que deba realizar en la terminación de la crianza de sus hijos. ¿Considera que las medidas de internamiento preventivo, dan resultados pedagógicos?

$\mathrm{R} / \mathrm{T}$. Esta medida pedagógica en el papel resulta muy efectiva para aquellos adolescentes que quizás por los avatares de la vida se ven envueltos por un accionar de su conducta mal direccionada y con esa reflexión educativa retoman su camino correcto. Pero en verdad cuando el adolescente es una persona curtida en el crimen y es repetitivo su actuar, nos encontramos que dicha medida no corresponde al fin deseado la rehabilitación completa en él y es cuando nos ponemos a pensar que hay que revisar y actualizar estos modelos pedagógicos impartidos en favor de estos adolescentes cuya finalidad es la de lograr su verdadera restauración en el restablecimiento de sus derechos.

¿Una medida privativa de la libertad, da resultados que controlen la participación de los adolescentes en futuros delitos?

$\mathrm{R} / \mathrm{T}$. De esta manera y mediante la privación de la libertad, de estos adolescente pienso que no es la mejor decisión, pero como realmente existe una verdadera debilidad y angustia institucional; en el que hacer con ellos, que cada día aumentan su presencia y reincidencia en el espectro de la delincuencia juvenil que azota a la vecindades y comunidades que les rodea: se hace necesario orientar seriamente una revisión al proceder del actual Sistema de Responsabilidad Penal para Adolecentes, institucionalmente, familiar y socialmente comprometido en garantizar que nuestros jóvenes alcancen sus ideales de ser felices con las garantías plenas de sus Derechos. 
¿Cuáles Considera son las causas más relevantes de la reincidencia en la comisión de delitos?

R/A. La educación, falta de apoyo de la familia, la falta de oportunidades dentro de la sociedad, que le garantizan nuevamente en reincidir regresando al mismo grupo o ambiente social de barrios, grupos y pesadillas de las pandillas que se constituyen cada día en las formas organizadas de la delincuencia juvenil en nuestro país.

¿Qué cree que se debe hacer para eliminar la reincidencia en la comisión de delitos por parte de los adolescentes?

R/T. Realizar un verdadero reconocimiento al papel de la corresponsabilidad de la Familia, Sociedad y Estado, con los cuales bajo una adecuada decisión de Políticas Publicas se determine de manera pronta y efectiva una mejor determinación.

\section{Entrevista 5}

Entrevistado: Autoridad Competente SRPA: Defensor de Familia. (Se identificará en el desarrollo de la investigación como Profesional 5)

Resumen Hoja de Vida: Abogado, especialista en Derecho de Familia. Magister en Derecho de Familia. Ex Defensor Público de la Defensoría del Pueblo, Docente Universitario. 5 años en el ejercicio como Defensor de Familia en el Sistema de Responsabilidad Penal para Adolescentes.

Se le informa los fines de la entrevista: Realizar una investigación acerca de la percepción de las autoridades y profesionales actores del SRPA, para presentar trabajo de grado, a fin de obtener el título de Magister en Psicología Jurídica de la Universidad Santo Tomas de Bogotá. 
Después de haber firmado el consentimiento informado, se procede a realizar entrevista. Se advierte que se guardará toda reserva sobre el contenido de la misma y será utilizada exclusivamente para los fines pertinentes ya explicados al inicio.

¿Cree Ud. que el estado colombiano está respondiendo a las necesidades del país, en términos de justicia penal para adolescentes?

R/A. Por medio de la Ley 1098 de 2006, se ha tratado de establecer una solución que mediante lo pedagógico, nos han llevado a replantear muchas de las sanciones que hoy en día están establecidas para los adolescentes, las cuales cada vez se están haciendo más cortas frente al proceso de acompañamiento de los jóvenes que las hacen insuficientes, en su efectividad, por cuanto que los adolescente conocen más ley lo cual hace que el nivel de evasión sea grande y vienen superando las medidas a la que son sometidos. Son insuficientes y muchas veces los traslados por privación de la libertad no se cumple por cuanto que se evaden, estos traslados no se cumplen por la carencia de espacios para ubicarlos, esto hace hacen que el sistema no opere como debe ser y para el cual está diseñado, se necesita un sistema más eficiente para cumplir con las sanciones y realizar el acompañamiento correspondiente y el procedimiento judicial ajustado fallado a la ley.

¿Cuáles son los tipos de sanciones más recurrentes?

R/A. El Internamiento Preventivo, el cual consiste en que el juez de control de garantías decreta, ya que la mayoría del adolescente se evaden con suma facilidad al momento de estar dentro del PRD lo que implica un riesgo razonable y es por ello que tratando de lograr su presencia dentro del mismo poniendo a salvo su compromiso de la reparación integral por su conducta cometida, esta se ejecuta en Centros de Internamientos Especializados cerrados. Otro tipo de sanción muy concurrente es la Amonestación, en la cual la autoridad judicial reconviene al 
adolescente y de paso a los familiares sobre las consecuencias del hecho en la cual la autoridad le llama la atención y así mismo deberán brindar las garantías necesarias para asegurar un mejor comportamiento de este adolescente en su entorno.

¿Cuáles son las medidas preventivas más recurrentes?

R/A. La amonestación, la prestación servicios sociales a la comunidad y la libertad vigilada la cual no podrá ser superior a dos años.

¿Considera que la ubicación en medio familiar, es una medida de restablecimiento de derechos adecuada?

R/A. No es adecuada por la falta de compromiso necesario y contundente por parte de la familia al momento de recibir al adolescente de nuevo en su seno familiar, en la medida en la que la familia no represente su verdadero papel como apoyo necesario a la recuperación de este adolescente en un buen desenvolvimiento de la convivencia en su comunidad no podríamos decir que la familia es garante para ellos, se hace necesario presentar un reestudio en el cual se logre compromisos efectivos del núcleo familiar, en su papel como representante de uno de los estamentos de la corresponsabilidad.

¿Considera que las medidas de internamiento preventivo, dan resultados pedagógicos?

$\mathrm{R} / \mathrm{T}$. Las medidas pedagógicas en los internamientos preventivos no constituyen ni llenan las expectativas en los adolescentes, es necesario implementar nuevas fórmulas que conquisten el lleno de ese cambio favorable de vida en los adolescentes.

¿Una medida privativa de la libertad, da resultados que controlen la participación de los adolescentes en futuros delitos?

$\mathrm{R} / \mathrm{T}$. En principio se vería como necesaria. Pero al tener en cuenta que unos de los dones más preciados es la libertad y sobre todo en los jóvenes, cuando apenas empiezan a desplegar en 
sus vidas, pensamos que no es lo más apropiado para ellos. Esta medida no responde a la prevención, ni garantiza en que el adolescente no vuelva a incurrir en conductas delictivas.

¿Las sanciones en medio cerrado, son eficaces?

R/T. No son eficaces, el adolescente, lo toma como forma de pasar el tiempo y evadir a los enemigos de la calle y de las barriadas e incluso lo utiliza como una forma de protegerse de la víctima y de los familiares de la misma.

¿El adolescente cumple el proceso pedagógico dentro del SRPA?

$\mathrm{R} / \mathrm{T}$. Generalmente no lo cumple por cuanto que no le es atractivo y no llena sus expectativas de vida.

¿Con qué frecuencia los adolescentes reinciden en la comisión de delitos?

R/T. En su mayoría los adolescentes que llegan al S.R.P.A. recaen con frecuencia en reincidencia hasta cumplir su mayoría de edad, quienes saben que la circunstancia procesal y legal cambia al cumplir los 18 años.

¿Cuáles Considera son las causas más relevantes de la reincidencia en la comisión de delitos?

R/T. La falta de garantías de una verdadera política pública que resuelva esta grave situación de desafíos constantes de los adolescentes en contra de sus corresponsales.

\section{Entrevista 6}

Entrevistado: Profesional Competente SRPA: Psicólogo Especializado grado 17. (Se identificará en el desarrollo de la investigación como Profesional 6)

Resumen Hoja de Vida: Psicóloga, especialista en Psicología Forense. Candidata a Magister en psicología del Desarrollo Humano. Docente Universitaria. Ex servidora Pública de la 
Defensoría del Pueblo. 4 años en el ejercicio como Psicóloga en el Instituto Colombiano de Bienestar Familiar en el Sistema de Responsabilidad Penal para Adolescentes.

Se le informa los fines de la entrevista: Realizar una investigación acerca de la percepción de las autoridades y profesionales actores del SRPA, para presentar trabajo de grado, a fin de obtener el título de Magister en Psicología Jurídica de la Universidad Santo Tomas de Bogotá.

Después de haber firmado el consentimiento informado, se procede a realizar entrevista. Se advierte que se guardará toda reserva sobre el contenido de la misma y será utilizada exclusivamente para los fines pertinentes ya explicados al inicio.

¿Cree Ud. que el estado colombiano está respondiendo a las necesidades del país, en términos de justicia penal para adolescentes?

R/T. Al realizar un análisis, que la estructura de la Responsabilidad Penal para Adolescentes tiene como finalidad lo de pedagógico, preventivo y restaurativo. Nos damos cuenta que desafortunadamente y probado por los datos que arroja 1 la comisión de delitos por estos jóvenes, tenemos que decir que no se cumple a su cabalidad los objetivos planteados y perseguidos por esta Ley.

¿Cómo realizan acciones restaurativas con los adolescentes?

R/A. El ejercicios que se efectúa al cumplimiento de la normatividad vigente al momento de realizar una intervención con los Adolescente involugrados mediante su conducta en situación de Responsabilidad Penal el profesional debe agotar el cumplimiento de sus funciones como tal.

Cuando al adolescente, es merecedor de una sanción amonestatatoria al mismo tiempo la misma se le impone a su familia responsable, a quienes se le hace garante de vigilar su accionar con la finalidad que aquel no vuel a incurrir en el mismo comportamiento. 
Otro tipo de sancion es la libertad asistida con servicio social comunitario.

Al adolescente se le hace un seguimiento cada seis meses, o se actualiza informacion basica en caso de tener audiencias en el juzgado.

Son muchos de los casos en los cuales se pierde el contacto con el Adolescente y el de su familiares, quienes por la situación del caso o de la conducta desplegada que choco con la narma penal, tienen que huir de la comunidad o veciindad, para protejerse de sus victimas o adversarios.

¿Qué opina sobre las medidas de protección para adolescentes?

$\mathrm{R} / \mathrm{T}$. Las medidas son más restrictivas que restablecedoras o restaurativas.

Una verdadera medida de protección debería ser más integral, tal como lo percibe el espíritu de la norma. Pero desafortunadamente, no se cumple con esto en su debida forma. Por cuanto que existes verdaderas fallas en el cumplimiento del Estado en el seguimiento al centímetro en el accionar conductual de estos jóvenes. Dando o permitiendo de esta manera una libertad al Adolescente de rencontrarse con su problemática delictiva, quien con sus pares negativos en forma conjunta y organizada enfrentan a la norma con mucho crecimiento en sus conductas.

¿Qué se debe hacer para prevenir la delincuencia juvenil?

R/A. Se debe trabajar dese la primera infancia, haciendo inversión social en educación, en fortalecimiento de los programas con familias y dando cumplimiento a los principios de la protección integral de los Adolescente y la de sus Familia, garantizando el sostén de todos sus miembros.

¿La familia asume su rol con suficiente responsabilidad dentro del proceso pedagógico del adolescente? 
R/A. El Adolescente que ingresan al SRPA, proceden de diferentes tipos de familia, la grave situación económica y social de la cual son víctimas estos jóvenes y su familia constituyen un cañón de lanza que asegura su situación de enfrentamiento a la norma penal en virtud de sus problemáticas conductas.

¿Cómo se involucra la familia en el proceso de los adolescentes?

R/A. En verdad es muy crítica la vinculación de la familia, cada día este fenómeno social de los adolescentes que ingresan al Sistema de Responsabilidad Penal, se detecta la falta de una orientación desde su adentro familiar, la cual al no contar con su involucración directamente en el proceso no garantiza una efectividad en la recuperación social de con vivencia del adolescente.

¿Qué acciones se toman con la familia?

$\mathrm{R} / \mathrm{T}$. Totalmente es nula, por cuanto que las medidas de amonestación no funcionan. La familia recibe al adolescente a través del mecanismo de reintegro al medio familiar y no ejercen el control y la supervisión estipulada por el Defensor de Familia y lo estipulado en la medida de libertad otorgada por la autoridad competente.

¿Cuáles son los problemas más recurrentes de estos adolescentes? y ¿Qué hacen para tratarlos?

R/T. El principal problema es la reincidencia y el otro problema es la evasión del medio familiar y/o de las instituciones donde es ubicado.

¿Qué cree que se debe hacer para eliminar la reincidencia en la comisión de delitos por parte de los adolescentes?

R/T. Crear programas sociales a fin de lograr la incursión y permanencia en las aulas escolares y programas de fortalecimiento familiar, en temas de proyectos productivos, temas de formación y fortalecimiento de valores, ejercicio de pautas de crianza y modelos de crianza. 
¿Qué aportes considera pueden hacerse desde el rol de la Psicología para que un adolescente no reincida en la comisión de delitos?

R/T. Realizar muchos más esfuerzos y responsabilidades, implementando la pedagogía reeducativa, para lo cual se requiere serias disposiciones y disponibilidad de tiempo, sin embargo, la alta cantidad de procesos no lo permiten. Se requiere ampliación de funcionarios en las instituciones de protección y ampliación de planta de personal en las entidades estatales, que permita brindar una atención más eficaz y pertinente.

\section{Entrevista 7}

Entrevistado: Autoridad Competente SRPA: Procuradora Judicial de Familia II. (Se identificará en el desarrollo de la investigación como Profesional 7)

Resumen Hoja de Vida: Abogada, especialista en Derecho de Familia. Magister en Derecho Penal. Ex fiscal delegada en asuntos penales. Ex fiscal delegada en Infancia y Adolescencia. Docente Universitaria. 5 años en el ejercicio como Procuradora de Familia en el Sistema de Responsabilidad Penal para Adolescentes.

Se le informa los fines de la entrevista: Realizar una investigación acerca de la percepción de los autoridades y profesionales actores del SRPA, para presentar trabajo de grado, a fin de obtener el título de Magister en Psicología Jurídica de la Universidad Santo Tomas de Bogotá.

Después de haber firmado el consentimiento informado, se procede a realizar entrevista. Se advierte que se guardará toda reserva sobre el contenido de la misma y será utilizada exclusivamente para los fines pertinentes ya explicados al inicio.

¿Cree Ud. que el estado colombiano está respondiendo a las necesidades del país, en términos de justicia penal para adolescentes? 
R/T. El sistema judicial Colombiano, está respondiendo en términos legales, toda vez que asume la norma, como un entramado judicial restaurativo. Desde lo pedagógico y diferencial; sin embargo, se requiere mayor atención en el tema de restablecimiento de derechos, toda vez que los adolescentes cuando no son sancionados, regresan a sus familias, sin que las autoridades competentes ejerzan una verdadera vigilancia en el cumplimiento de la medida de libertad asistida.

¿Cómo realizan acciones restaurativas con los adolescentes?

R/A. Las acciones que se implementan en la realidad son para estricto cumplimiento de la norma. Asi por ejemplo, cuando un adolescente es sancioonado con una medida de amonestacion, se debería hacer seguimiento semestral, por parte de las autoridades encargadas del restablecimento de derechos, en este caso el ICBF, sin embargo este segumiento no se cumple a cabalidad. Y a mi modo de ver, esto es una de las puertas que el SRPA, deja entre abiertas, ya que el adolescente y su familia, asumen, que esta es una libertad sin compromiso alguno y que el adolescentre puede continuar su vida como lo venía haciendo, incumpliendo los compromisos adquiridos con el SRPA. En muchas ocasiones el adolescente aprovecha esta falta de seguimientos para evadir la asistencia a audiencias o en muchos casos cambiar de ciudad de residencia. No existe un control eficiente, que asegure la presencia del adolecente durante el proceso y mucho menos que vuelva a incurrir en acciones delictivas.

¿Qué opina sobre las medidas de protección para adolescentes?

R/T. Considero que se aplican muchas medidas restrictivas, dejando a un lado el verdadero sentido, restaurativo, pedagógico y diferencial. Pero estas medidas restrictivas se aplican como ultima ratio, como última opción, como respuesta a las fallas del mismo SRPA, ya que el juez otorga libertades por delitos menores o cuando el adolescente ha ingresado por 
primera vez al sistema. Sin embargo muchas veces se otorga libertad varias veces, tras la reincidencia del adolescente. Y es allí donde radica principalmente la falla del sistema penal de adolescentes, porque al no existir un verdadero proceso pedagógico, que sea productivo para la resocialización del adolescente, éste vuelve a incurrir en la comisión de delitos vuelve a ingresar al sistema. De esta forma la justicia se torna restrictiva, porque se incrementan las medidas de internamiento preventivo y de privación de libertad.

¿Qué se debe hacer para prevenir la delincuencia juvenil?

R/A. Implementar más medidas pedagógicas, más medidas de servicio social. Impulsar los convenios educativos con entidades privadas o estatales, que conlleven a mejorar la formación personal del adolescente. Diseñar políticas públicas desde la primera infancia, que brinden opciones reales de vida digna al adolescente y de esta forma cuando crezca no se vea con predisposición a la comisión de delitos.

¿La familia asume su rol con suficiente responsabilidad dentro del proceso pedagógico del adolescente?

R/A. A la familia le hace falta mayor compromiso. Involucrase más en el proceso de restablecimiento de derechos y el proceso restaurativo. En la mayoría de los casos los padres se niegan a asumir su responsabilidad dentro del proceso o prefieren mantenerse aislados. En numerosas ocasiones solicitan a las autoridades que el adolescente sea privado de la libertad, argumentando que su hijo "se les ha salido de las manos". En otros casos, cuando se les otorga libertad, la familia solicita al ICBF, representado en el Defensor de Familia, para que el adolescente sea ubicado en medio institucional y se niegan a asumir los cuidados del adolescente. Rechazan la medida de reintegro al medio familiar, o simplemente no asisten al llamado del Defensor de Familia para hacerse cargo del adolescente. 
¿Cómo se involucra la familia en el proceso de los adolescentes?

R/A. La familia, no responde a los requerimientos del Defensor de Familia, o de las autoridades como Fiscales o jueces. Se mantienen ausentes, dejando la responsabilidad al ICBF. O cuando los reciben con una medida de amonestación, dejan a los adolescentes a su libre albedrio. Es más el mismo día que se les otorga libertad y son reintegrados a su medio familiar. En ese mismo momento el adolescente sale nuevamente a la calle a delinquir. Hay ausencia de control y de supervisión por parte de padres y familiares.

¿Qué acciones se toman con la familia?

R/T. Ninguna. Las medidas de amonestación no son funcionales. No hay labor pedagógica a la familia. Esta evade su responsabilidad y se niega a asumir el proceso de control y supervisión que se compromete al firmar un acta de amonestación en ICBF.

¿Cuáles son los problemas más recurrentes de estos adolescentes? y ¿Qué hacen para tratarlos?

R/T. En primer lugar problema la reincidencia en la comisión de delitos y en segundo lugar está la evasión del medio familiar y/o de las instituciones donde es ubicado.

¿Qué cree que se debe hacer para eliminar la reincidencia en la comisión de delitos por parte de los adolescentes?

R/T. Diseñar una política pública adecuada, que responda a la realidad social y familiar de los adolescentes, que contrarreste situaciones de pobreza extrema y adecuar acciones formativas eficaces. Deben crearse además programas eficaces en temas de crianza, en temas de fortalecimiento de valores. Yo creo que el estado está dejando a las familias solas en el proceso de crianza de los niños y adolescentes. 
¿Qué aportes considera pueden hacerse desde el rol del Procurador de Familia para que un adolescente no reincida en la comisión de delitos?

$\mathrm{R} / \mathrm{T}$. Impulsar medidas restaurativas, medidas de acciones pedagógicas y medidas que impulsen a la familia a involucrarse más en el proceso con el adolescente. 
Preguntas orientadoras

\begin{tabular}{|c|c|c|c|}
\hline $\begin{array}{l}\text { Categorías: } \\
\text { Percepciones sobre }\end{array}$ & Sub categorías & Preguntas para profesionales & $\begin{array}{ll}\text { Preguntas para autoridades } \\
\text { competentes }\end{array}$ \\
\hline $\begin{array}{l}\text { Principios de la } \\
\text { Protección integral } \\
\text { en el Sistema de } \\
\text { Responsabilidad }\end{array}$ & $\begin{array}{l}\text { Noción de protección } \\
\text { integral en el SRPA }\end{array}$ & $\begin{array}{l}\text { ¿Cree Ud. que el estado colombiano está } \\
\text { respondiendo a las necesidades del país, en } \\
\text { términos de justicia penal para } \\
\text { adolescentes? }\end{array}$ & $\begin{array}{l}\text { ¿Cree Ud. que el estado colombiano } \\
\text { está respondiendo a las necesidades } \\
\text { del país, en términos de justicia penal } \\
\text { para adolescentes? }\end{array}$ \\
\hline \multirow[t]{3}{*}{$\begin{array}{l}\text { Penal } \\
\text { adolescentes }\end{array}$} & $\begin{array}{l}\text { Principio del interés } \\
\text { superior en el SRPA }\end{array}$ & $\begin{array}{l}\text { ¿Cómo realizan acciones restaurativas con } \\
\text { los adolescentes? }\end{array}$ & $\mathrm{xx}$ \\
\hline & $\begin{array}{l}\text { Niños y adolescentes } \\
\text { del SRPA como } \\
\text { sujetos de derechos }\end{array}$ & $\begin{array}{l}\text { ¿Qué opina sobre las medidas de protección } \\
\text { para adolescentes? }\end{array}$ & $\begin{array}{l}\text { ¿Cuáles son los tipos de sanciones mas } \\
\text { recurrentes? }\end{array}$ \\
\hline & $\begin{array}{l}\text { Prevención de su } \\
\text { amenaza y vulneración } \\
\text { de los derechos en el } \\
\text { SRPA }\end{array}$ & $\begin{array}{l}\text { ¿Qué se debe hacer para prevenir la } \\
\text { delincuencia juvenil? }\end{array}$ & $\begin{array}{l}\text { ¿Cuáles son las medidas preventivas } \\
\text { más recurrentes? }\end{array}$ \\
\hline $\begin{array}{l}\text { Proceso } \\
\text { Adminsitrativo de } \\
\text { Restablecimiento de } \\
\text { Derechos en el }\end{array}$ & $\begin{array}{l}\text { Objetivos del PARD } \\
\text { en el SRPA }\end{array}$ & $\mathrm{xx}$ & $\begin{array}{l}\text { ¿Considera que la ubicación en medio } \\
\text { familiar, es una medida de } \\
\text { restablecimiento de derechos } \\
\text { adecuada? }\end{array}$ \\
\hline
\end{tabular}




\begin{tabular}{|c|c|c|c|}
\hline $\begin{array}{l}\text { Sistema de } \\
\text { Responsabilidad para } \\
\text { Adolescentes }\end{array}$ & $\begin{array}{l}\text { Fases del PARD en el } \\
\text { SRPA }\end{array}$ & $\begin{array}{l}\text { ¿Cómo realizan acciones restaurativas con } \\
\text { los adolescentes? }\end{array}$ & $\begin{array}{l}\text { ¿Considera que las medidas de } \\
\text { internamiento preventivo, dan } \\
\text { resultados pedagógicos? }\end{array}$ \\
\hline & $\begin{array}{lr}\text { Sanciones } & \text { como } \\
\text { medidas } & \text { de } \\
\text { restablecimiento } & \text { de } \\
\text { derechos } & \end{array}$ & $\begin{array}{l}\text { ¿La familia asume su rol con suficiente } \\
\text { responsabilidad dentro del proceso } \\
\text { pedagógico del adolescente? }\end{array}$ & $\begin{array}{l}\text { ¿Una medida privativa de la libertad, } \\
\text { da resultados que controlen la } \\
\text { participación de los adolescentes en } \\
\text { futuros delitos? }\end{array}$ \\
\hline $\begin{array}{lr}\text { Garantías } & \text { de } \\
\text { derechos en } & \text { el } \\
\text { Sistema } & \text { de } \\
\text { Responsabilidad } & \\
\text { Penal para }\end{array}$ & $\begin{array}{l}\text { Estado en la } \\
\text { restauración de } \\
\text { derechos en el SRPA }\end{array}$ & $\begin{array}{l}\text { ¿Qué opina sobre las medidas de protección } \\
\text { para adolescentes? } \\
\text { ¿Cómo se involucra la familia en el proceso } \\
\text { de los adolescentes? } \\
\text { ¿Qué acciones se toman con la familia? }\end{array}$ & $\begin{array}{l}\text { ¿Las sanciones en medio cerrado, son } \\
\text { eficaces? } \\
\text { ¿El adolescente cumple e proceso } \\
\text { pedagógico dentro del SRPA? }\end{array}$ \\
\hline Adolescente & $\begin{array}{ll}\text { Seguimiento } & y \\
\text { evaluación de las } \\
\text { garantía de derechos } \\
\text { en el SRPA }\end{array}$ & $\begin{array}{l}\text { 1. ¿Cuáles son los problemas más } \\
\text { recurrentes de estos adolescentes? y ¿Qué } \\
\text { hacen para tratarlos? } \\
\text { 2. ¿Qué cree que se debe hacer para eliminar } \\
\text { la reincidencia en la comisión de delitos por } \\
\text { parte de los adolescentes? } \\
\text { 3. ¿Qué aportes considera usted pueden } \\
\text { hacerse desde el rol del trabajador social y } \\
\text { los psicólogos para que un adolescente no } \\
\text { reincida en la comisión de delitos? }\end{array}$ & $\begin{array}{l}\text { 1 ¿Con qué frecuencia los } \\
\text { adolescentes reinciden en la comisión } \\
\text { de delitos? } \\
\text { 2. ¿Cuáles Considera son las causas } \\
\text { más relevantes de la reincidencia en la } \\
\text { comisión de delitos? } \\
\text { 3. ¿Qué cree que se debe hacer para } \\
\text { eliminar la reincidencia en la comisión } \\
\text { de delitos por parte de los } \\
\text { adolescentes? }\end{array}$ \\
\hline
\end{tabular}


4. ¿Los adolescentes reincidentes acatan las sanciones de tipo pedagógico? 
A partir de las categorías evidenciadas en el apartado anterior y con el fin de cumplir con los objetivos de la presente investigación se llevaron a cabo una serie de entrevistas como se mencionó previamente las cuales se analizaron por medio de un análisis de contenido de tipo categorial, el cual es comprendido como un tipo de análisis documental con el cual se busca comprender el significado del contenido del relato o el discurso obtenido, en este caso de las respuestas obtenidas entorno a las categorías de investigación (López, 2002). En este orden de ideas las respuestas obtenidas a partir de las entrevistas realizadas se ordenaron en 3 matrices, entorno a los principios de la protección integral en el Sistema de Responsabilidad Penal para adolescentes, el proceso administrativo de restablecimiento de derechos en el Sistema de Responsabilidad para Adolescentes y finalmente las garantías de derechos en el Sistema de Responsabilidad Penal para Adolescente. 
Definición de categorías y subcategorías deductivas

Categorías: Percepciones Subcategorías

Protección integral en el Noción de protección integral en el SRPA

Sistema de Responsabilidad Principio del interés superior en el SRPA

Penal para adolescentes $\quad$ Niños y adolescentes del SRPA como sujetos de derechos

Prevención de su amenaza y vulneración de los derechos en el SRPA

Proceso Adminsitrativo de Objetivos del PARD en el SRPA

Restablecimiento de Fases del PARD en el SRPA

Derechos en el Sistema de Sanciones como medidas de restablecimiento de derechos

Responsabilidad para Medida de restablecimiento de derechos

Adolescentes

Garantías de derechos en el Estado en la restauración de derechos en el SRPA

Sistema de Responsabilidad Seguimiento y evaluación de las garantía de derechos en el SRPA

Penal para Adolescente 


\section{Resultados}

\section{Tabla 4.}

\section{Matriz Análisis categorial Principios de la Protección integral en el Sistema de Responsabilidad Penal para adolescentes}

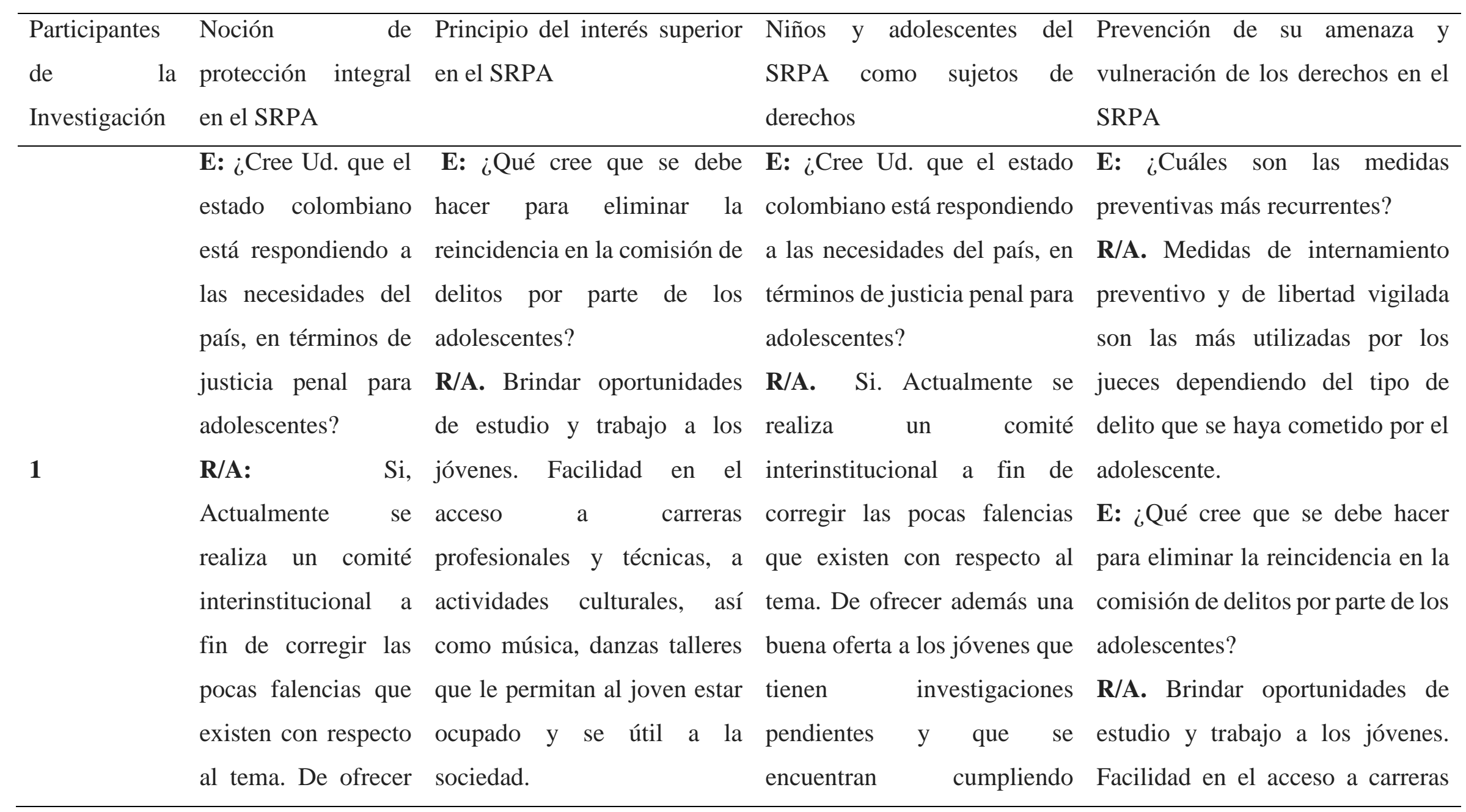




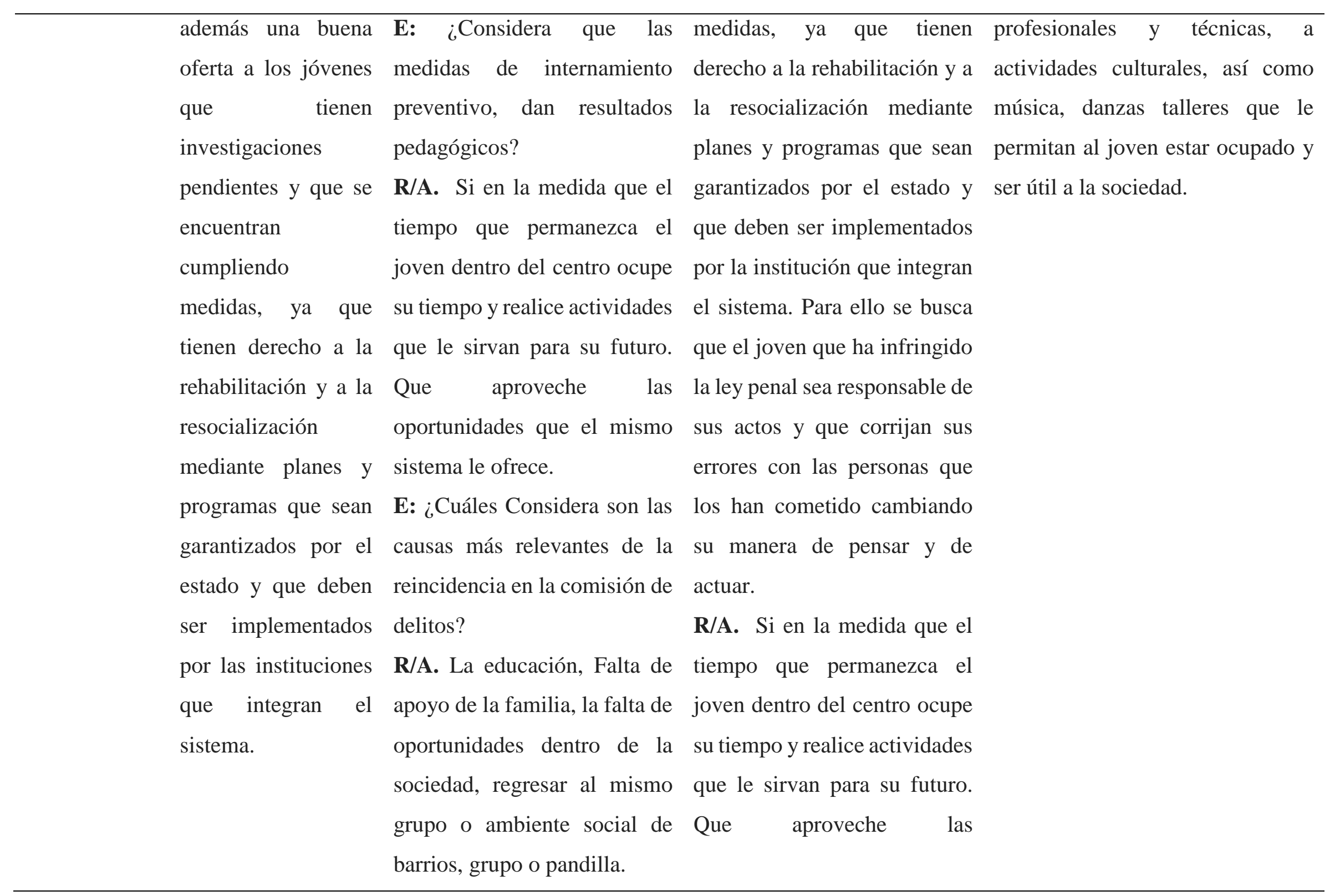




\begin{tabular}{|c|c|c|c|c|}
\hline & & & $\begin{array}{l}\text { oportunidades que el mismo } \\
\text { sistema le ofrece. } \\
\text { E: ¿Cuáles Considera son las } \\
\text { causas más relevantes de la } \\
\text { reincidencia en la comisión de } \\
\text { delitos? } \\
\text { R/A. La educación, Falta de } \\
\text { apoyo de la familia, la falta de } \\
\text { oportunidades dentro de la } \\
\text { sociedad, regresar al mismo } \\
\text { grupo o ambiente social de } \\
\text { barrios, o pandilla. grupo }\end{array}$ & \\
\hline 2 & $\begin{array}{l}\text { E: ¿Cree Ud. que el } \\
\text { estado colombiano } \\
\text { está respondiendo a } \\
\text { las necesidades del } \\
\text { país, en términos de } \\
\text { justicia penal para } \\
\text { adolescentes? } \\
\text { R/A. El principio y } \\
\text { fin último del } \\
\text { sistema de }\end{array}$ & $\begin{array}{l}\text { E: ¿Cree Ud. que el estado } \\
\text { colombiano está respondiendo } \\
\text { a las necesidades del país, en } \\
\text { términos de justicia penal para } \\
\text { adolescentes? } \\
\text { R/A. El principio y fin último } \\
\text { del sistema de responsabilidad } \\
\text { penal para adolescentes es } \\
\text { pedagógico, preventivo y } \\
\text { restaurativo. Sin embargo, si }\end{array}$ & $\begin{array}{l}\text { E: ¿Cree Ud. que el estado } \\
\text { colombiano está respondiendo } \\
\text { a las necesidades del país, en } \\
\text { términos de justicia penal para } \\
\text { adolescentes? } \\
\text { R/A. El principio y fin último } \\
\text { del sistema de responsabilidad } \\
\text { penal para adolescentes es } \\
\text { pedagógico, preventivo y } \\
\text { restaurativo. Sin embargo, si }\end{array}$ & $\begin{array}{l}\text { E: ¿Qué se debe hacer para } \\
\text { prevenir la delincuencia juvenil? } \\
\text { R/A. Para prevención de la } \\
\text { delincuencia juvenil, debe } \\
\text { trabajarse desde la primera } \\
\text { infancia, haciendo inversión social } \\
\text { en educación, en fortalecimiento } \\
\text { de programas productivos } \\
\text { familiares, que garanticen el } \\
\text { sostenimiento de todos los }\end{array}$ \\
\hline
\end{tabular}




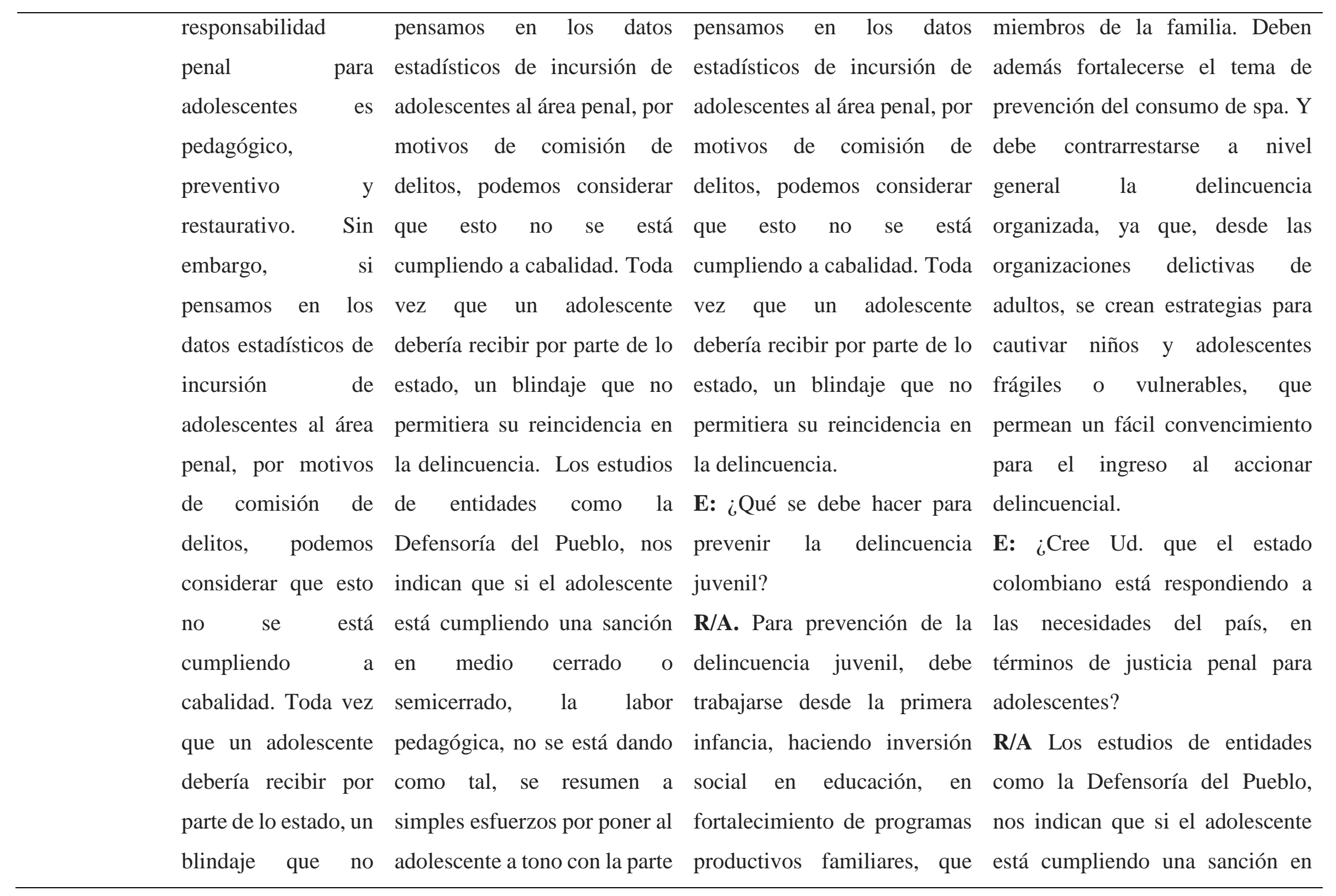




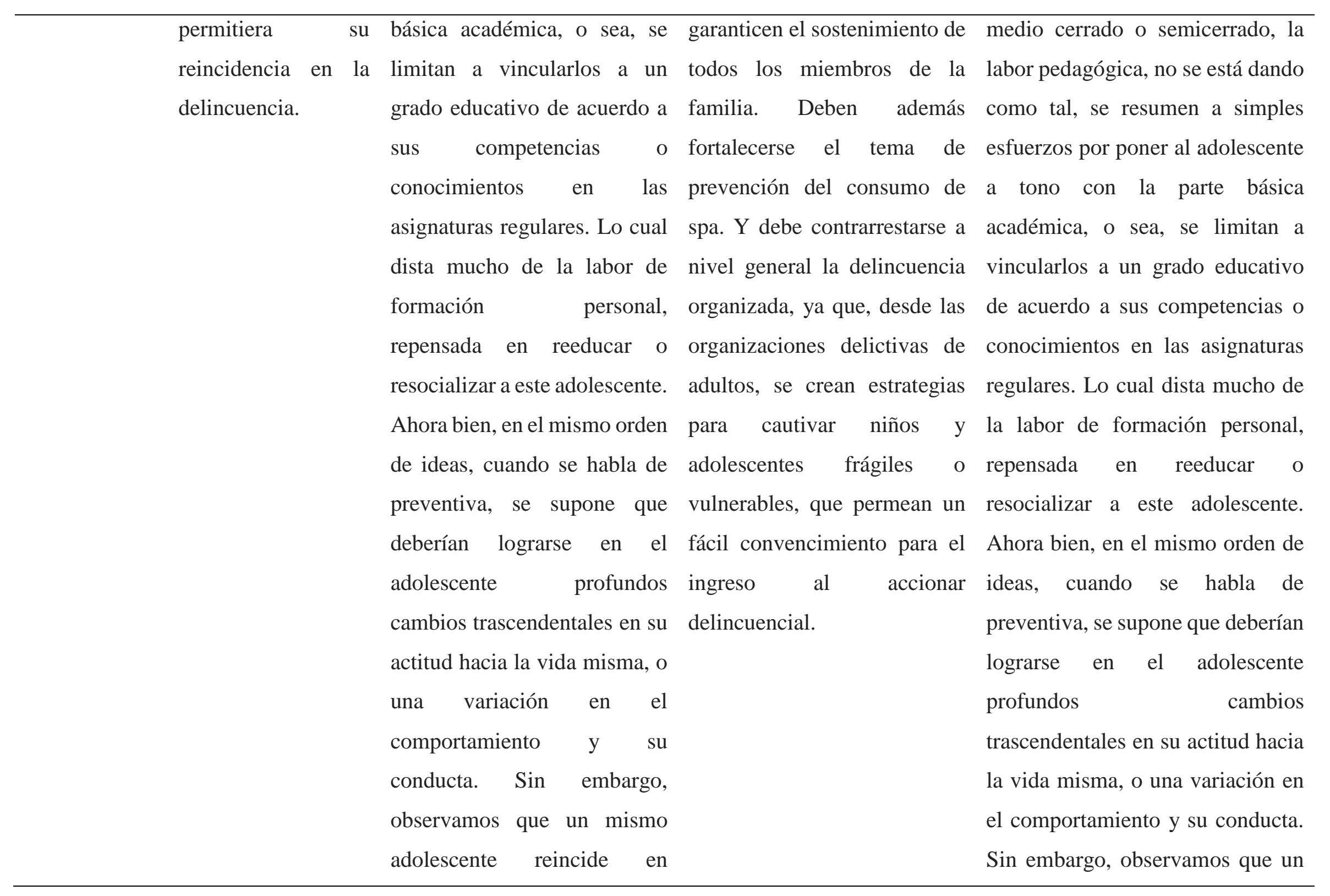




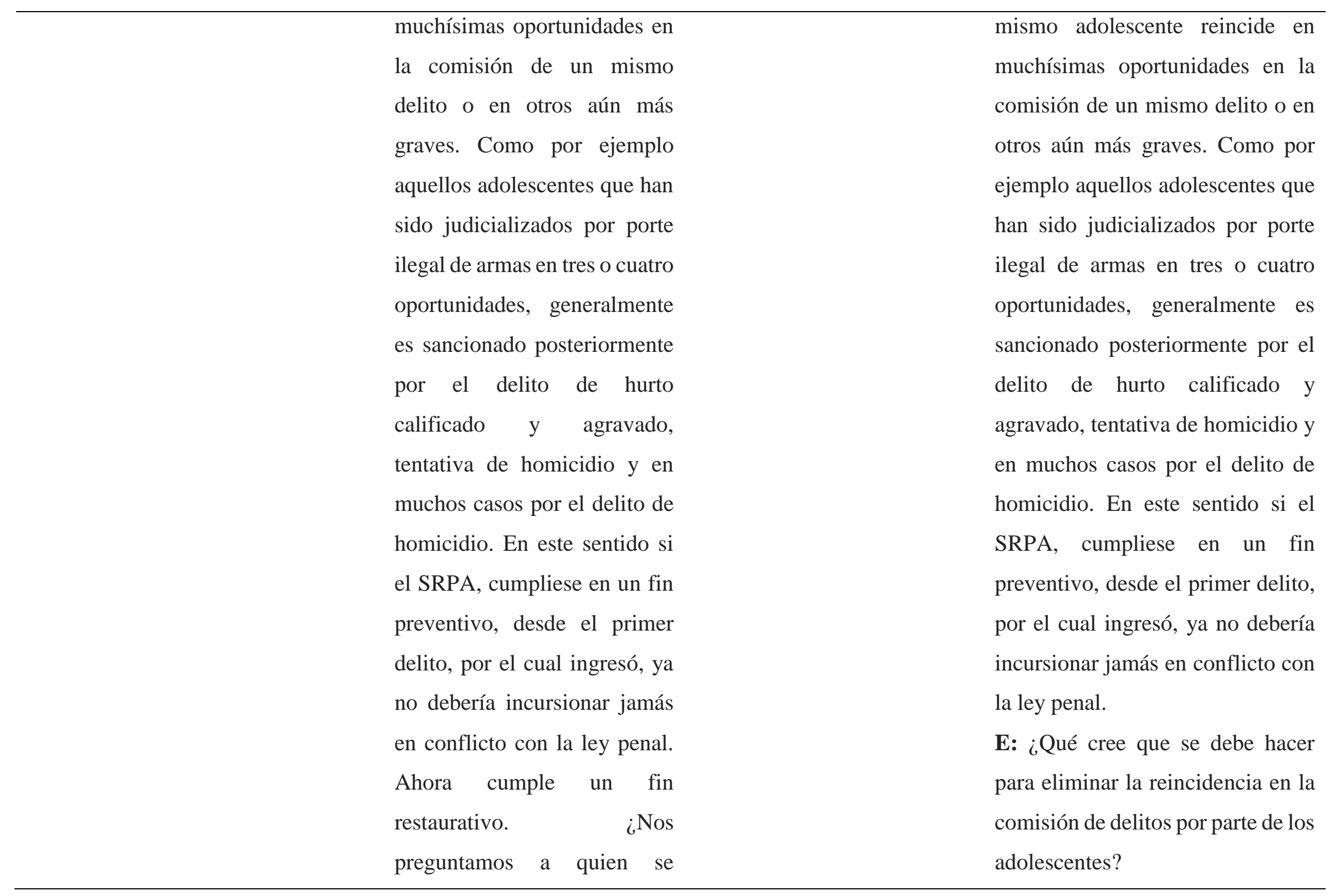




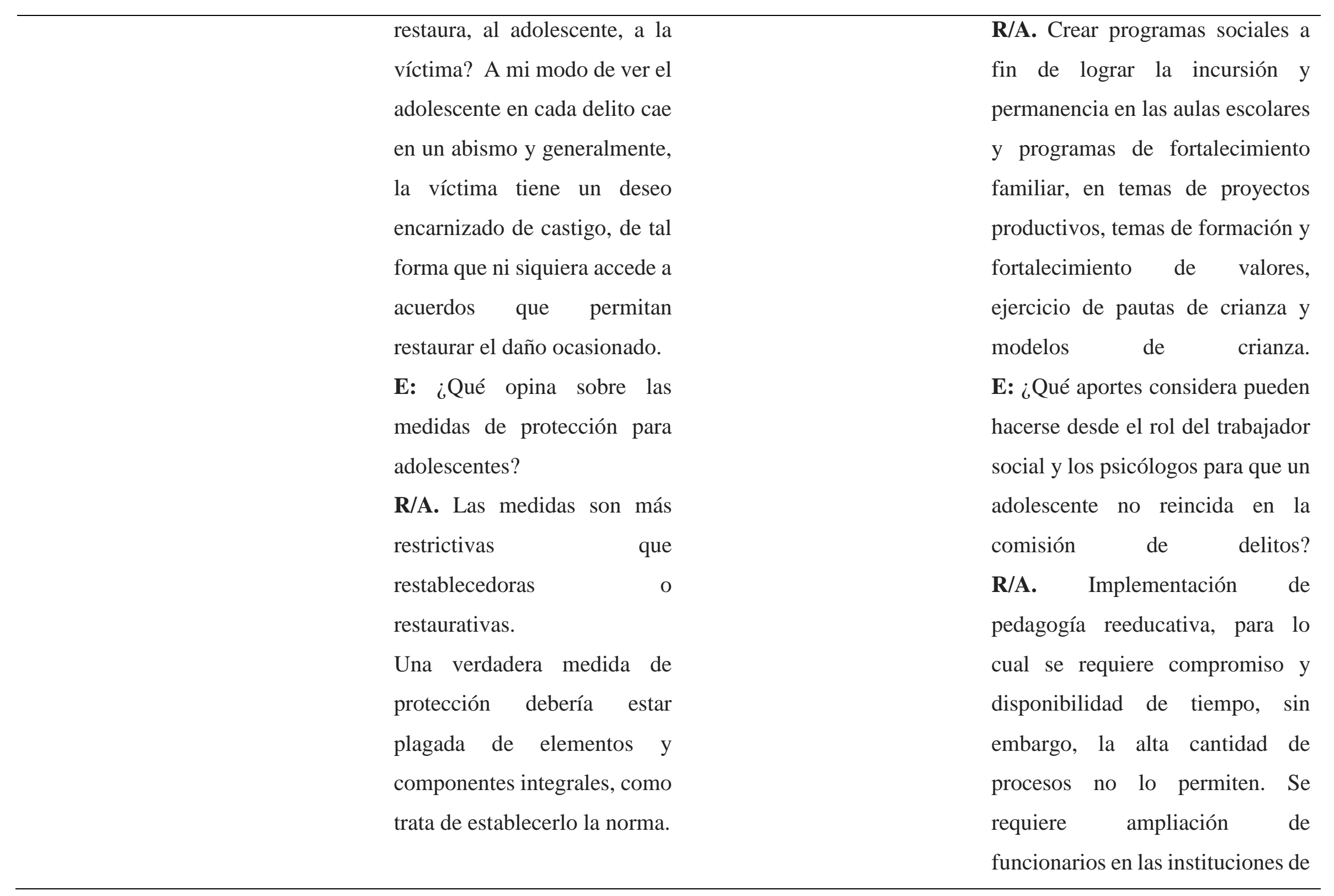




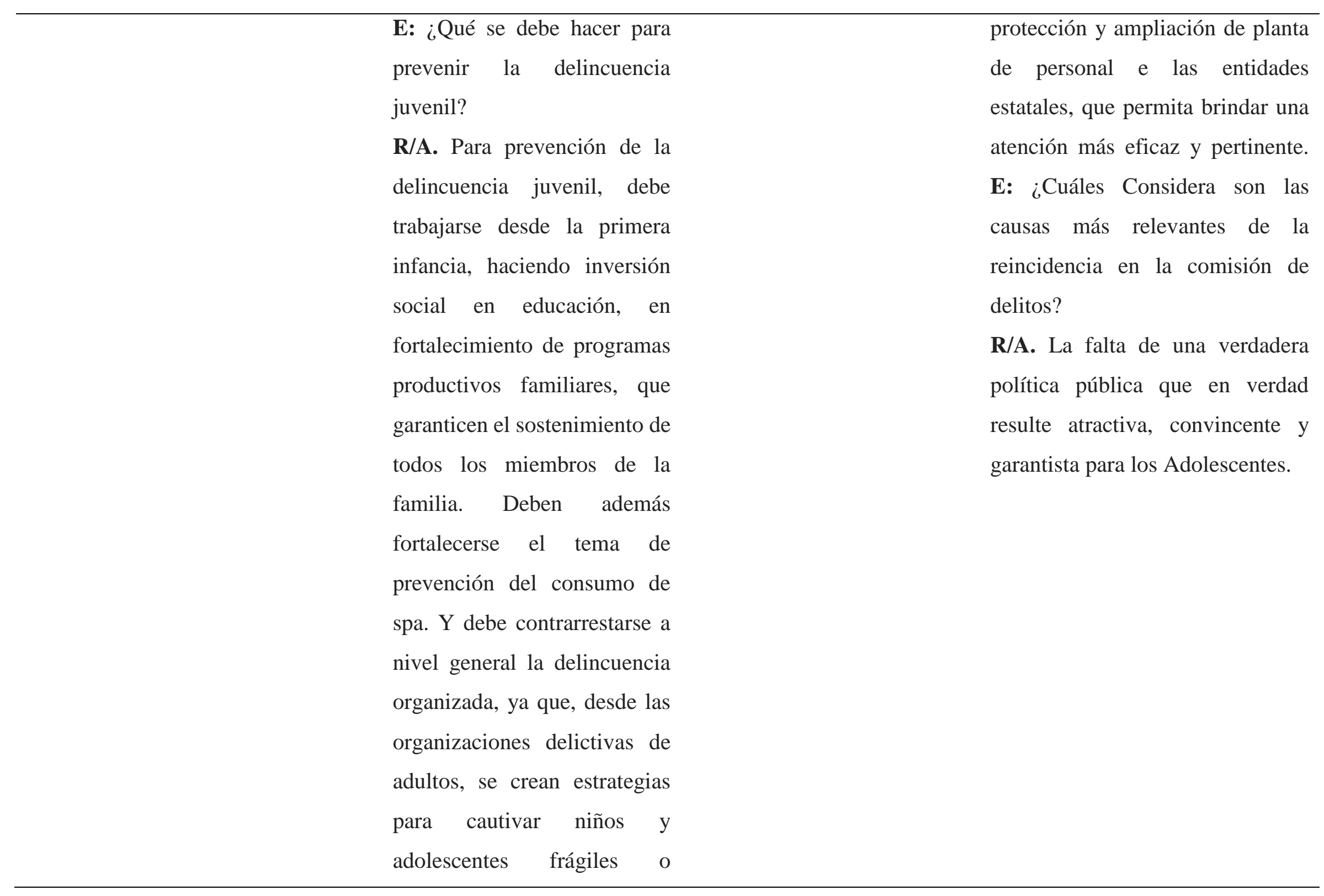




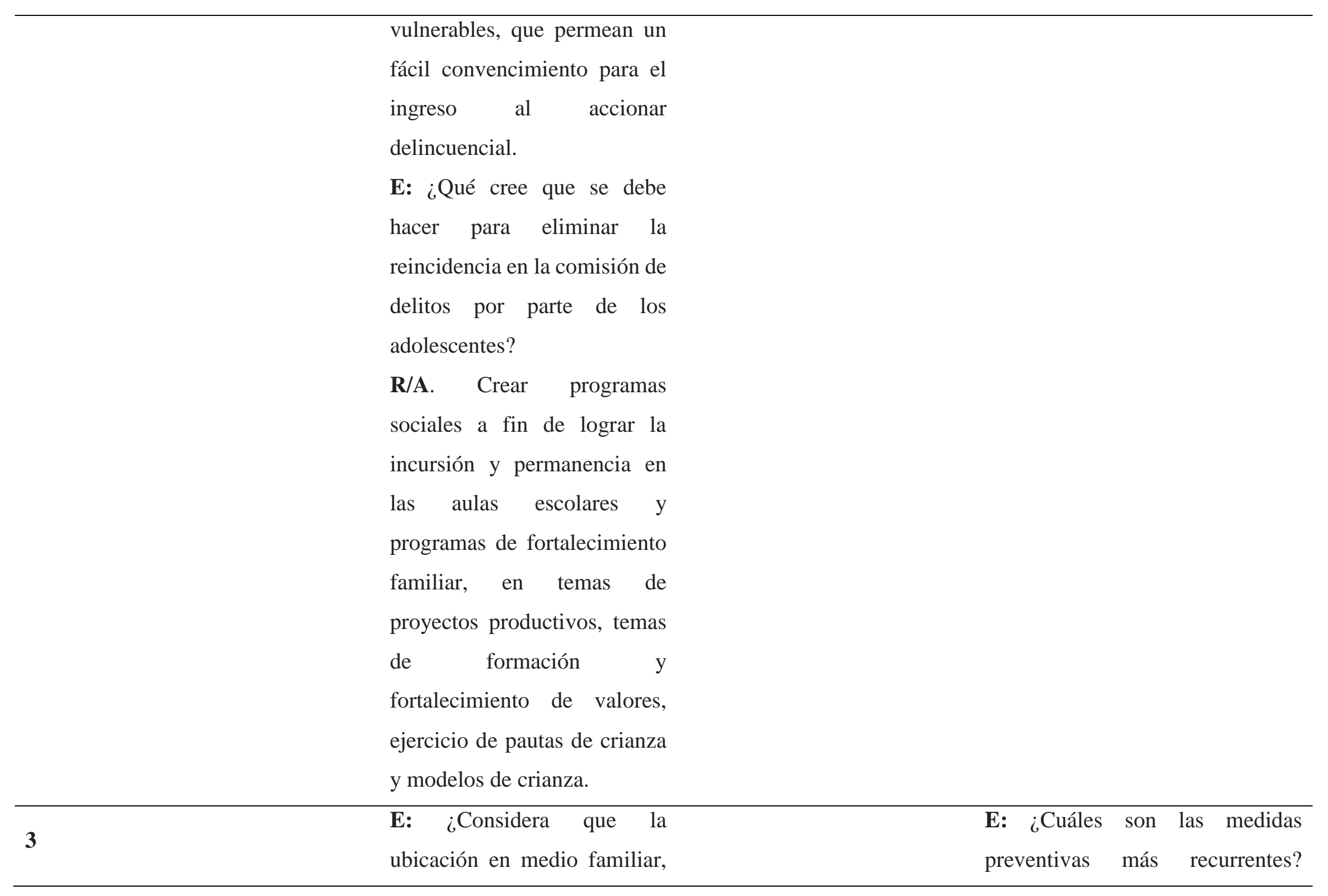




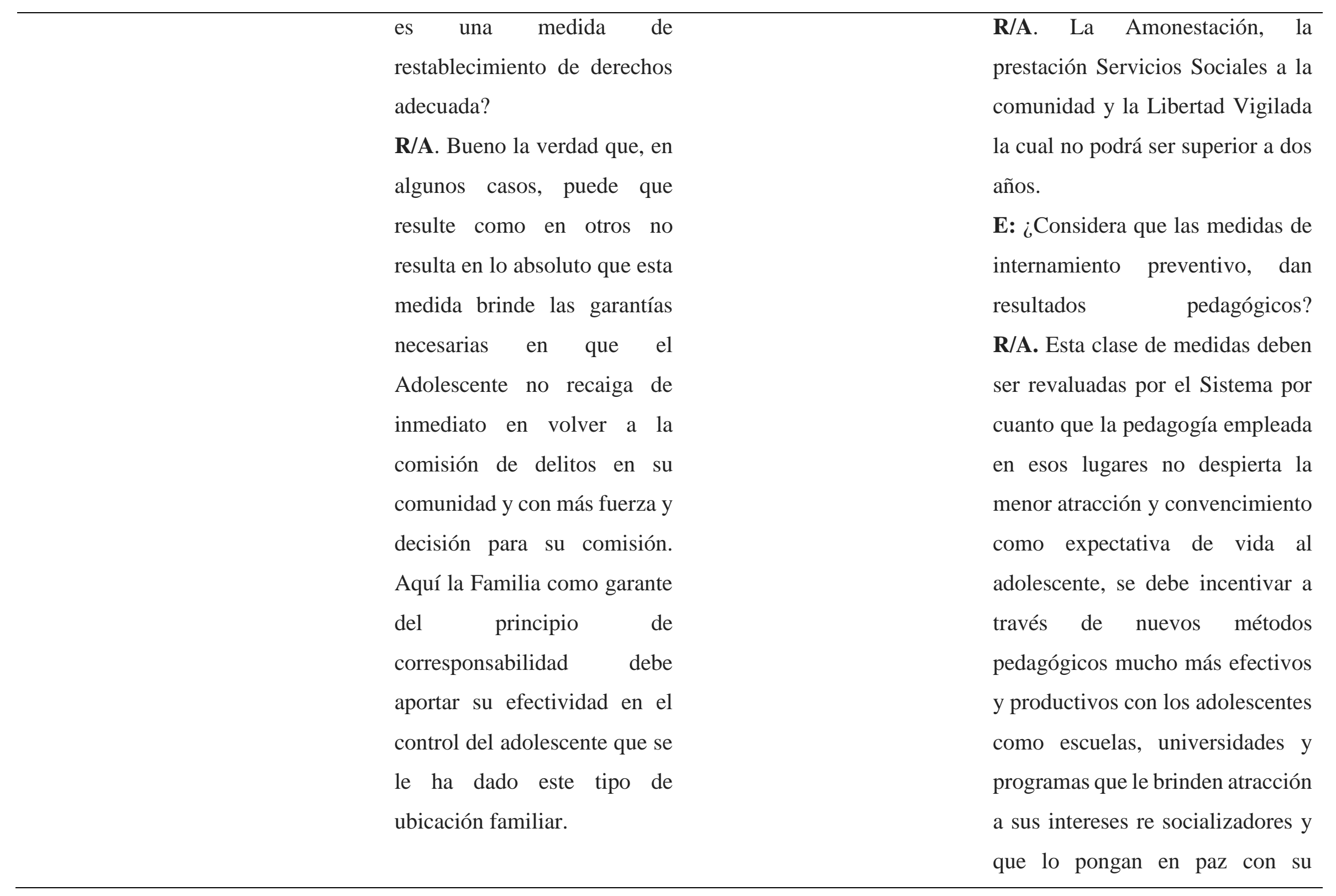




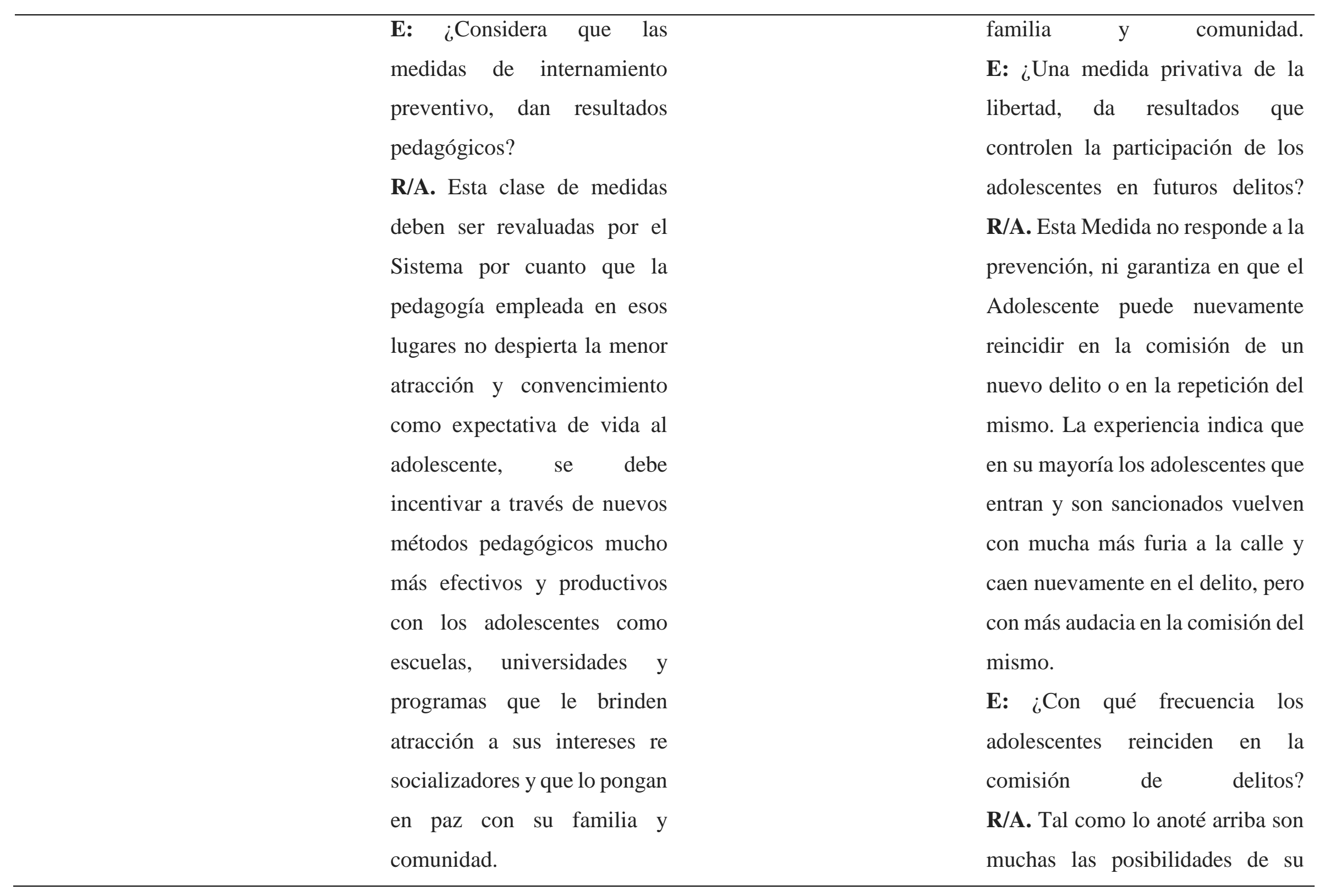




\begin{tabular}{|c|c|c|c|c|}
\hline & & $\begin{array}{l}\text { E: ¿Cuáles Considera son las } \\
\text { causas más relevantes de la } \\
\text { reincidencia en la comisión de } \\
\text { delitos? } \\
\text { R/A. La falta de una verdadera } \\
\text { política pública que en verdad } \\
\text { resulte atractiva, convincente } \\
\text { y garantista para los } \\
\text { Adolescentes }\end{array}$ & & $\begin{array}{l}\text { reincidencia por cuanto que no se } \\
\text { realiza una verdadera prevención y } \\
\text { garantía a la no repetición de sus } \\
\text { conductas } \\
\text { E: ¿Cuáles Considera son las } \\
\text { causas más relevantes de la } \\
\text { reincidencia en la comisión de } \\
\text { delitos? } \\
\text { R/A. La falta de una verdadera } \\
\text { política pública que en verdad } \\
\text { resulte atractiva, convincente y } \\
\text { garantista para los Adolescentes. }\end{array}$ \\
\hline 4 & $\begin{array}{l}\text { E: ¿Cree Ud. que el } \\
\text { estado colombiano } \\
\text { está respondiendo a } \\
\text { las necesidades del } \\
\text { país, en términos de } \\
\text { justicia penal para } \\
\text { adolescentes? } \\
\text { R/A. Bueno en los } \\
\text { últimos tiempos se } \\
\text { están creando }\end{array}$ & $\begin{array}{l}\text { E: ¿Cree Ud. que el estado } \\
\text { colombiano está respondiendo } \\
\text { a las necesidades del país, en } \\
\text { términos de justicia penal para } \\
\text { adolescentes? } \\
\text { R/A. Bueno en los últimos } \\
\text { tiempos se están creando } \\
\text { algunos mecanismos a fin de } \\
\text { corregir las grandes lagunas } \\
\text { que existen con respecto a esta }\end{array}$ & $\begin{array}{l}\text { E: ¿Cree Ud. que el estado } \\
\text { colombiano está respondiendo } \\
\text { a las necesidades del país, en } \\
\text { términos de justicia penal para } \\
\text { adolescentes? } \\
\text { R/A. Bueno en los últimos } \\
\text { tiempos se están creando } \\
\text { algunos mecanismos a fin de } \\
\text { corregir las grandes lagunas } \\
\text { que existen con respecto a esta }\end{array}$ & $\begin{array}{l}\text { E: ¿Cuáles son las medidas } \\
\text { preventivas más frecuentes? } \\
\text { R/A. La verdad que las Medidas } \\
\text { más recurrentes son la de } \\
\text { internamiento preventivo y de } \\
\text { libertad vigilada, en las cuales, los } \\
\text { jueces acuden a ellas teniendo en } \\
\text { cuenta el tipo de delito en que se } \\
\text { encuentre involucrado el } \\
\text { Adolescente. }\end{array}$ \\
\hline
\end{tabular}




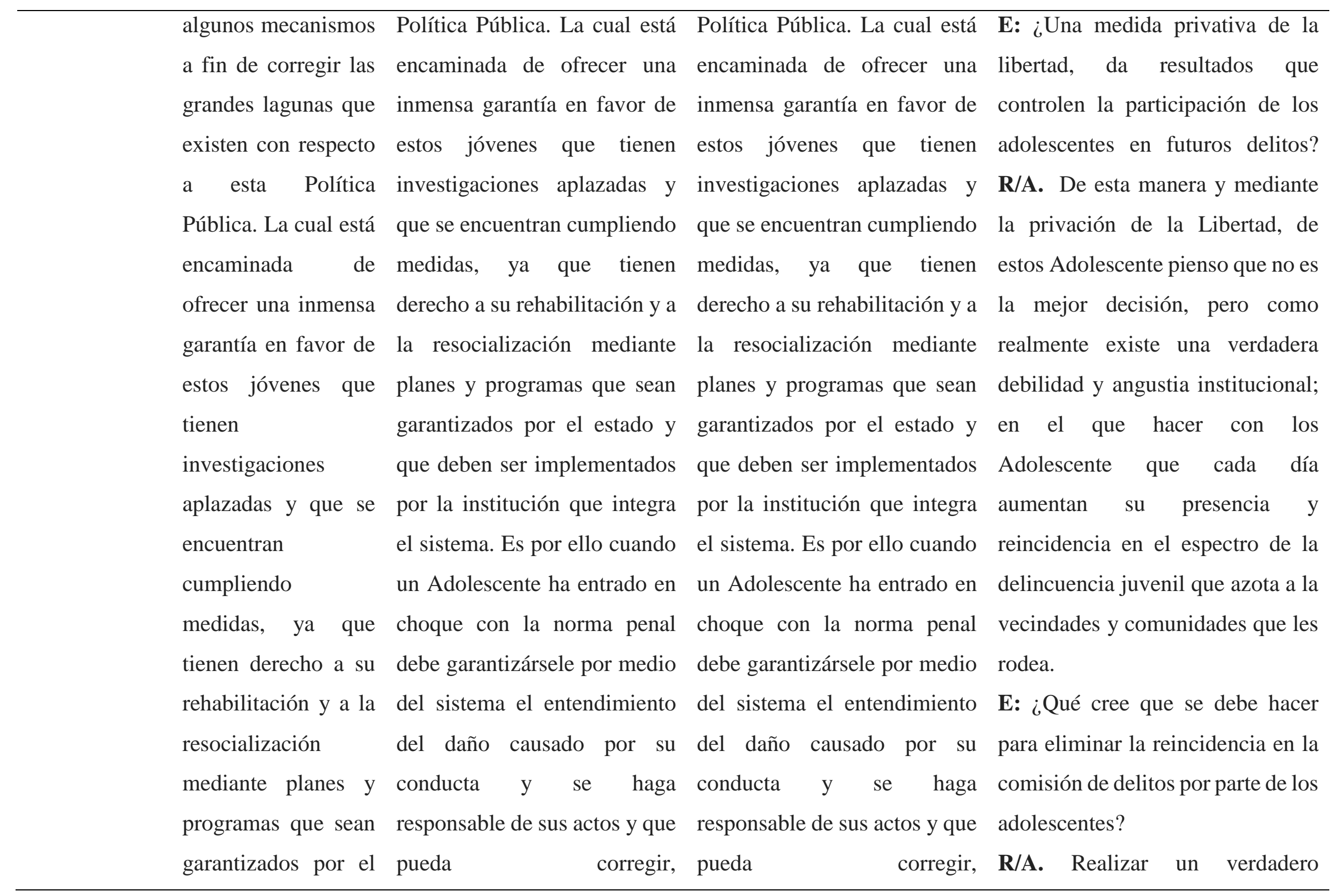




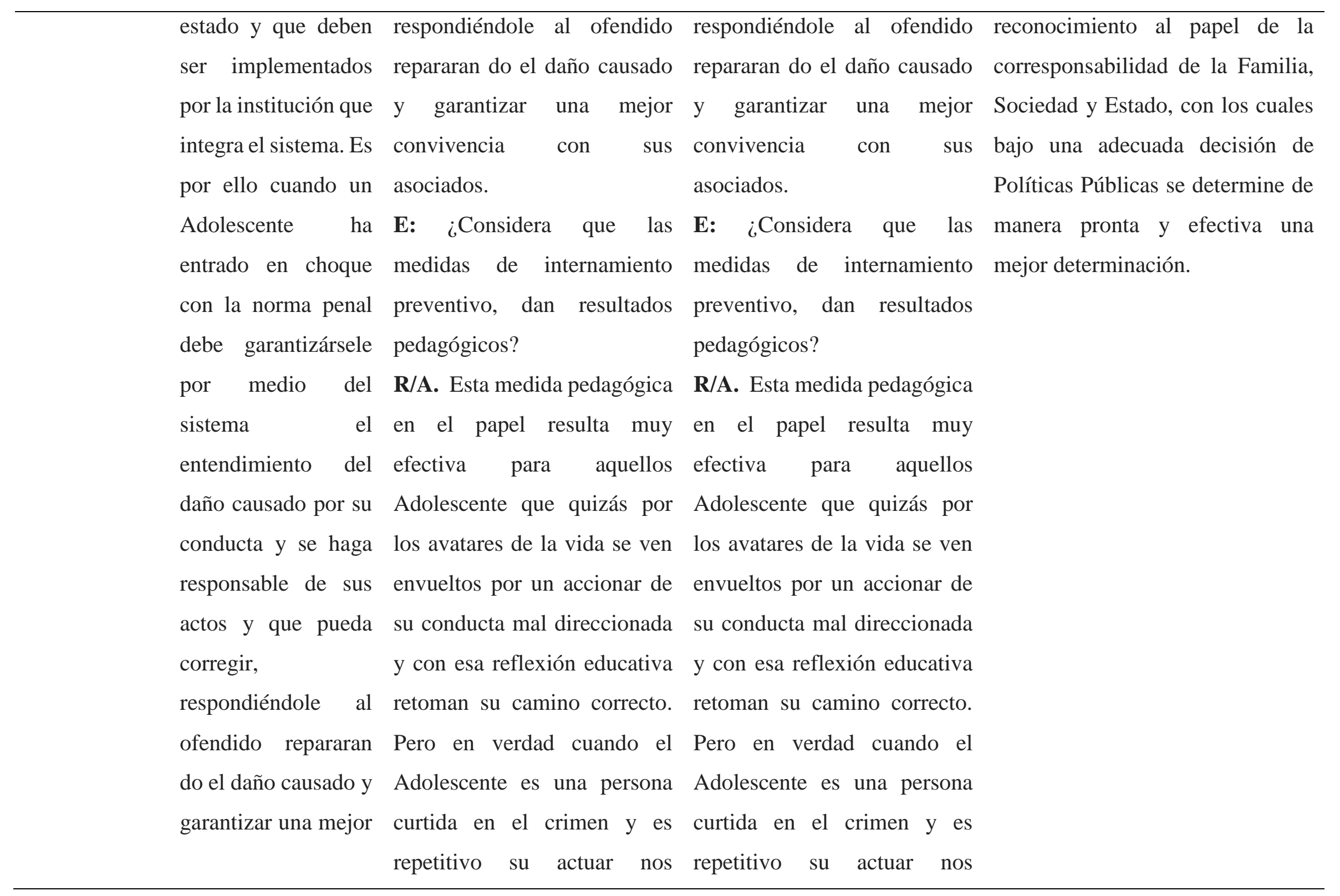




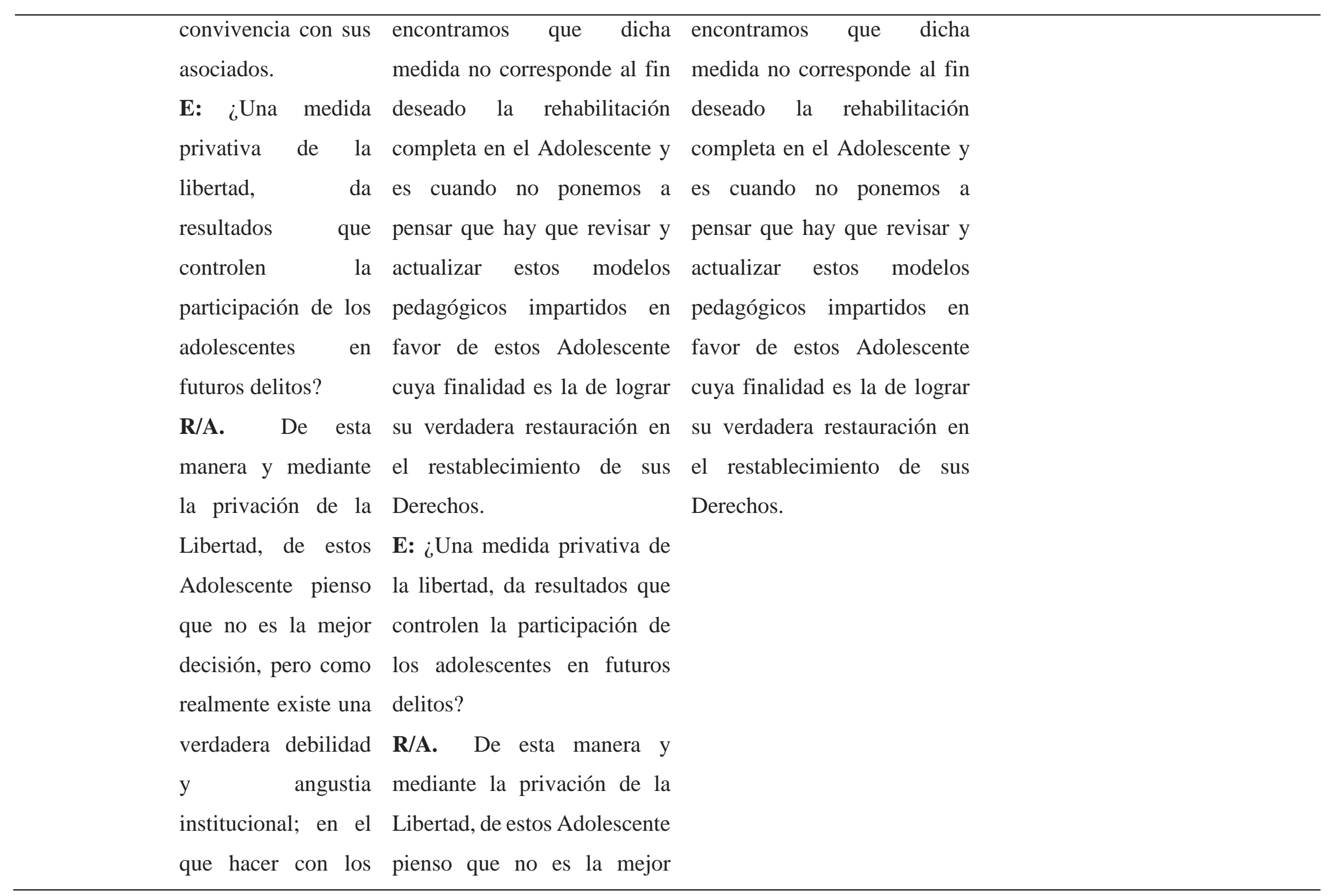




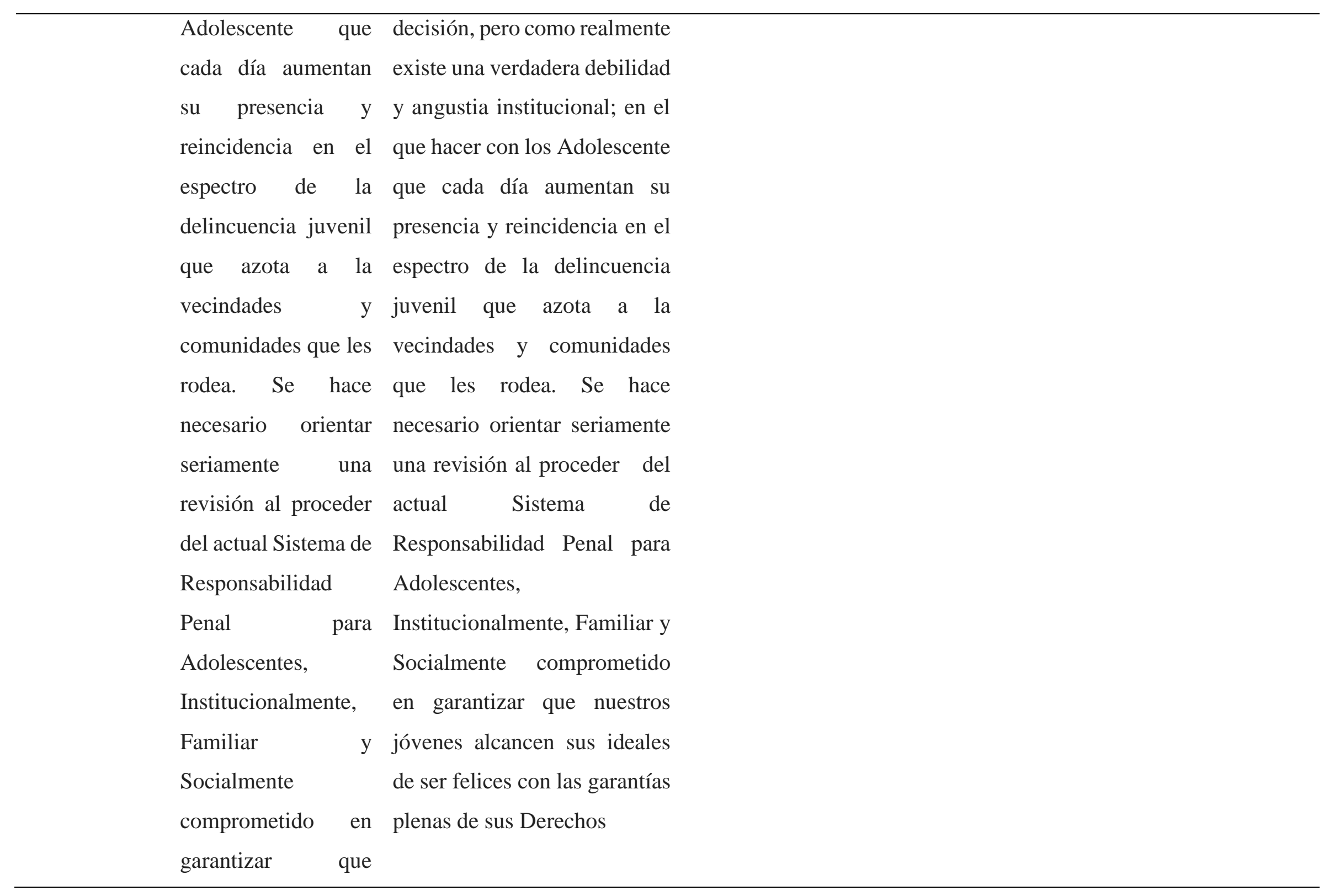




\begin{tabular}{|c|}
\hline $\begin{array}{l}\text { nuestros jóvenes } \\
\text { alcancen sus ideales } \\
\text { de ser felices con las } \\
\text { garantías plenas de } \\
\text { sus Derechos. } \\
\text { E: ¿Cuáles } \\
\text { Considera son las } \\
\text { causas más } \\
\text { relevantes de la } \\
\text { reincidencia en la } \\
\text { comisión de delitos? } \\
\text { R/A. La educación, } \\
\text { Falta de apoyo de la } \\
\text { familia, la falta de } \\
\text { oportunidades } \\
\text { dentro de la } \\
\text { sociedad, que le } \\
\text { garantizan } \\
\text { nuevamente en } \\
\text { reincidir regresando } \\
\text { al mismo grupo o } \\
\text { ambiente social de }\end{array}$ \\
\hline
\end{tabular}




\begin{tabular}{|c|}
\hline $\begin{array}{l}\text { barrios, grupos y } \\
\text { pesadillas de las } \\
\text { pandillas que se } \\
\text { constituyen cada día } \\
\text { en las formas } \\
\text { organizadas de la } \\
\text { delincuencia juvenil } \\
\text { en nuestro país. } \\
\text { E: ¿Qué cree que se } \\
\text { debe hacer para } \\
\text { eliminar la } \\
\text { reincidencia en la } \\
\text { comisión de delitos } \\
\text { por parte de los } \\
\text { adolescentes? } \\
\text { R/A. Realizar un } \\
\text { verdadero la Familia, } \\
\text { reconocimiento al } \\
\text { papel de la } \\
\text { corresponsabilidad } \\
\text { de la Estado, } \\
\text { Sociedad y }\end{array}$ \\
\hline
\end{tabular}




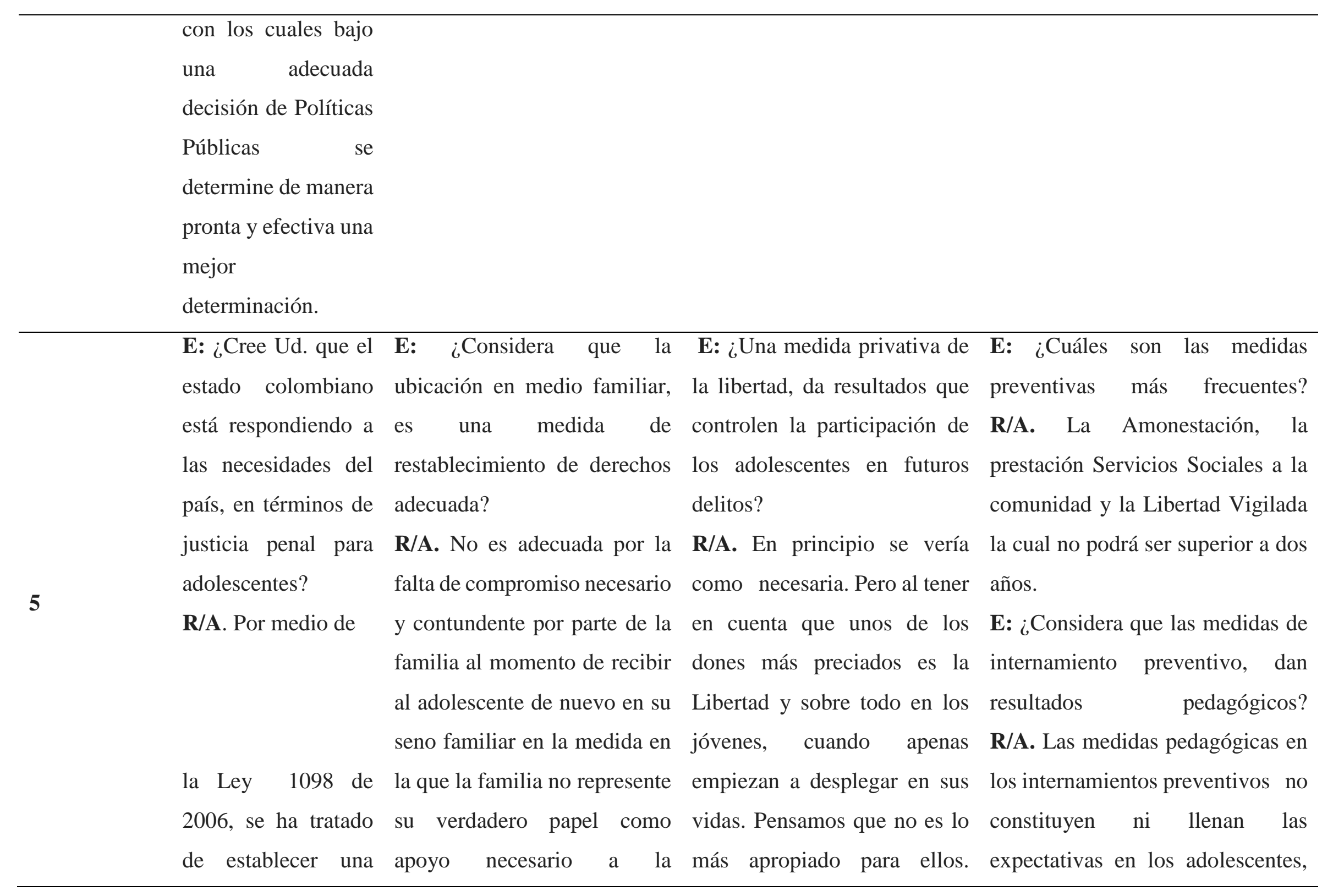




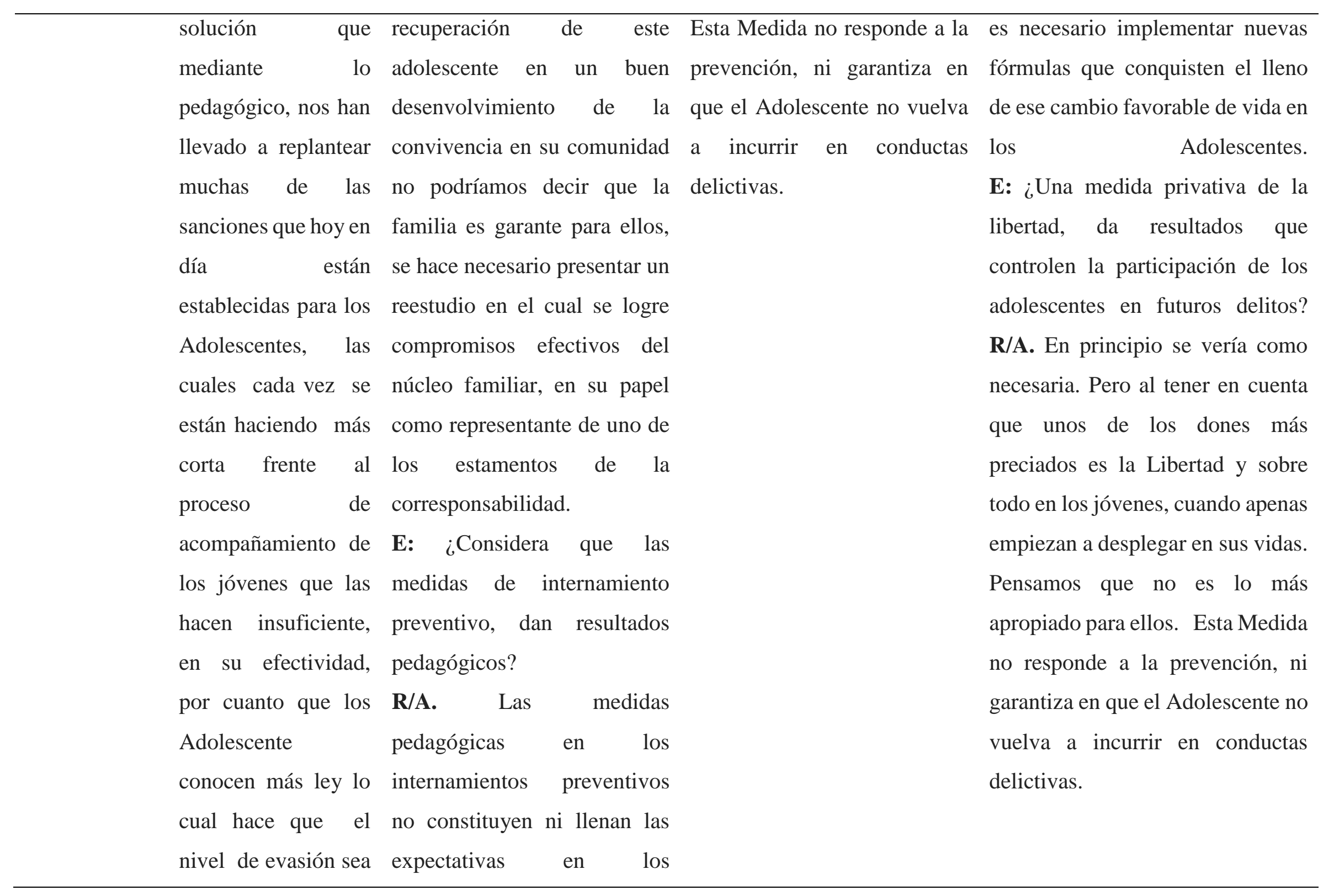




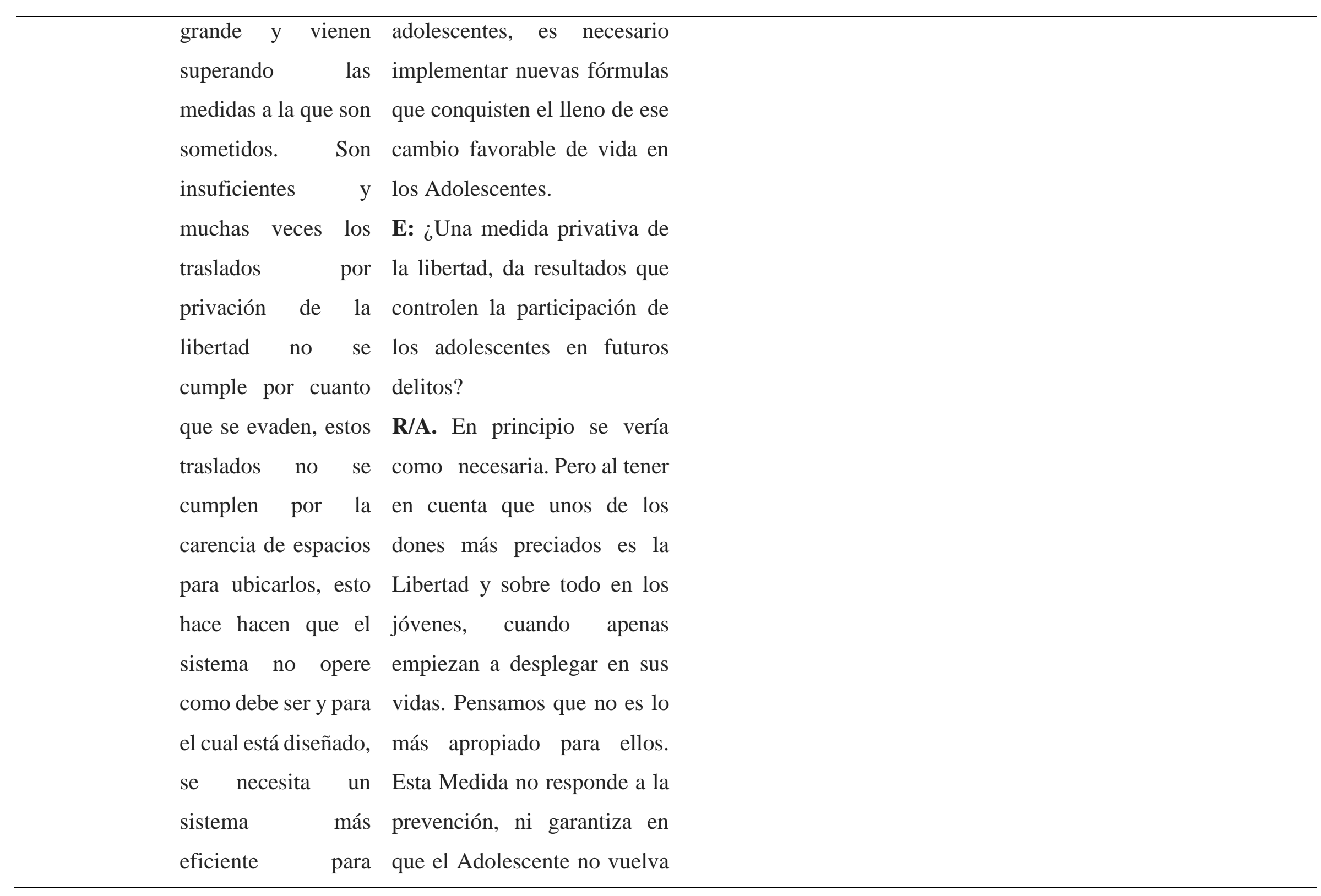




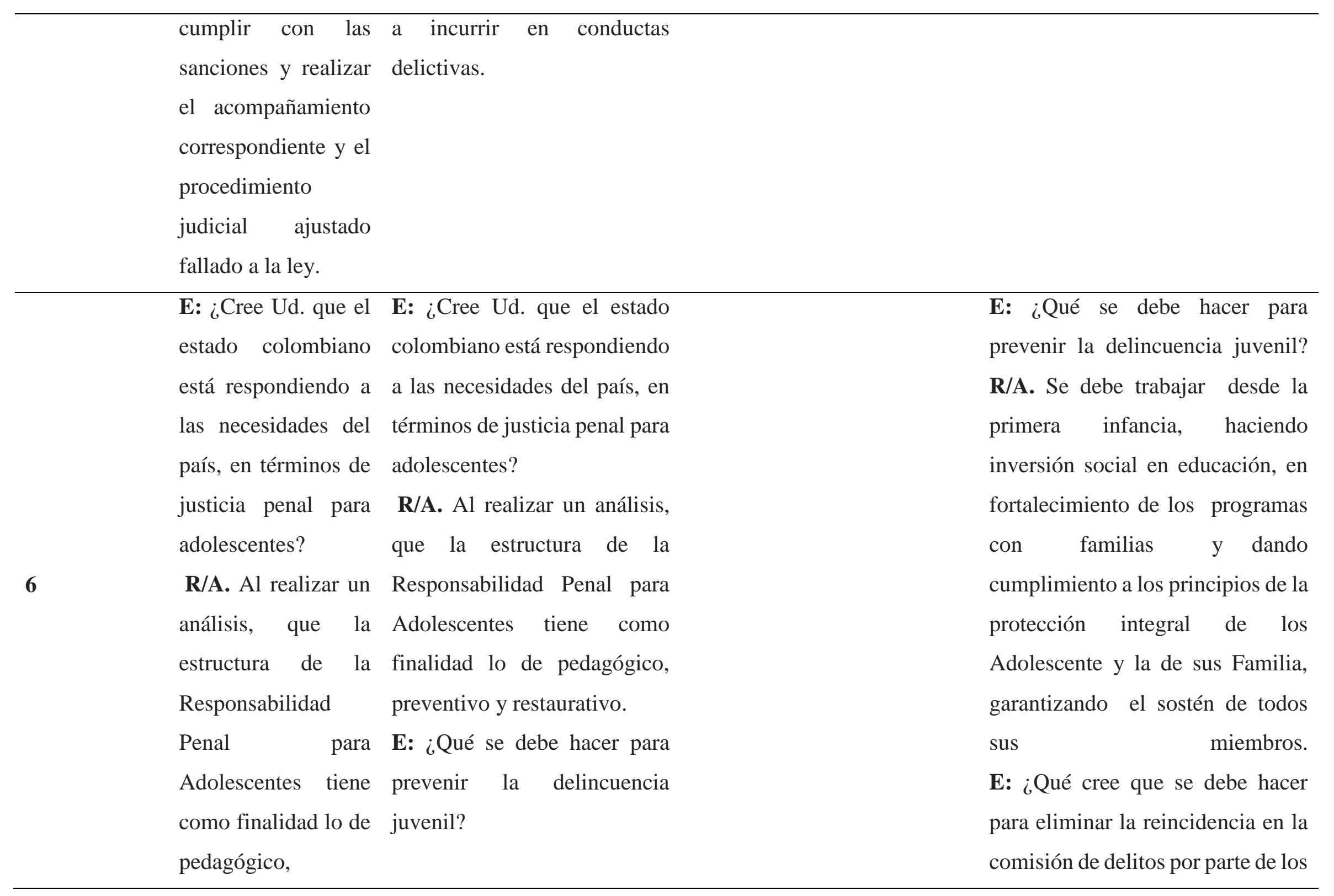




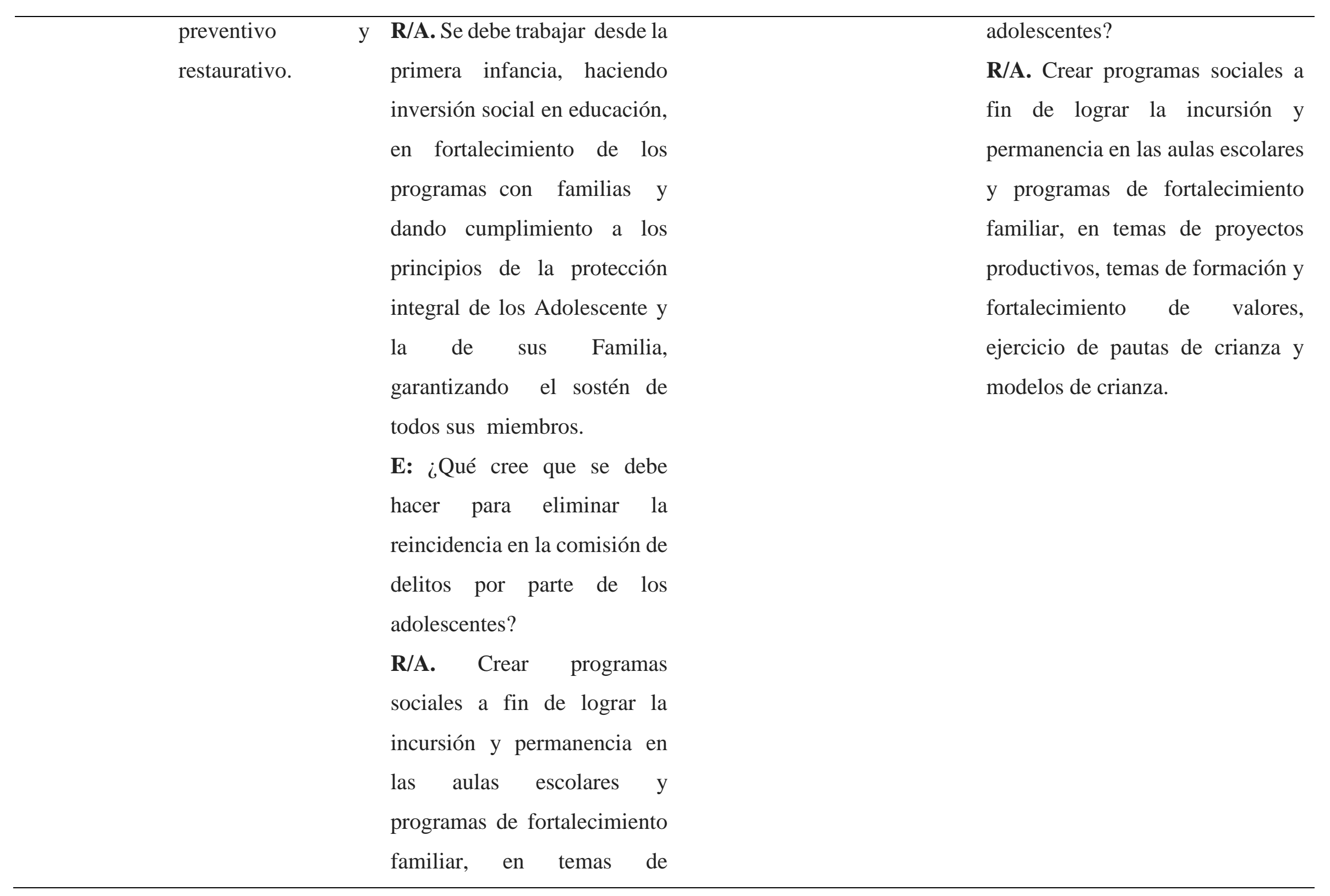




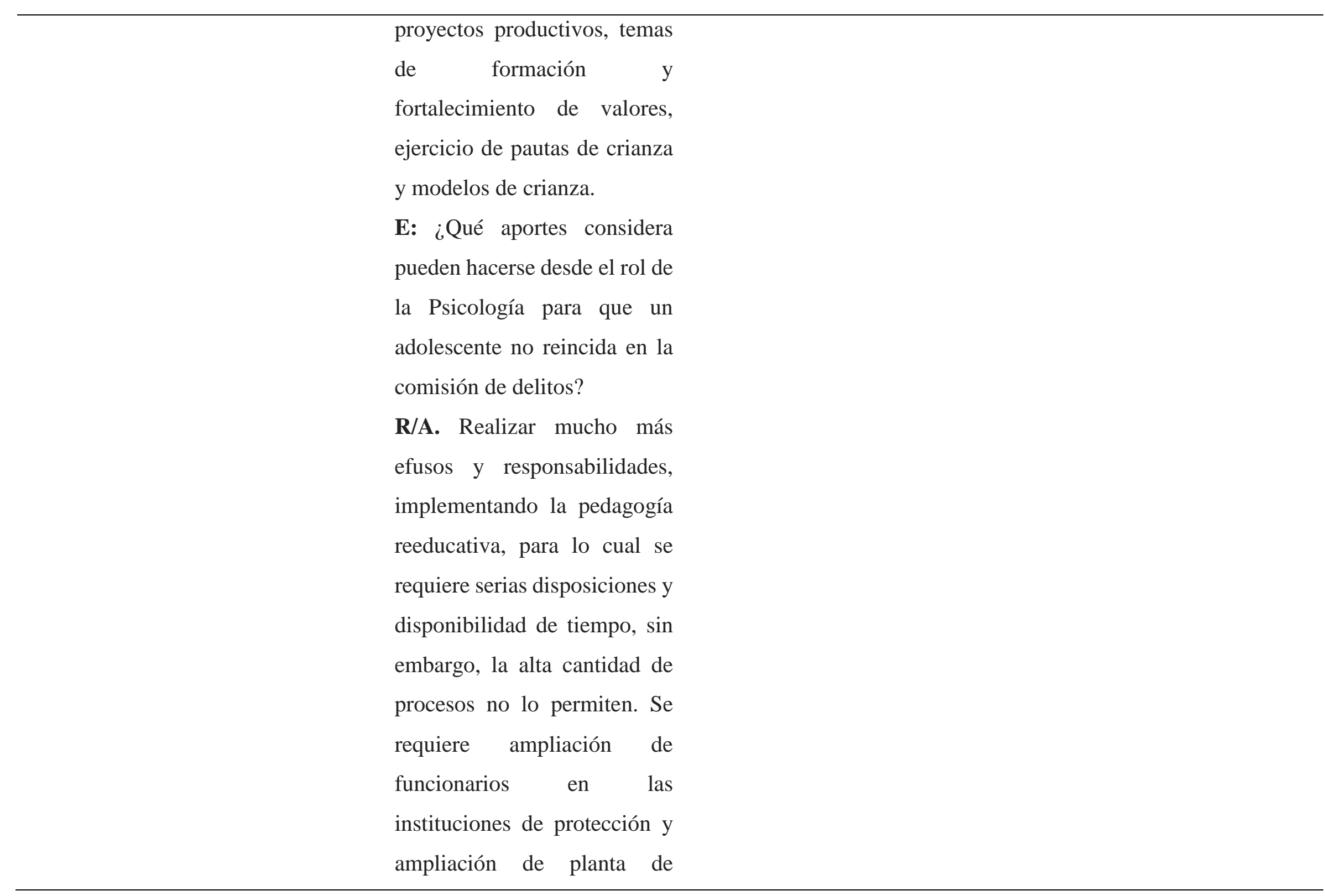




\begin{tabular}{|c|c|c|c|c|}
\hline & & $\begin{array}{l}\text { personal e las entidades } \\
\text { estatales, que permita brindar } \\
\text { una atención más eficaz y } \\
\text { pertinente. }\end{array}$ & & \\
\hline 7 & $\begin{array}{l}\text { E: ¿Cree Ud. que el } \\
\text { estado colombiano } \\
\text { está respondiendo a } \\
\text { las necesidades del } \\
\text { país, en términos de } \\
\text { justicia penal para } \\
\text { adolescentes? } \\
\text { R/A. El sistema } \\
\text { judicial colombiano, } \\
\text { está respondiendo en } \\
\text { términos legales, } \\
\text { toda vez que asume } \\
\text { la norma, como un } \\
\text { entramado judicial } \\
\text { restaurativo. Desde } \\
\text { lo pedagógico y } \\
\text { diferencial }\end{array}$ & $\begin{array}{l}\text { E: ¿Cree Ud. que el estado } \\
\text { colombiano está respondiendo } \\
\text { a las necesidades del país, en } \\
\text { términos de justicia penal para } \\
\text { adolescentes? } \\
\text { R/A. El sistema judicial } \\
\text { colombiano, } \\
\text { respondiendo en términos } \\
\text { legales, toda vez que asume la } \\
\text { norma, como un entramado } \\
\text { judicial restaurativo. Desde lo } \\
\text { pedagógico y diferencial. Sin } \\
\text { embargo, se requiere mayor } \\
\text { atención en el tema de } \\
\text { restablecimiento de derechos, } \\
\text { toda vez que los adolescentes } \\
\text { cuando no son sancionados, } \\
\text { regresan a sus familias, sin }\end{array}$ & $\begin{array}{l}\text { E: ¿Cree Ud. que el estado } \\
\text { colombiano está respondiendo } \\
\text { a las necesidades del país, en } \\
\text { términos de justicia penal para } \\
\text { adolescentes? } \\
\text { R/A. El sistema judicial } \\
\text { Colombiano, está } \\
\text { respondiendo en términos } \\
\text { legales, toda vez que asume la } \\
\text { norma, como un entramado } \\
\text { judicial restaurativo. Desde lo } \\
\text { pedagógico y diferencial. Sin } \\
\text { embargo, se requiere mayor } \\
\text { atención en el tema de } \\
\text { restablecimiento de derechos, } \\
\text { toda vez que los adolescentes } \\
\text { cuando no son sancionados, } \\
\text { regresan a sus familias, sin }\end{array}$ & $\begin{array}{l}\text { E: ¿Qué se debe hacer para } \\
\text { prevenir la delincuencia juvenil? } \\
\text { R/A. Implementar más medidas } \\
\text { pedagógicas, más medidas de } \\
\text { servicio social. Impulsar los } \\
\text { convenios educativos con } \\
\text { entidades privadas o estatales, que } \\
\text { conlleven a mejorar la formación } \\
\text { personal del adolescente. Diseñar } \\
\text { políticas públicas desde la primera } \\
\text { infancia, que brinden opciones } \\
\text { reales de vida digna al adolescente } \\
\text { y de esta forma cuando crezca no } \\
\text { se vea con predisposición a la } \\
\text { comisión de delitos. } \\
\text { E: ¿Qué cree que se debe hacer } \\
\text { para eliminar la reincidencia en la } \\
\text { comisión de delitos por parte de los }\end{array}$ \\
\hline
\end{tabular}




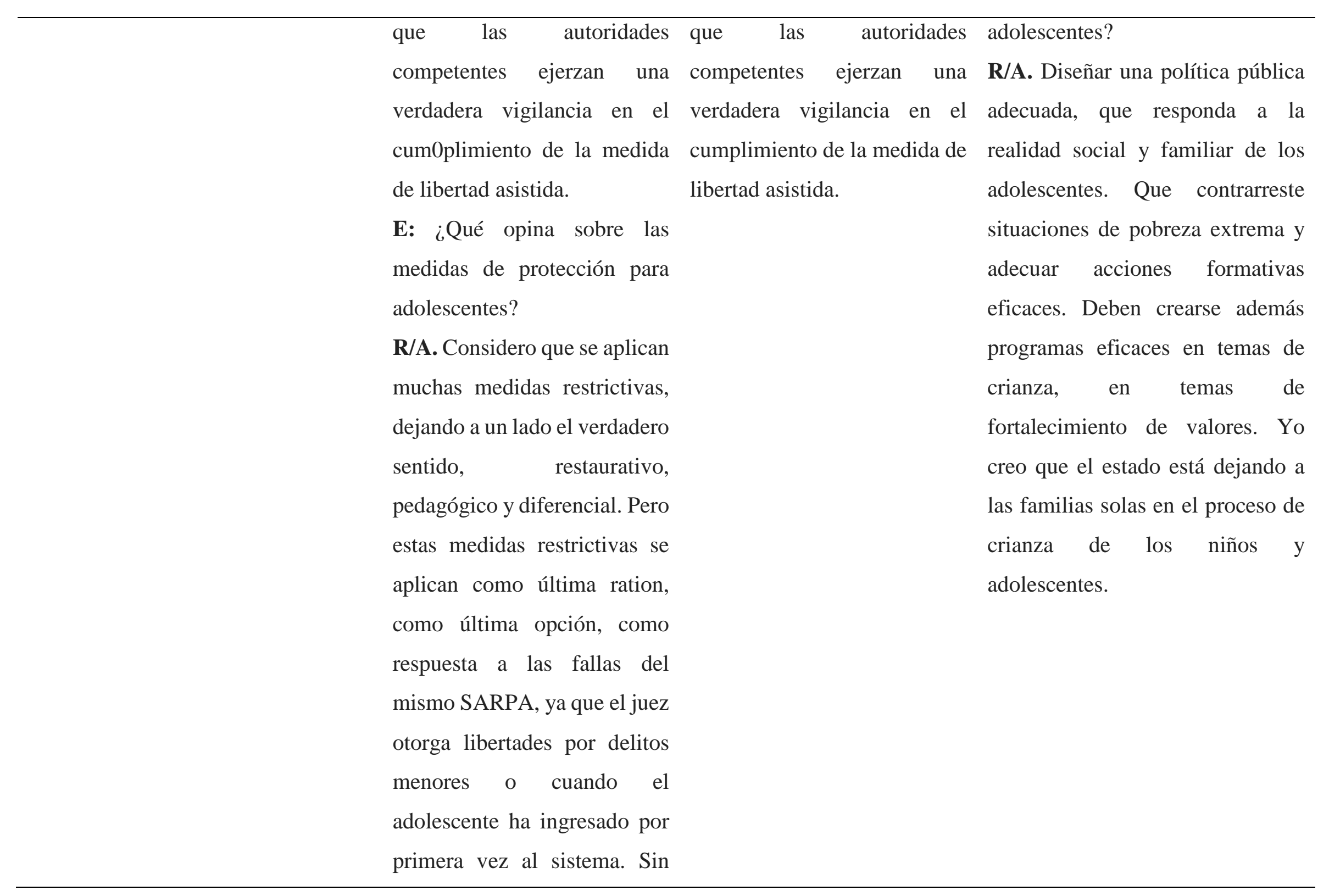




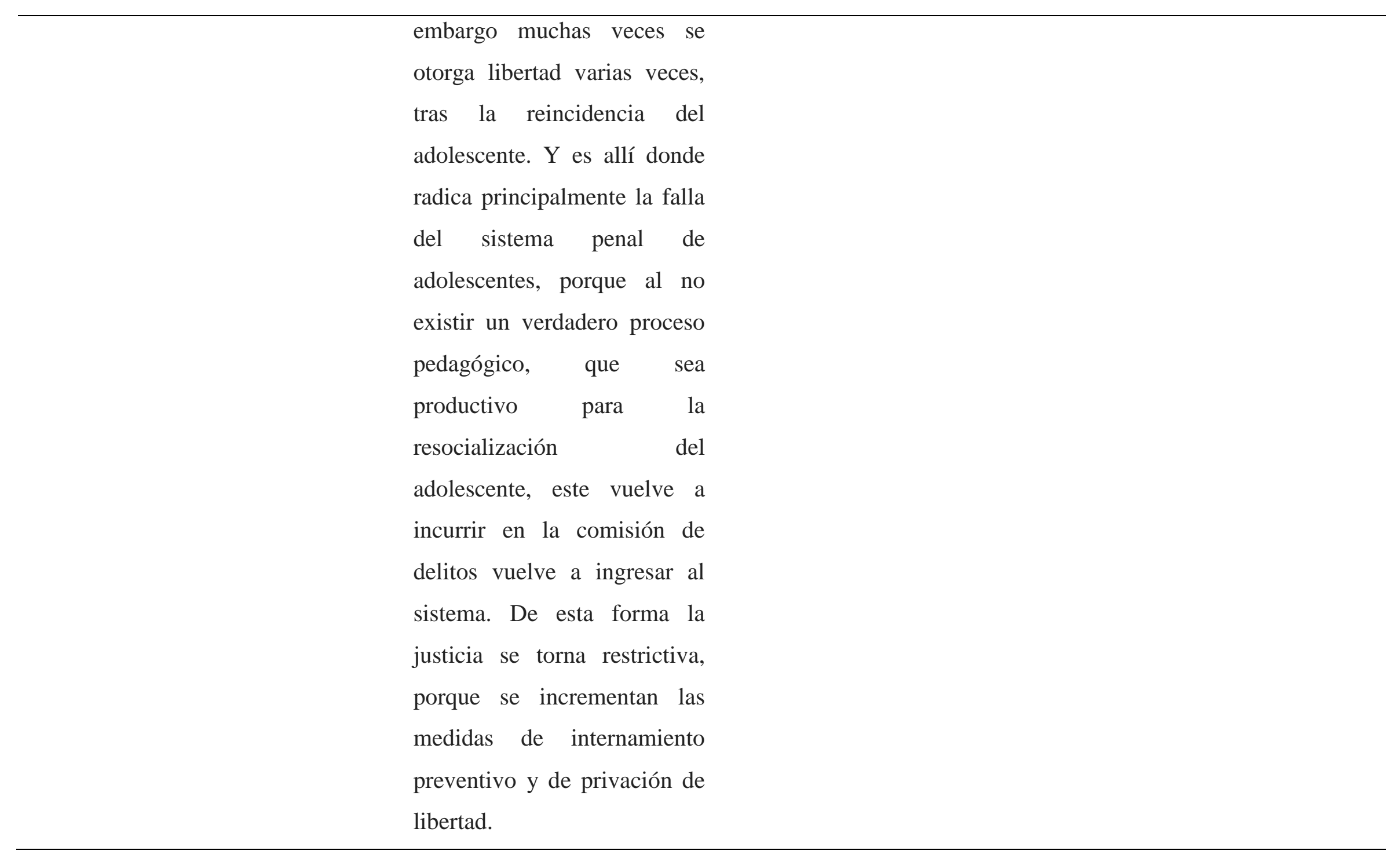




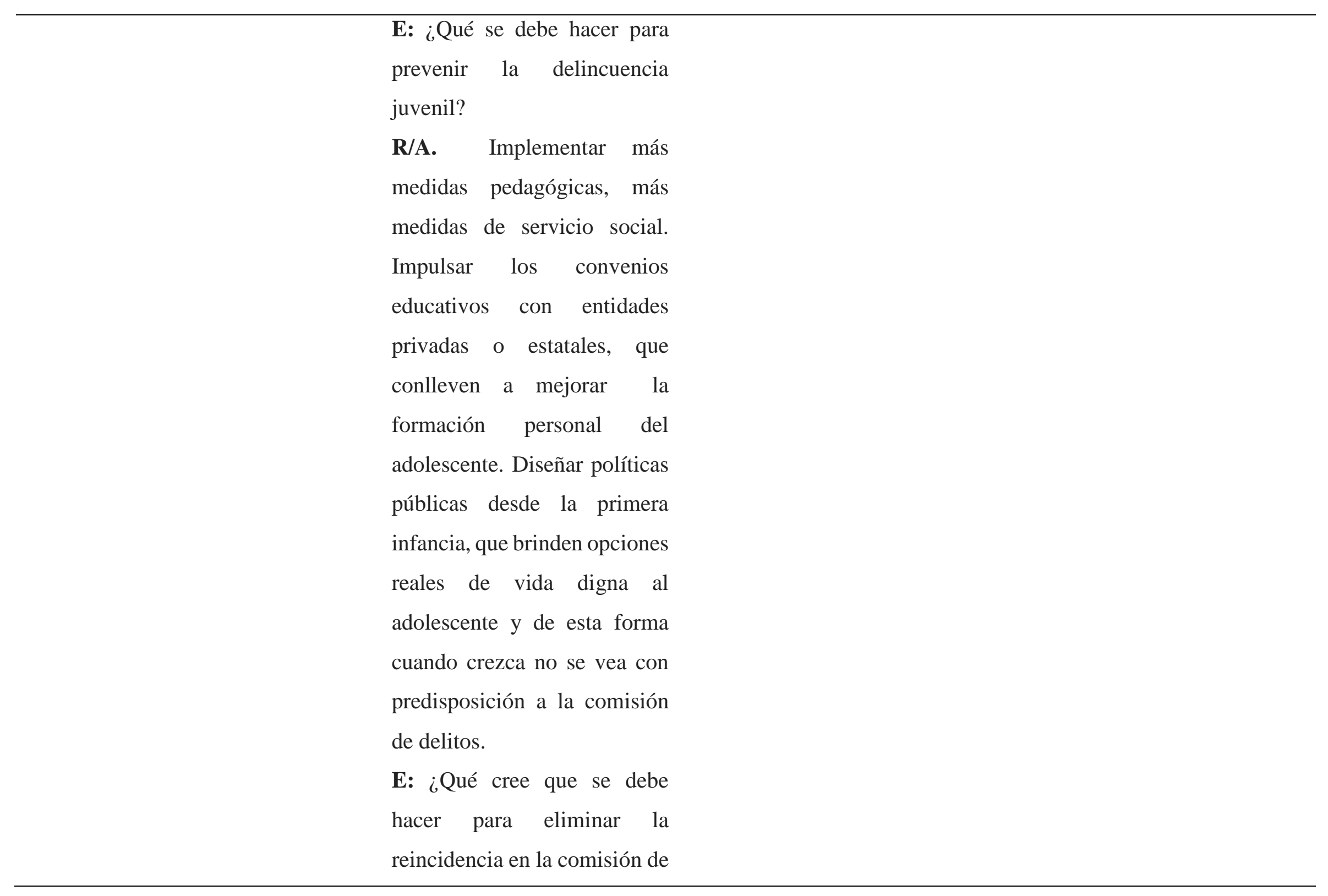




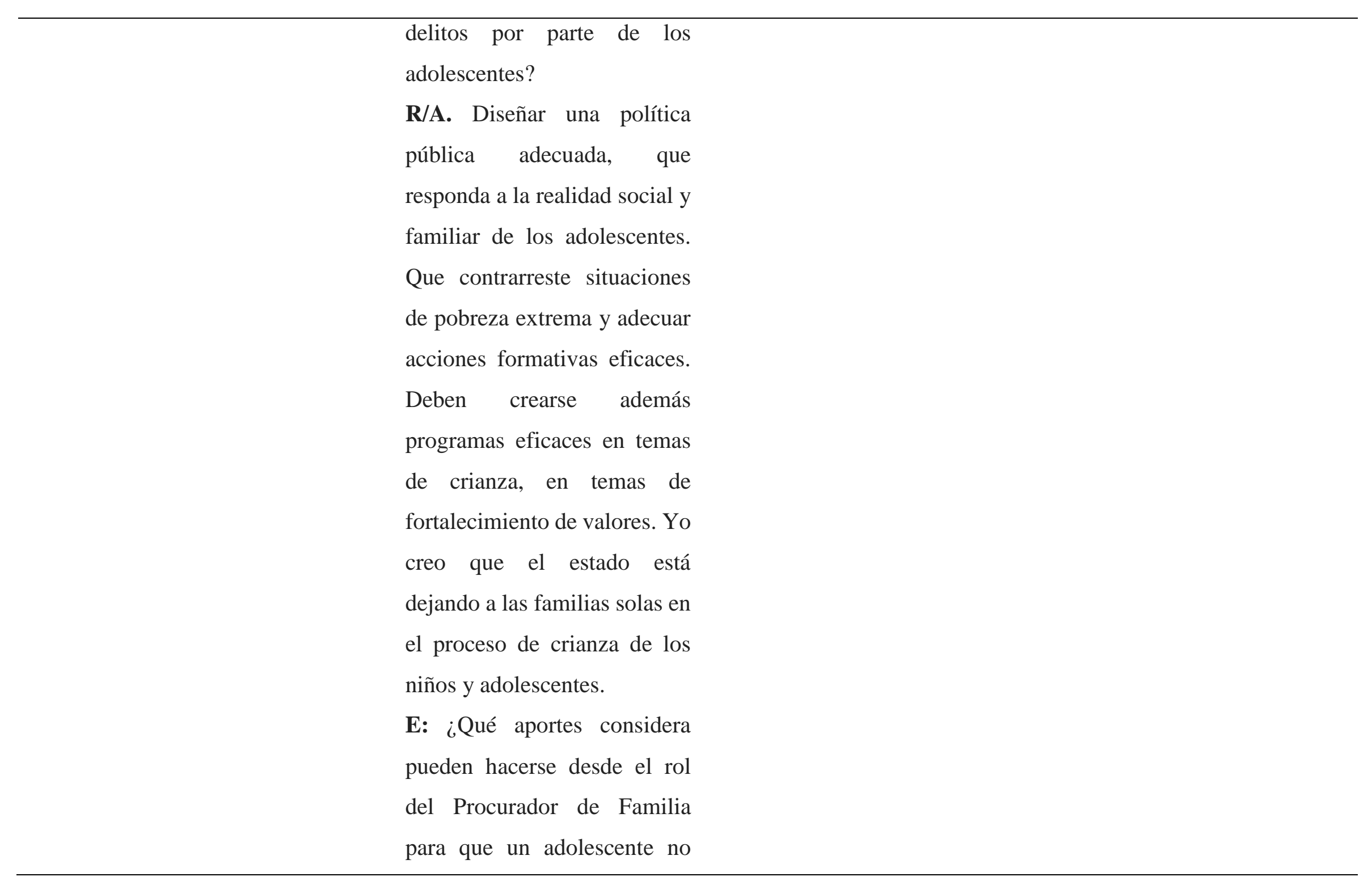




\begin{tabular}{l}
\hline reincida en la comisión de \\
delitos? \\
R/A. Impulsar medidas \\
restaurativas, medidas de \\
acciones pedagógicas y \\
medidas que impulsen a la \\
familia a involucrarse más en \\
el proceso con el adolescente.
\end{tabular}


Tabla 5

\section{Matriz sobre el Proceso Administrativo de Restablecimiento de Derechos en el Sistema de Responsabilidad para Adolescentes}

\begin{tabular}{|c|c|c|c|c|}
\hline $\begin{array}{l}\text { Actores de la } \\
\text { Investigación }\end{array}$ & Objetivos del PARD en el SRPA & $\begin{array}{l}\text { Fases del PARD en el } \\
\text { SRPA }\end{array}$ & $\begin{array}{ll}\text { Medidas } & \text { de } \\
\text { restablecimiento } & \text { de } \\
\text { derechos } & \end{array}$ & $\begin{array}{l}\text { Sanciones como medidas de } \\
\text { restablecimiento de derechos }\end{array}$ \\
\hline 1 & $\begin{array}{l}\text { E: ¿Cree Ud. que el estado } \\
\text { colombiano está respondiendo a } \\
\text { las necesidades del país, en } \\
\text { términos de justicia penal para } \\
\text { adolescentes? } \\
\text { R/A. Si. Actualmente se realiza } \\
\text { un comité interinstitucional a fin } \\
\text { de corregir las pocas falencias que } \\
\text { existen con respecto al tema. De } \\
\text { ofrecer además una buena oferta a } \\
\text { los jóvenes que tienen } \\
\text { investigaciones pendientes y que } \\
\text { se encuentran cumpliendo } \\
\text { medidas, ya que tienen derecho a } \\
\text { la rehabilitación y a la }\end{array}$ & $\begin{array}{l}\text { E: ¿Cree Ud. que el } \\
\text { estado colombiano está } \\
\text { respondiendo a las } \\
\text { necesidades del país, en } \\
\text { términos de justicia penal } \\
\text { para adolescentes? } \\
\text { R/A. Si. Actualmente se } \\
\text { realiza un comité } \\
\text { interinstitucional a fin de } \\
\text { corregir las pocas } \\
\text { falencias que existen con } \\
\text { respecto al tema. De } \\
\text { ofrecer además una buena } \\
\text { oferta a los jóvenes que } \\
\text { tienen investigaciones }\end{array}$ & $\begin{array}{l}\text { E: ¿Considera que las } \\
\text { medidas de } \\
\text { internamiento dan } \\
\text { preventivo, } \\
\text { resultados pedagógicos? } \\
\text { R/A. Si en la medida } \\
\text { que el tiempo que } \\
\text { permanezca el joven } \\
\text { dentro del centro ocupe } \\
\text { su tiempo y realice } \\
\text { actividades que le sirvan } \\
\text { para su futuro. Que } \\
\text { aproveche las } \\
\text { oportunidades que el } \\
\text { mismo sistema le ofrece. }\end{array}$ & $\begin{array}{l}\text { E: ¿Cuáles son los tipos de } \\
\text { sanciones más recurrentes? } \\
\text { R/A. La amonestación, } \\
\text { prestación de servicios } \\
\text { sociales a la comunidad, } \\
\text { libertad } \\
\text { internamiento en medio } \\
\text { semicerrado. } \\
\text { E: ¿Cuáles son las medidas } \\
\text { preventivas más frecuentes? } \\
\text { R/A. } \\
\text { internamiento preventivo y } \\
\text { de libertad vigilada son las } \\
\text { más utilizadas por los jueces } \\
\text { dependiendo del tipo de }\end{array}$ \\
\hline
\end{tabular}




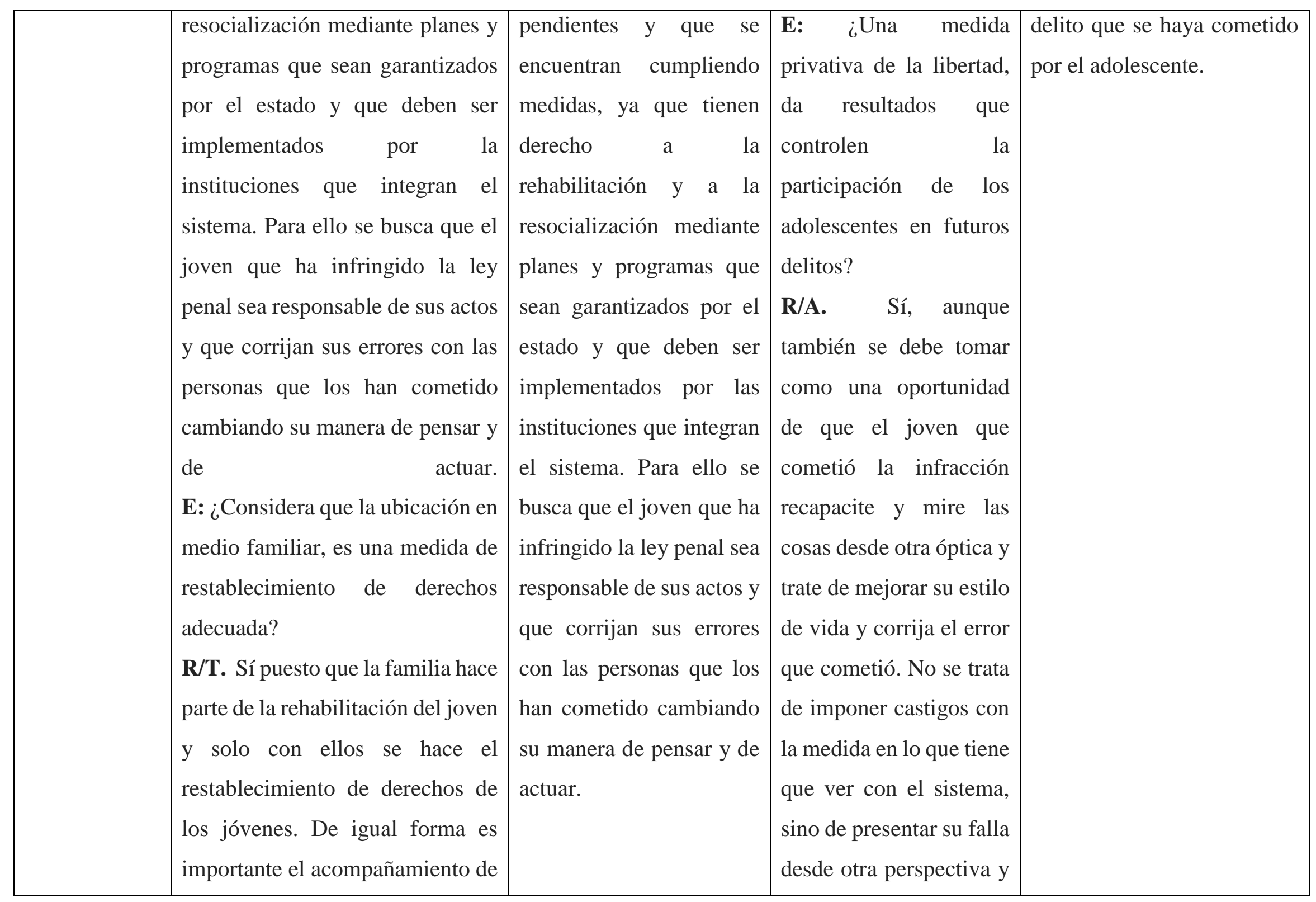




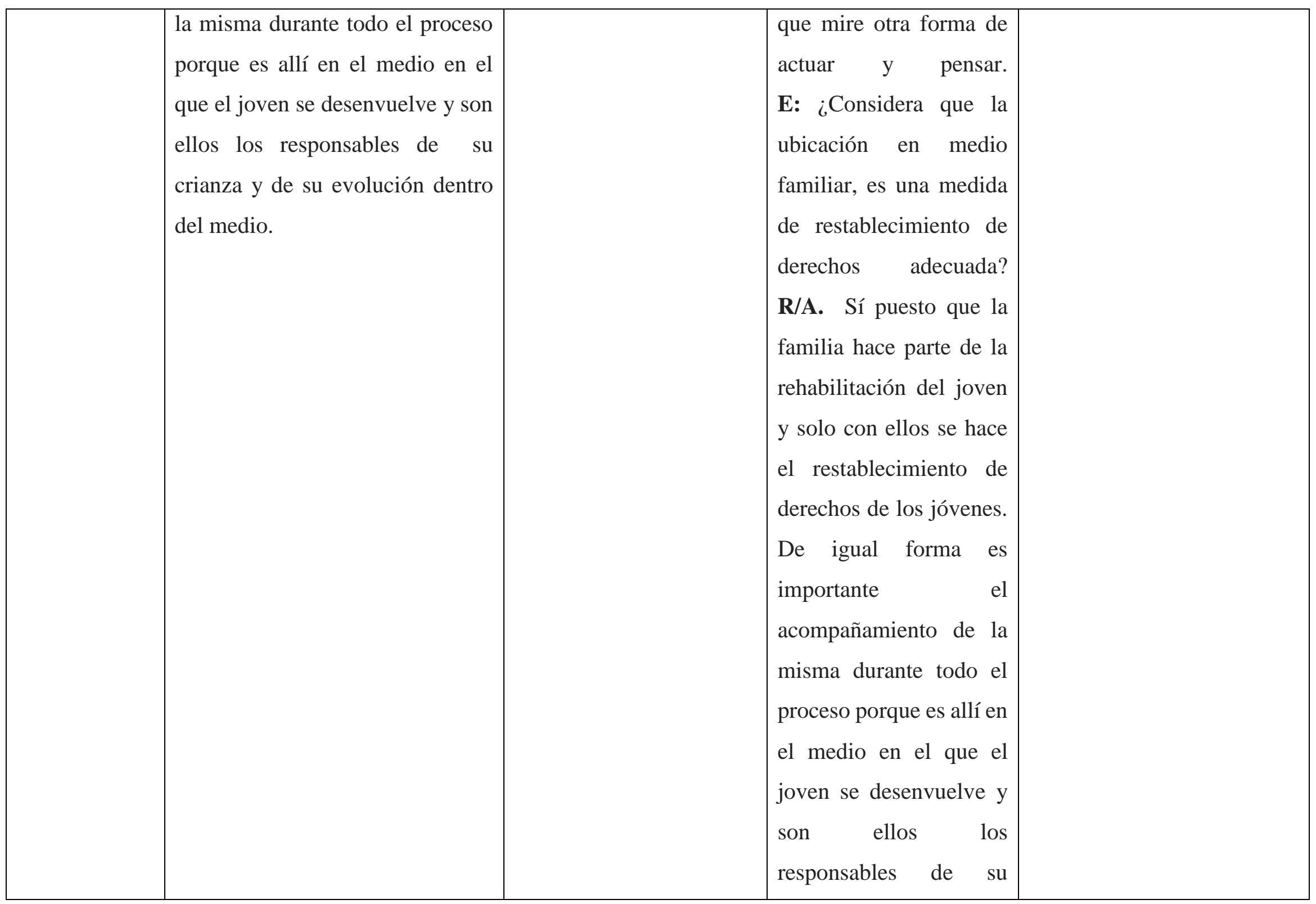




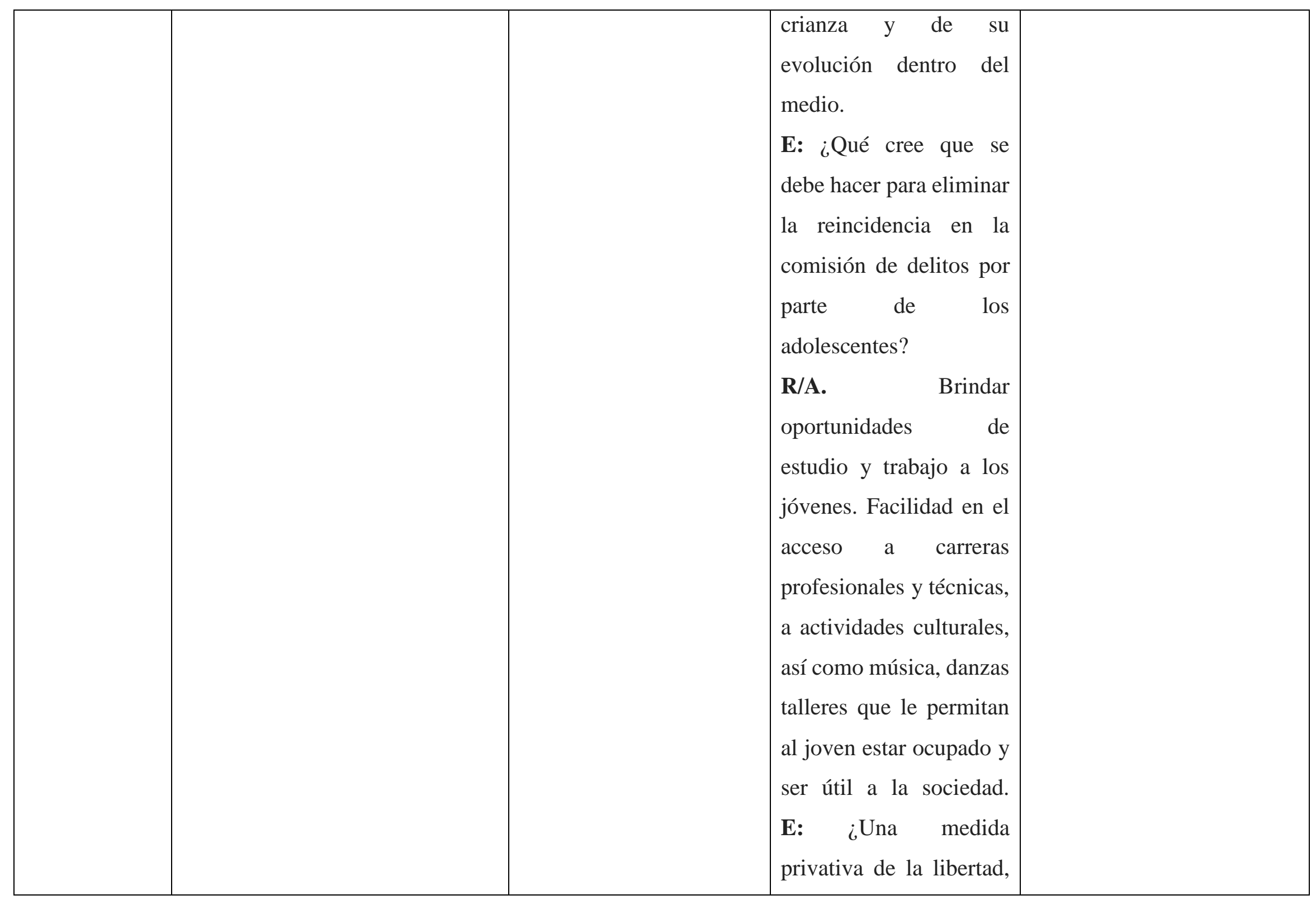




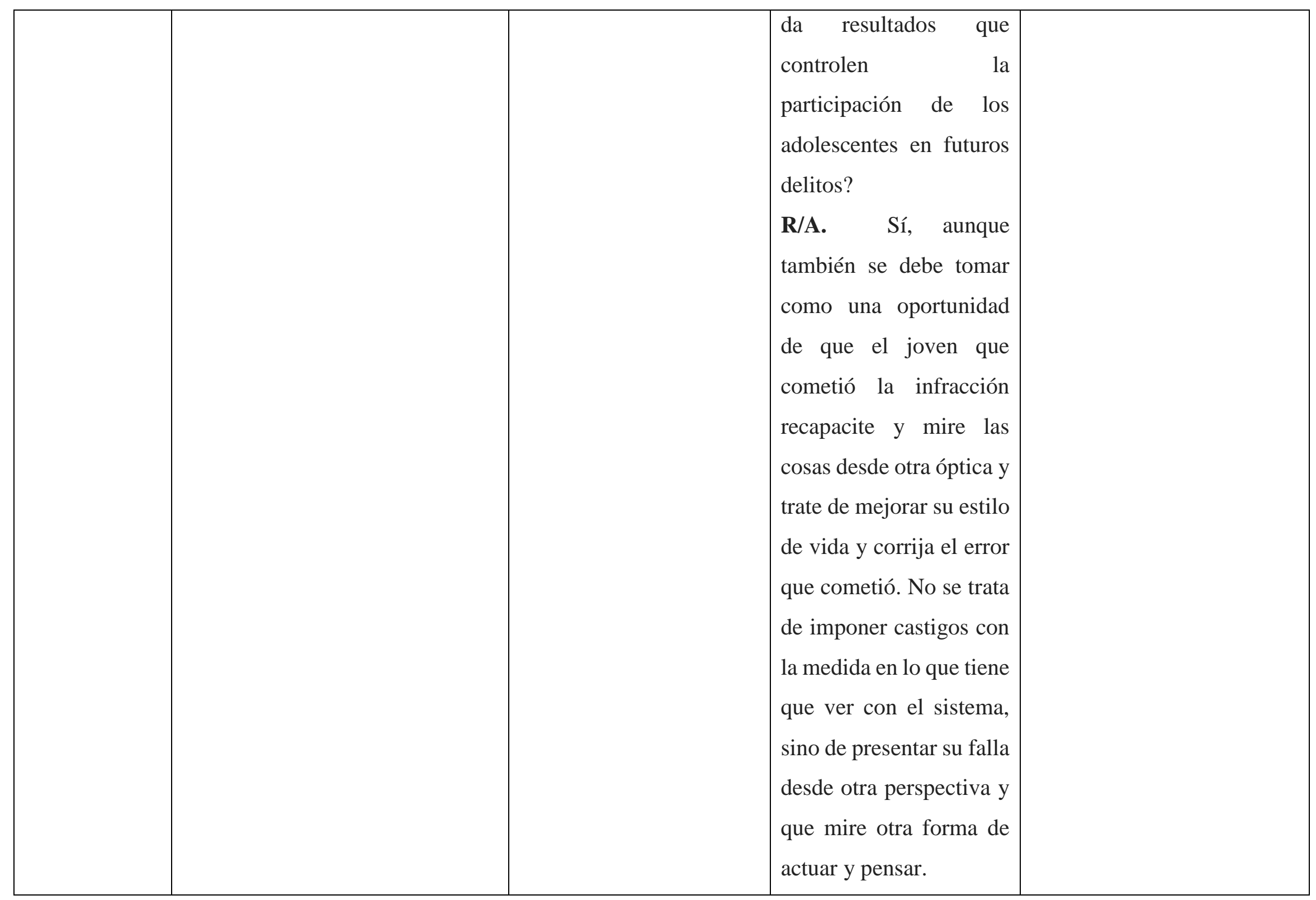




\begin{tabular}{|c|c|c|c|c|}
\hline 2 & $\begin{array}{l}\text { E: ¿Cree Ud. que el estado } \\
\text { colombiano está respondiendo a } \\
\text { las necesidades del país, en } \\
\text { términos de justicia penal para } \\
\text { adolescentes? } \\
\text { R/A. El principio y fin último del } \\
\text { sistema de responsabilidad penal } \\
\text { para adolescentes es pedagógico, } \\
\text { preventivo y restaurativo. Sin } \\
\text { embargo, si pensamos en los datos } \\
\text { estadísticos de incursión de } \\
\text { adolescentes al área penal, por } \\
\text { motivos de comisión de delitos, } \\
\text { podemos considerar que esto no } \\
\text { se está cumpliendo a cabalidad. } \\
\text { Toda vez que un adolescente } \\
\text { debería recibir por parte de lo } \\
\text { estado, un blindaje que no } \\
\text { permitiera su reincidencia en la } \\
\text { delincuencia. Los estudios de } \\
\text { entidades como la Defensoría del } \\
\text { Pueblo, nos indican que, si el }\end{array}$ & $\begin{array}{l}\text { E: ¿Cómo realizan } \\
\text { acciones restaurativas con } \\
\text { los adolescentes? } \\
\text { R/A. Las acciones que se } \\
\text { implementan en la } \\
\text { realidad son para estricto } \\
\text { cumplimiento de las } \\
\text { funciones del servidor } \\
\text { público. } \\
\text { El adolescente, se } \\
\text { sanciona en primera } \\
\text { instancia con una } \\
\text { amonestación, la cual } \\
\text { implica un compromiso } \\
\text { por parte de la familia y } \\
\text { del mismo adolescente. } \\
\text { Otro tipo de sanción es la } \\
\text { libertad asistida con } \\
\text { servicio social } \\
\text { comunitario. } \\
\begin{array}{l}\text { De acuerdo a la carga } \\
\text { laboral del servidor }\end{array}\end{array}$ & $\begin{array}{l}\text { E: ¿Qué opina sobre las } \\
\text { medidas de protección } \\
\text { para adolescentes? } \\
\text { R/A. Las medidas son } \\
\text { más restrictivas que } \\
\text { restablecedoras } \\
\text { restaurativas. } \\
\text { Una verdadera medida } \\
\text { de protección debería } \\
\text { estar plagada de } \\
\text { elementos } \\
\text { componentes integrales, } \\
\text { como trata de } \\
\text { establecerlo la norma. } \\
\text { Sin embargo, solo se } \\
\text { brindan garantías a } \\
\text { medias. Debido a que el } \\
\text { estado no tiene la } \\
\text { capacidad para adelantar } \\
\text { acciones eficaces en } \\
\text { temas de oportunidades } \\
\text { educativas o laborales }\end{array}$ & $\begin{array}{l}\text { E: ¿Cómo realizan acciones } \\
\text { restaurativas con los } \\
\text { adolescentes? } \\
\text { R/A. Las acciones que se } \\
\text { implementan en la realidad } \\
\text { son para estricto } \\
\text { cumplimiento de las } \\
\text { funciones del servidor } \\
\text { público. } \\
\text { El adolescente, se sanciona } \\
\text { en primera instancia con una } \\
\text { amonestación, la cual } \\
\text { implica un compromiso por } \\
\text { parte de la familia y del } \\
\text { mismo adolescente. } \\
\text { Otro tipo de sanción es la } \\
\text { libertad asistida con servicio } \\
\text { social comunitario. } \\
\text { Conocimiento de la } \\
\text { situación actual de cada } \\
\text { adolescente. En no pocas } \\
\text { ocasiones se pierde el }\end{array}$ \\
\hline
\end{tabular}




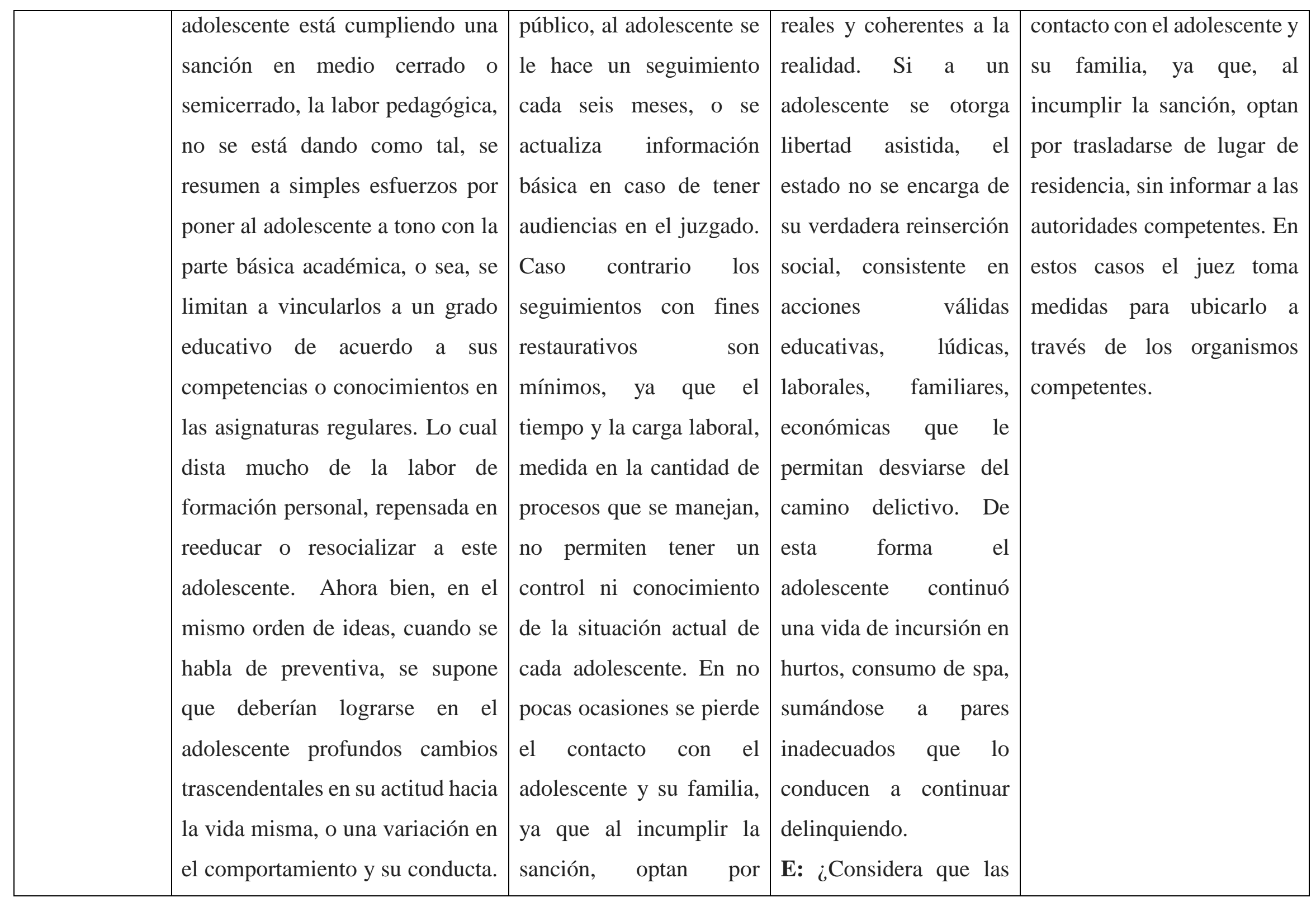




\begin{tabular}{|c|c|c|c|}
\hline & $\begin{array}{l}\text { Sin embargo, observamos que un } \\
\text { mismo adolescente reincide en } \\
\text { muchísimas oportunidades en la } \\
\text { comisión de un mismo delito o en } \\
\text { otros aún más graves. Como por } \\
\text { ejemplo aquellos adolescentes } \\
\text { que han sido judicializados por } \\
\text { porte ilegal de armas en tres o } \\
\text { cuatro oportunidades, } \\
\text { generalmente es sancionado } \\
\text { posteriormente por el delito de } \\
\text { hurto calificado y agravado, } \\
\text { tentativa de homicidio y en } \\
\text { muchos casos por el delito de } \\
\text { homicidio. En este sentido si el } \\
\text { SRPA, cumpliese en un fin } \\
\text { preventivo, desde el primer delito, } \\
\text { por el cual ingresó, ya no debería } \\
\text { incursionar jamás en conflicto con } \\
\text { la ley penal. Ahora cumple un fin } \\
\text { restaurativo. ¿Nos preguntamos a } \\
\text { quien se restaura, al adolescente, a }\end{array}$ & $\begin{array}{l}\text { trasladarse de lugar de } \\
\text { residencia, sin informar a } \\
\text { las autoridades } \\
\text { competentes. En estos } \\
\text { casos el juez toma } \\
\text { medidas para ubicarlo a } \\
\text { través de los organismos } \\
\text { competentes. }\end{array}$ & $\begin{array}{l}\text { medidas de } \\
\text { internamiento } \\
\text { preventivo, dan } \\
\text { resultados pedagógicos? } \\
\text { R/A. Si en la medida } \\
\text { que el tiempo que } \\
\text { permanezca el joven } \\
\text { dentro del centro ocupe } \\
\text { su tiempo y realice } \\
\text { actividades que le sirvan } \\
\text { para su futuro. Que } \\
\text { aproveche las } \\
\text { oportunidades que el } \\
\text { mismo sistema le ofrece. }\end{array}$ \\
\hline
\end{tabular}




\begin{tabular}{|c|c|c|c|c|}
\hline & $\begin{array}{l}\text { la víctima? A mi modo de ver el } \\
\text { adolescente en cada delito cae en } \\
\text { un abismo y generalmente, la } \\
\text { víctima tiene un deseo } \\
\text { encarnizado de castigo, de tal } \\
\text { forma que ni siquiera accede a } \\
\text { acuerdos que permitan restaurar el } \\
\text { daño ocasionado. }\end{array}$ & & & \\
\hline 3 & & $\begin{array}{l}\text { E: ¿Cree Ud. que el } \\
\text { estado colombiano está } \\
\text { respondiendo a las } \\
\text { necesidades del país, en } \\
\text { términos de justicia penal } \\
\text { para adolescentes? } \\
\text { R/A. Frente a la pregunta } \\
\text { es importante tener en } \\
\text { cuenta que atreves de la } \\
\text { Ley } 1098 \text { de 2006, se } \\
\text { realizaron esfuerzos } \\
\text { bastante grande, para } \\
\text { reformular las nuevas } \\
\text { sanciones establecidas, a }\end{array}$ & $\begin{array}{l}\text { E: ¿Cree Ud. que el } \\
\text { estado colombiano está } \\
\text { respondiendo a las } \\
\text { necesidades del país, en } \\
\text { términos de justicia } \\
\text { penal para adolescentes? } \\
\text { R/A. Frente a la } \\
\text { pregunta es importante } \\
\text { tener en cuenta que } \\
\text { atreves de la Ley } 1098 \\
\text { de 2006, se realizaron } \\
\text { esfuerzos bastante } \\
\text { grande, para reformular } \\
\text { las nuevas sanciones }\end{array}$ & $\begin{array}{l}\text { E: ¿Cuáles son los tipos de } \\
\text { sanciones más recurrentes? } \\
\text { R/A. Bueno los tipos de } \\
\text { Sanciones más recurren que } \\
\text { se le impone a los } \\
\text { Adolescente que entran en } \\
\text { choque con la Norma Penal } \\
\text { son: El Internamiento } \\
\text { Preventivo, la cual consiste } \\
\text { que en cualquier momento } \\
\text { del proceso y antes de la } \\
\text { audiencia de juicio, el juez } \\
\text { de control de garantía, como } \\
\text { último recurso la decreta, por }\end{array}$ \\
\hline
\end{tabular}




\begin{tabular}{|c|c|c|c|c|}
\hline & & $\begin{array}{l}\text { través de un carácter } \\
\text { pedagógico } \\
\text { restaurativo }, \quad \text { sin } \\
\text { embargo la dinámica } \\
\text { social, nos han llevado a } \\
\text { replantear muchas de las } \\
\text { sanciones que hoy en día } \\
\text { están establecida de } \\
\text { carácter pedagógico y } \\
\text { judicial para los } \\
\text { Adolescentes, las cuales } \\
\text { cada vez se están } \\
\text { haciendo más corta frente } \\
\text { al proceso de } \\
\text { acompañamiento de los } \\
\text { jóvenes que las hacen } \\
\text { insuficiente, en su } \\
\text { efectividad, por cuanto } \\
\text { que los Adolescente } \\
\text { conocen más ley, con el } \\
\text { fin de evitar que les sean } \\
\text { lo cual hace que el nivel }\end{array}$ & $\begin{array}{l}\text { establecidas, a través de } \\
\text { un carácter pedagógico } \\
\text { y restaurativo, sin } \\
\text { embargo la dinámica } \\
\text { social, nos han llevado a } \\
\text { replantear muchas de las } \\
\text { sanciones que hoy en } \\
\text { día están establecida de } \\
\text { carácter pedagógico y } \\
\text { judicial para los } \\
\text { Adolescentes, las cuales } \\
\text { cada vez se están } \\
\text { haciendo más corta } \\
\text { frente al proceso de } \\
\text { acompañamiento de los } \\
\text { jóvenes que las hacen } \\
\text { insuficiente, en su } \\
\text { efectividad, por cuanto } \\
\text { que los Adolescente } \\
\text { conocen más ley, con el } \\
\text { fin de evitar que les sean } \\
\text {; lo cual hace que el }\end{array}$ & $\begin{array}{l}\text { cuanto que en la mayoría de } \\
\text { los casos el Adolescente o } \\
\text { los Adolescentes sobre ellos } \\
\text { existe riesgo razonable de } \\
\text { que se evadirá del proceso, } \\
\text { existe temor fundado que } \\
\text { destruirá u obstaculizara las } \\
\text { pruebas o existe peligro } \\
\text { grave para la víctima, el } \\
\text { denunciante, el testigo o la } \\
\text { comunidad en la cual se } \\
\text { generó la exteriorización de } \\
\text { su conducta criminal. } \\
\text { Este tipo de sanción } \\
\text { recurrente es } \\
\text { Internamiento preventivo, } \\
\text { este tipo de sanción opera en } \\
\text { los casos en que, conforme a } \\
\text { la gravedad del delito sería } \\
\text { admisible la privación de la } \\
\text { libertad. Esta se ejecuta en } \\
\text { Centros de Internamientos }\end{array}$ \\
\hline
\end{tabular}




\begin{tabular}{|c|c|c|c|c|}
\hline & & $\begin{array}{l}\text { de evasión sea grande y } \\
\text { vienen superando las } \\
\text { medidas a la que son } \\
\text { sometidos. } \\
\text { insuficientes y muchas } \\
\text { veces los traslados por } \\
\text { privación de la libertad no } \\
\text { se cumple por cuanto que } \\
\text { se evaden, estos traslados } \\
\text { no se cumplen por la } \\
\text { carencia de espacios para } \\
\text { ubicarlos, esto hace hacen } \\
\text { que el sistema no opere } \\
\text { como debe ser y para el } \\
\text { cual está diseñado, se } \\
\text { necesita un sistema más } \\
\text { eficiente para cumplir con } \\
\text { las sanciones y realizar el } \\
\text { acompañamiento } \\
\text { correspondiente y el } \\
\text { procedimiento judicial } \\
\text { ajustado fallado a la ley. }\end{array}$ & $\begin{array}{l}\text { nivel de evasión sea } \\
\text { grande y vienen } \\
\text { superando las medidas a } \\
\text { la que son sometidos. } \\
\text { E: ¿Considera que la } \\
\text { ubicación en medio } \\
\text { familiar, es una medida } \\
\text { de restablecimiento de } \\
\text { derechos adecuada? } \\
\text { R/A. Bueno la verdad } \\
\text { que, en algunos casos, } \\
\text { puede que resulte como } \\
\text { en otros no resulta en lo } \\
\text { absoluto que esta } \\
\text { medida brinde las } \\
\text { garantías necesarias en } \\
\text { que el Adolescente no } \\
\text { recaiga de inmediato en } \\
\text { volver a la comisión de } \\
\text { delitos en su comunidad } \\
\text { y con más fuerza y } \\
\text { decisión para su }\end{array}$ & $\begin{array}{l}\text { Especializados cerrados, en } \\
\text { los cuales los Adolescentes } \\
\text { procesados están separados } \\
\text { de los ya condenados. } \\
\text { Otro tipo de sanción muy } \\
\text { concurrente es } \\
\text { Amonestación, en la cual la } \\
\text { autoridad judicial } \\
\text { competente recrimina al } \\
\text { adolescente sobre las } \\
\text { consecuencias del hecho en } \\
\text { tuvo participación y por el } \\
\text { cual se encuentra vinculado } \\
\text { al proceso y por lo cual debe } \\
\text { reparar el daño causado, en } \\
\text { todo el caso deberá asistir a } \\
\text { un curso educativo sobre } \\
\text { respeto a los derechos } \\
\text { humanos y convivencia } \\
\text { ciudadana el cual estará a } \\
\text { cargo del Instituto de } \\
\text { Estudio del Ministerio }\end{array}$ \\
\hline
\end{tabular}




\begin{tabular}{|c|c|c|c|}
\hline & & $\begin{array}{l}\text { comisión. Aquí la } \\
\text { Familia como garante } \\
\text { del principio de } \\
\text { corresponsabilidad debe } \\
\text { aportar su efectividad en } \\
\text { el control del } \\
\text { adolescente que se le ha } \\
\text { dado este tipo de } \\
\text { ubicación familiar. }\end{array}$ & $\begin{array}{l}\text { Público. } \\
\text { Las reglas de conductas, que } \\
\text { también es muy frecuente es } \\
\text { la imposición de la } \\
\text { Autoridad Judicial al } \\
\text { adolescente de obligaciones } \\
\text { para regular su modo vida y } \\
\text { así como la de promover su y } \\
\text { asegurar su formación. Esta } \\
\text { sanción no podrá exceder de } \\
\text { dos años. }\end{array}$ \\
\hline 4 & $\begin{array}{l}\text { E: ¿Cree Ud. que el estado } \\
\text { colombiano está respondiendo a } \\
\text { las necesidades del país, en } \\
\text { términos de justicia penal para } \\
\text { adolescentes? } \\
\text { R/A. Bueno en los últimos } \\
\text { tiempos se están creando algunos } \\
\text { mecanismos a fin de corregir las } \\
\text { grandes lagunas que existen con } \\
\text { respecto a esta Política Pública. } \\
\text { La cual está encaminada de }\end{array}$ & $\begin{array}{l}\text { E: ¿Considera que las } \\
\text { medidas de } \\
\text { internamiento } \\
\text { preventivo, dan } \\
\text { resultados pedagógicos? } \\
\text { R/A. Esta medida } \\
\text { pedagógica en el papel } \\
\text { resulta muy efectiva } \\
\text { para aquellos } \\
\text { Adolescente que quizás } \\
\text { por los avatares de la }\end{array}$ & $\begin{array}{l}\text { E: ¿Cuáles son los tipos de } \\
\text { sanciones más recurrentes? } \\
\text { R/A. La amonestación, } \\
\text { prestación de servicios } \\
\text { sociales a la comunidad, } \\
\text { libertad vigilada, } \\
\text { internamiento en medio } \\
\text { semicerrado. }\end{array}$ \\
\hline
\end{tabular}




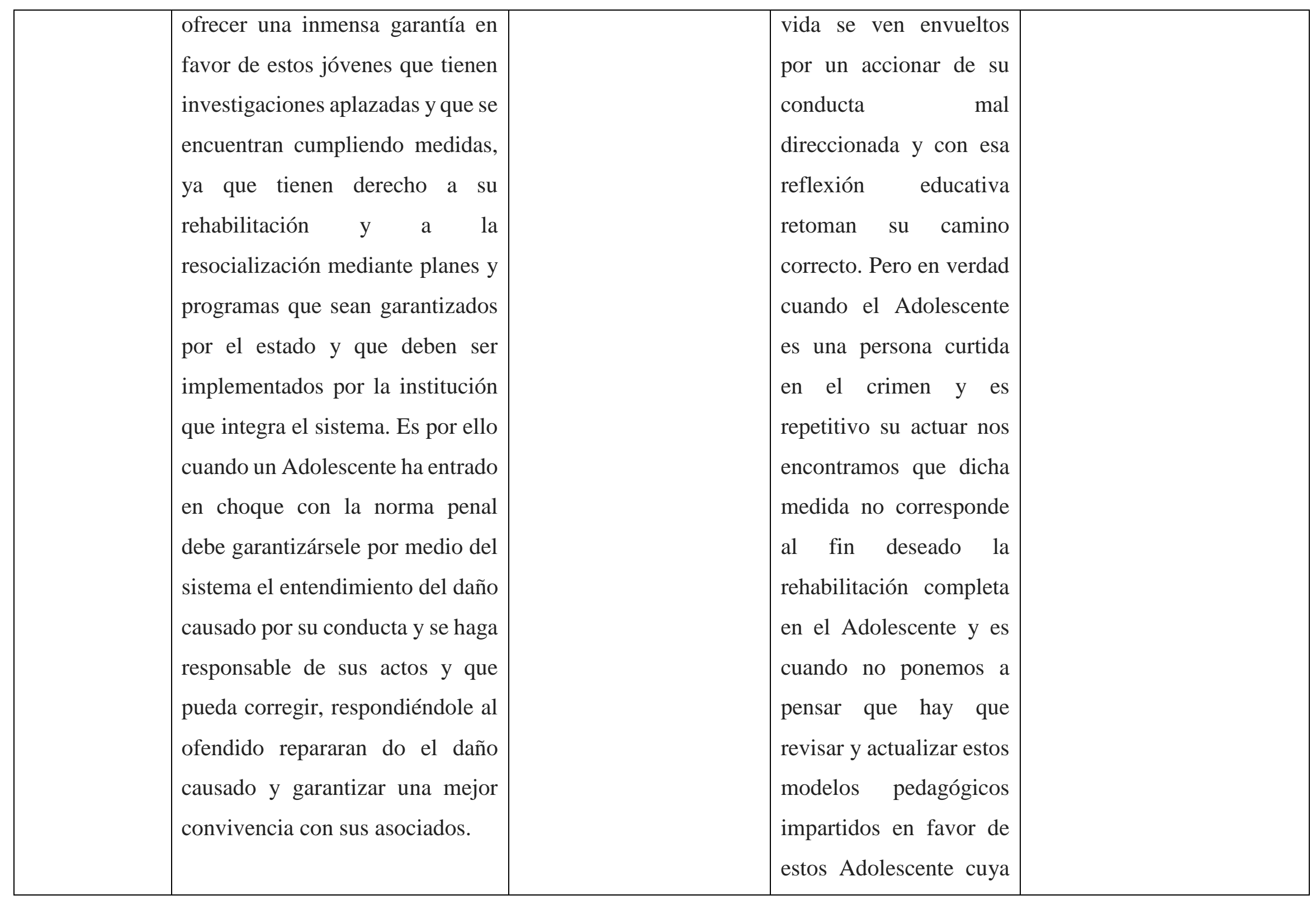




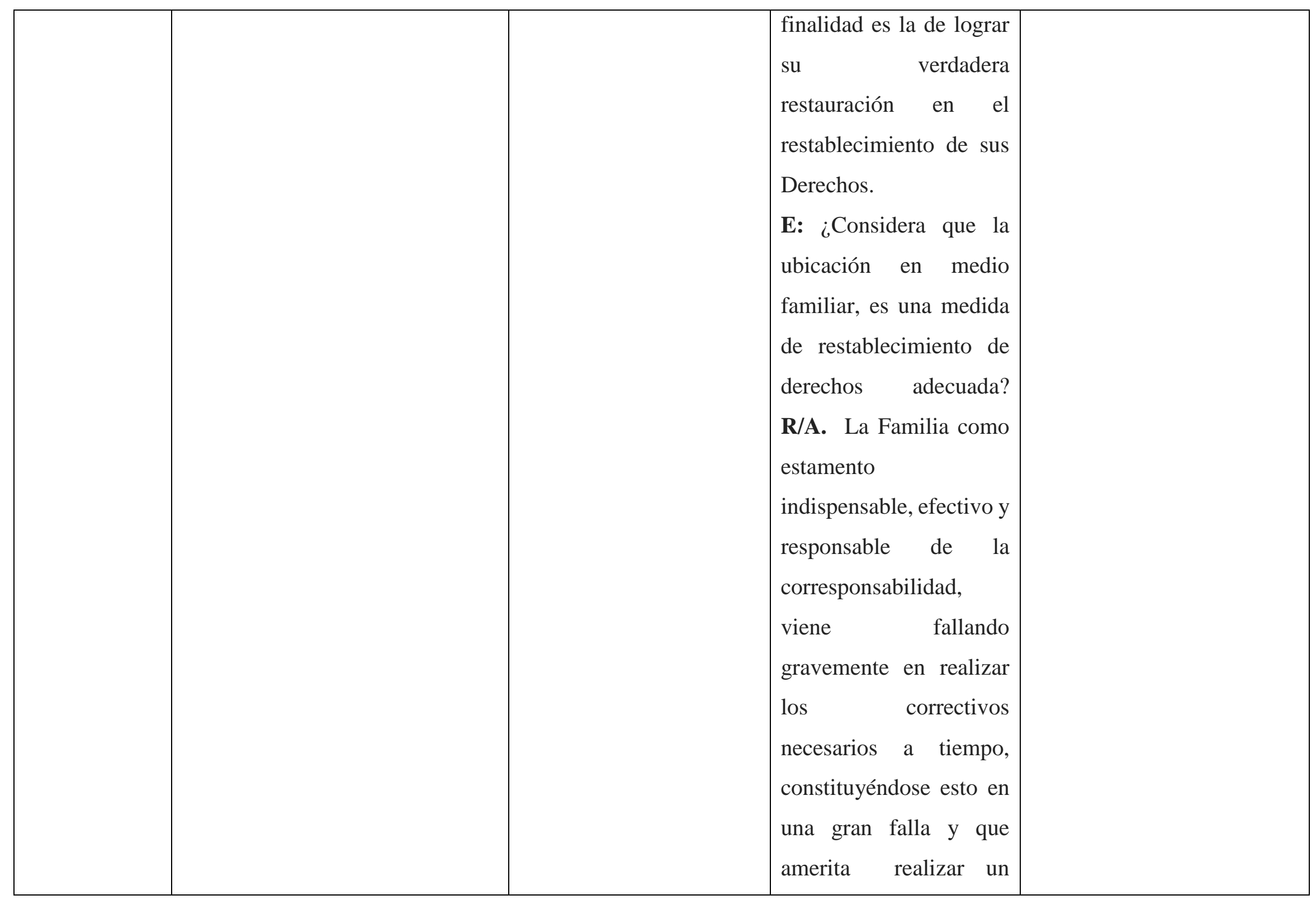




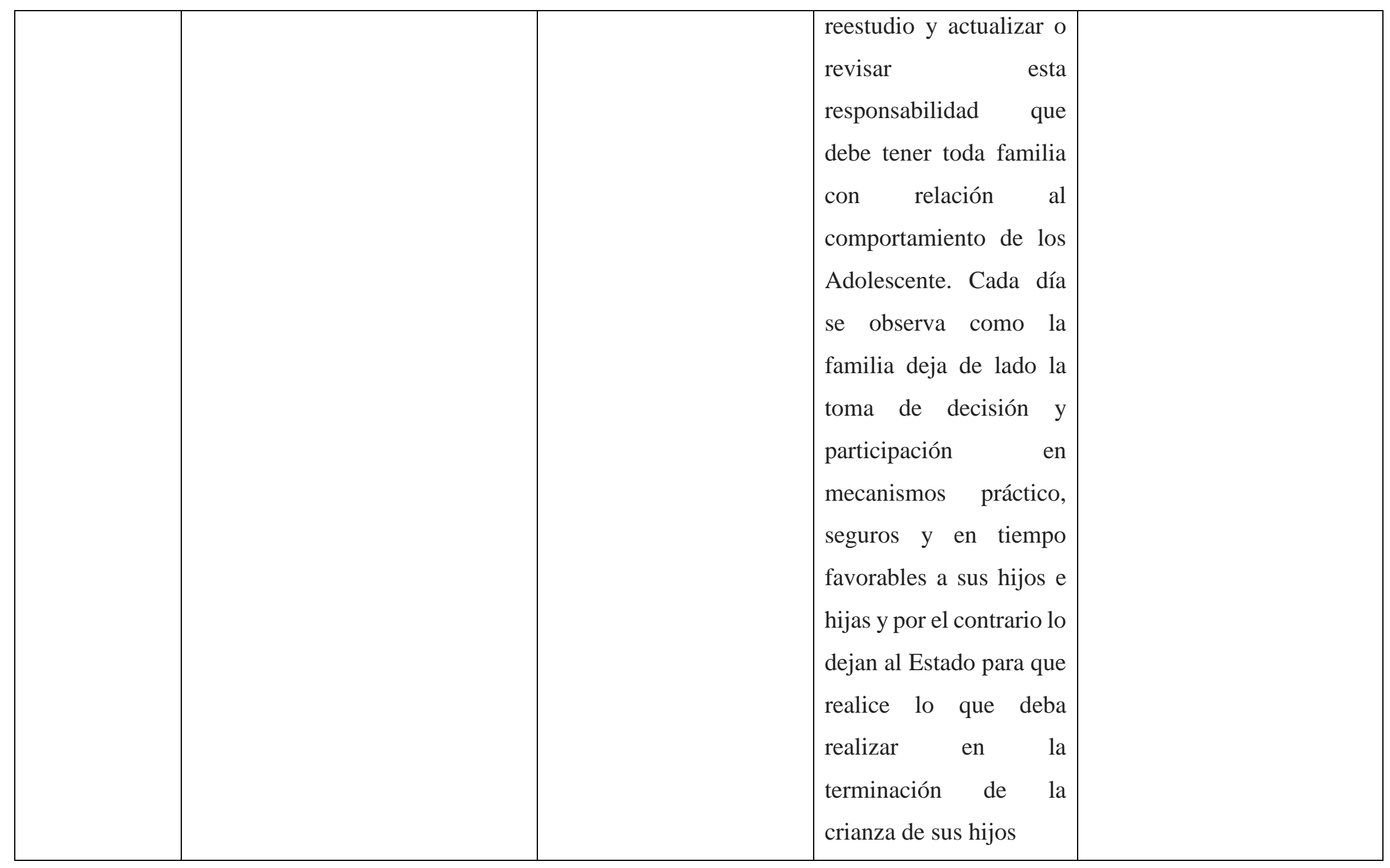




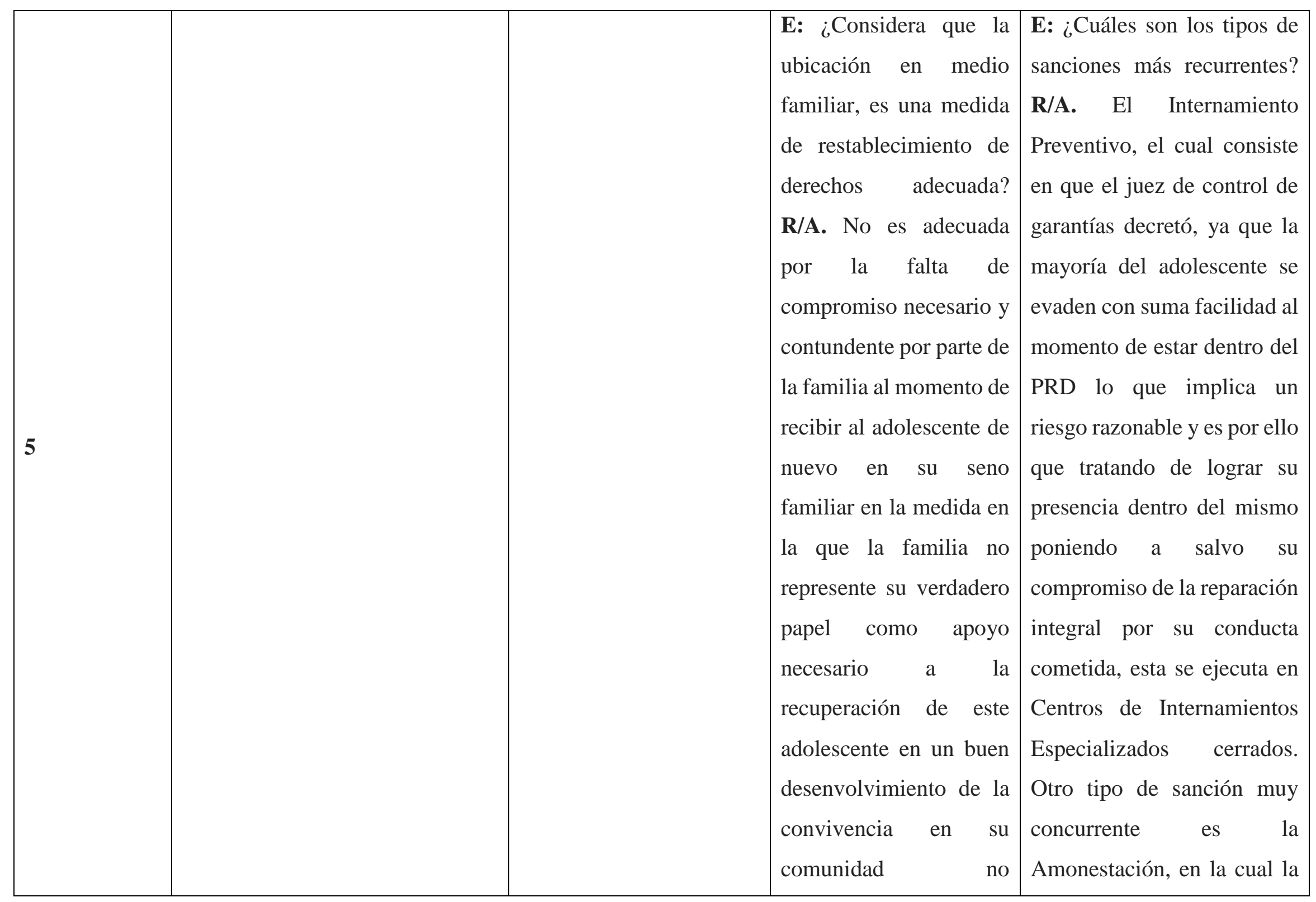




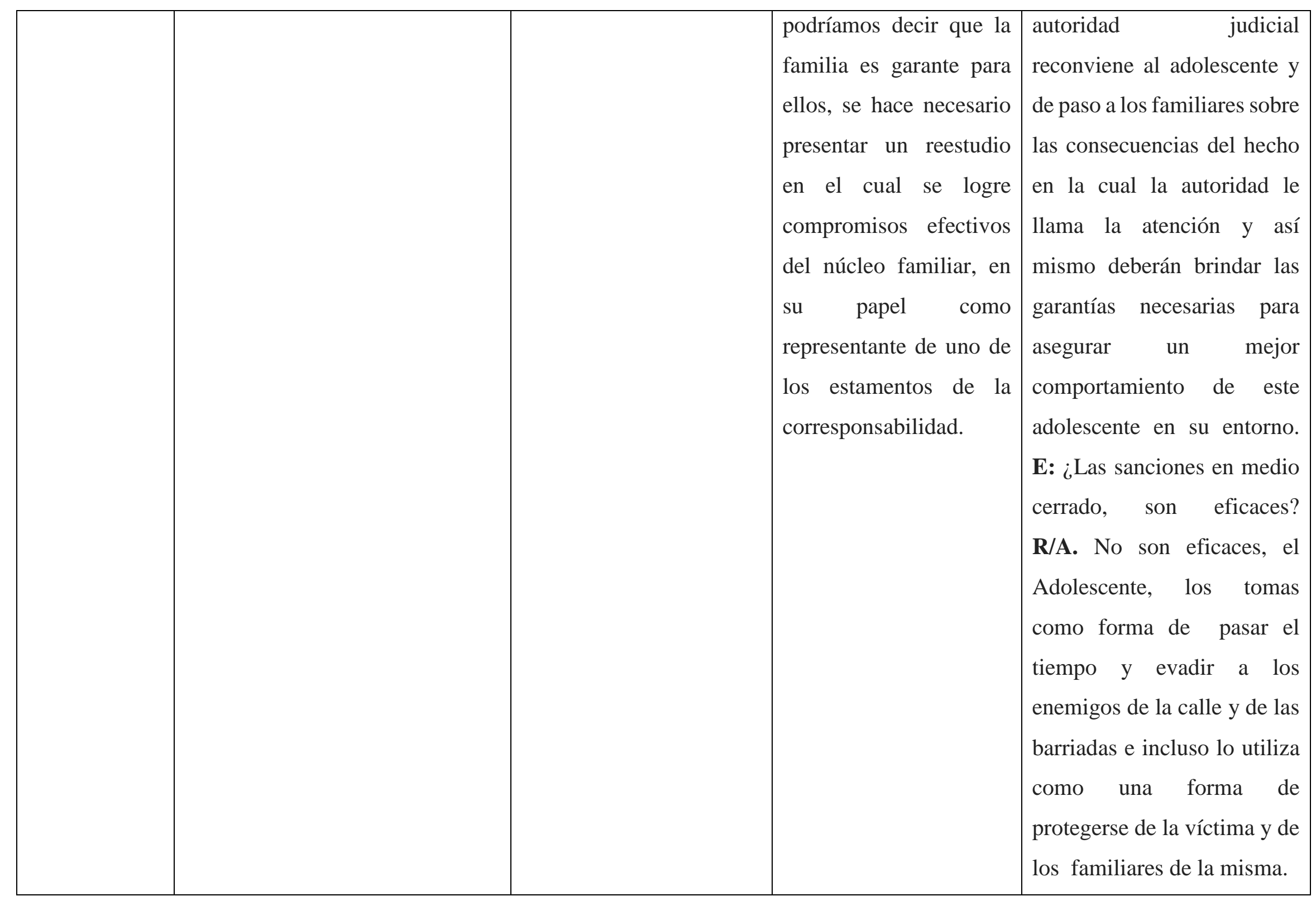




\begin{tabular}{|c|c|c|c|c|}
\hline 6 & $\begin{array}{l}\text { E: ¿Cree Ud. que el estado } \\
\text { colombiano está respondiendo a } \\
\text { las necesidades del país, en } \\
\text { términos de justicia penal para } \\
\text { adolescentes? } \\
\text { R/T. Al realizar un análisis, que } \\
\text { la estructura de la } \\
\text { Responsabilidad Penal para } \\
\text { Adolescentes tiene como } \\
\text { finalidad lo de pedagógico, } \\
\text { preventivo y restaurativo. Nos } \\
\text { damos cuenta } \\
\text { desafortunadamente y probado } \\
\text { por los datos que arroja la la } \\
\text { comisión de delitos por estos } \\
\text { jóvenes, tenemos que decir que no } \\
\text { se cumple a su cabalidad los } \\
\text { objetivos planteados } \\
\text { perseguidos por esta Ley. }\end{array}$ & $\begin{array}{l}\text { E: ¿Cómo realizan } \\
\text { acciones restaurativas con } \\
\text { los adolescentes? } \\
\text { R/A. El ejercicio que se } \\
\text { efectúa al cumplimiento } \\
\text { de la normatividad } \\
\text { vigente al momento de } \\
\text { realizar una intervención } \\
\text { con los Adolescente } \\
\text { involucrados mediante su } \\
\text { conducta en situación de } \\
\text { Responsabilidad Penal el } \\
\text { profesional debe agotar el } \\
\text { cumplimiento de sus } \\
\text { funciones como tal. } \\
\text { Cuando al adolescente, es } \\
\text { merecedor de una sanción } \\
\text { amonestatoria al mismo } \\
\text { tiempo la misma se le } \\
\text { impone a su familia } \\
\text { responsable, a quienes se } \\
\text { le hace garante de vigilar }\end{array}$ & $\begin{array}{l}\text { E: ¿Cómo realizan } \\
\text { acciones restaurativas } \\
\text { con los adolescentes? } \\
\text { R/A. El ejercicio que se } \\
\text { efectúa al cumplimiento } \\
\text { de la normatividad } \\
\text { vigente al momento de } \\
\text { realizar una intervención } \\
\text { con los Adolescente } \\
\text { involucrados mediante } \\
\text { su conducta en situación } \\
\text { de Responsabilidad } \\
\text { Penal el profesional } \\
\text { debe agotar } \\
\text { cumplimiento de sus } \\
\text { funciones como tal. }\end{array}$ & $\begin{array}{l}\text { E: ¿Cómo realizan acciones } \\
\text { restaurativas con los } \\
\text { adolescentes? } \\
\text { R/A. El ejercicio que se } \\
\text { efectúa al cumplimiento de } \\
\text { la normatividad vigente al } \\
\text { momento de realizar una } \\
\text { intervención con los } \\
\text { Adolescente involucrados } \\
\text { mediante su conducta en } \\
\text { situación de } \\
\text { Responsabilidad Penal el } \\
\text { profesional debe agotar el } \\
\text { cumplimiento de sus } \\
\text { funciones como tal. } \\
\text { Cuando al adolescente, es } \\
\text { merecedor de una sanción } \\
\text { amonestatoria al mismo } \\
\text { tiempo la misma se le } \\
\text { impone a su familia } \\
\text { responsable, a quienes se le } \\
\text { hace garante de vigilar su }\end{array}$ \\
\hline
\end{tabular}




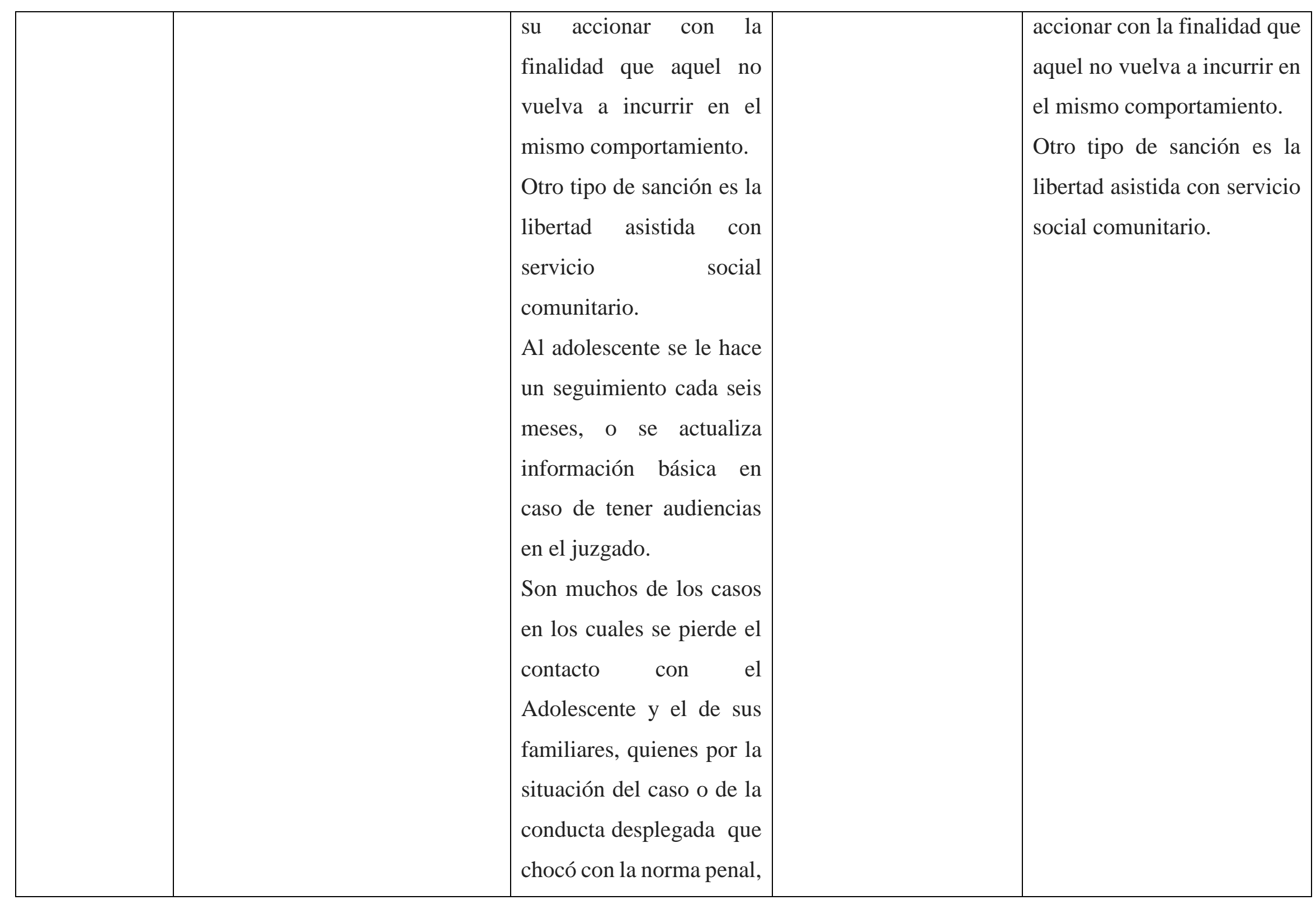




\begin{tabular}{|c|c|c|c|}
\hline & $\begin{array}{l}\text { tienen que huir de la } \\
\text { comunidad o vecindad, } \\
\text { para protegerse de sus } \\
\text { víctimas o adversarios. }\end{array}$ & & \\
\hline 7 & & $\begin{array}{l}\text { E: ¿Cómo realizan } \\
\text { acciones restaurativas } \\
\text { con los adolescentes? } \\
\text { R/A. Las acciones que } \\
\text { se implementan en la } \\
\text { realidad son para } \\
\text { estricto cumplimiento de } \\
\text { la norma. Así por } \\
\text { ejemplo cuando un } \\
\text { adolescente es } \\
\text { sancionado con una } \\
\text { medida de am } \\
\text { contestación, se debería } \\
\text { hacer seguimiento } \\
\text { semestral, por parte de } \\
\text { las autoridades } \\
\text { encargadas } \\
\text { restablecimiento del de }\end{array}$ & \\
\hline
\end{tabular}




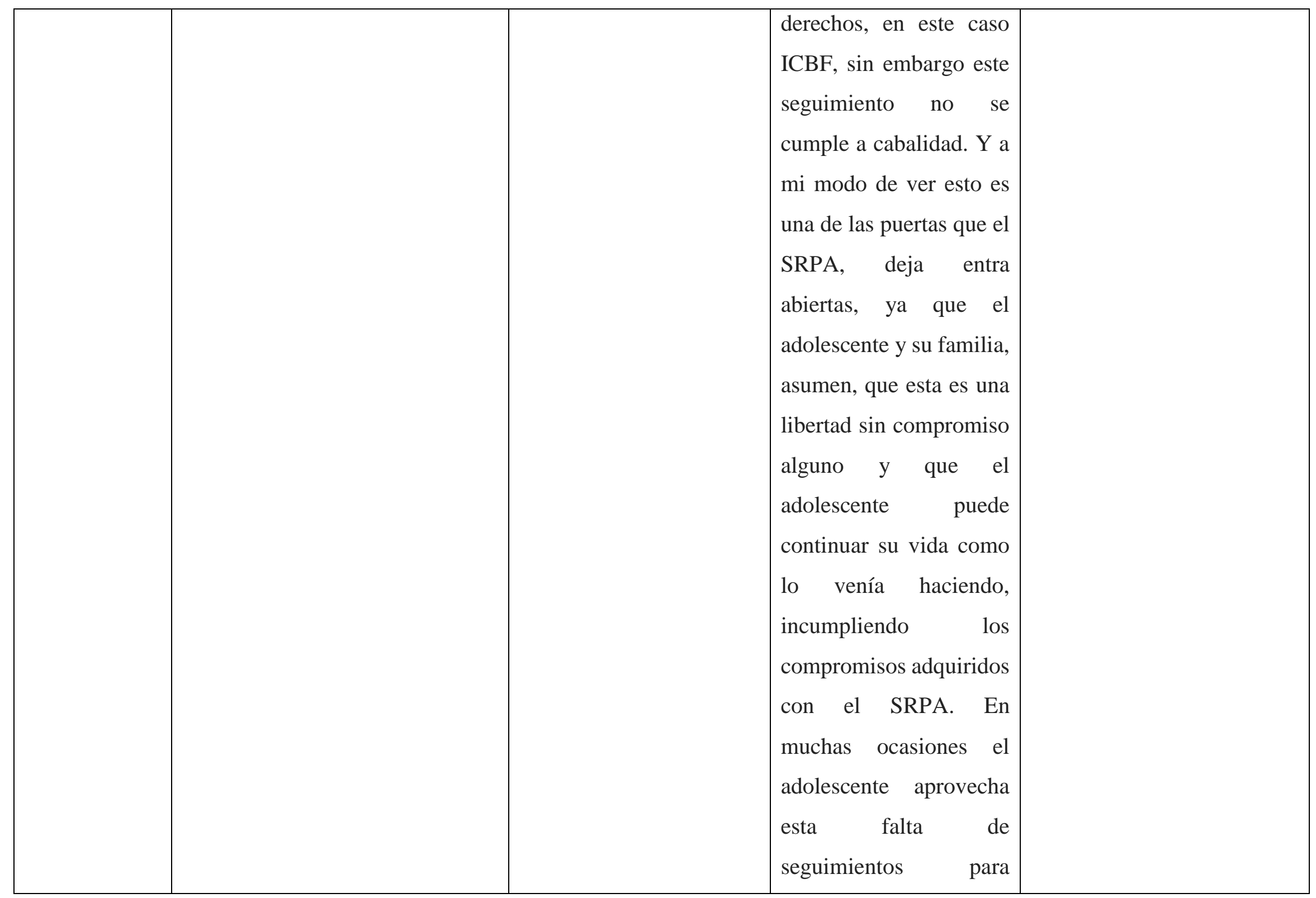




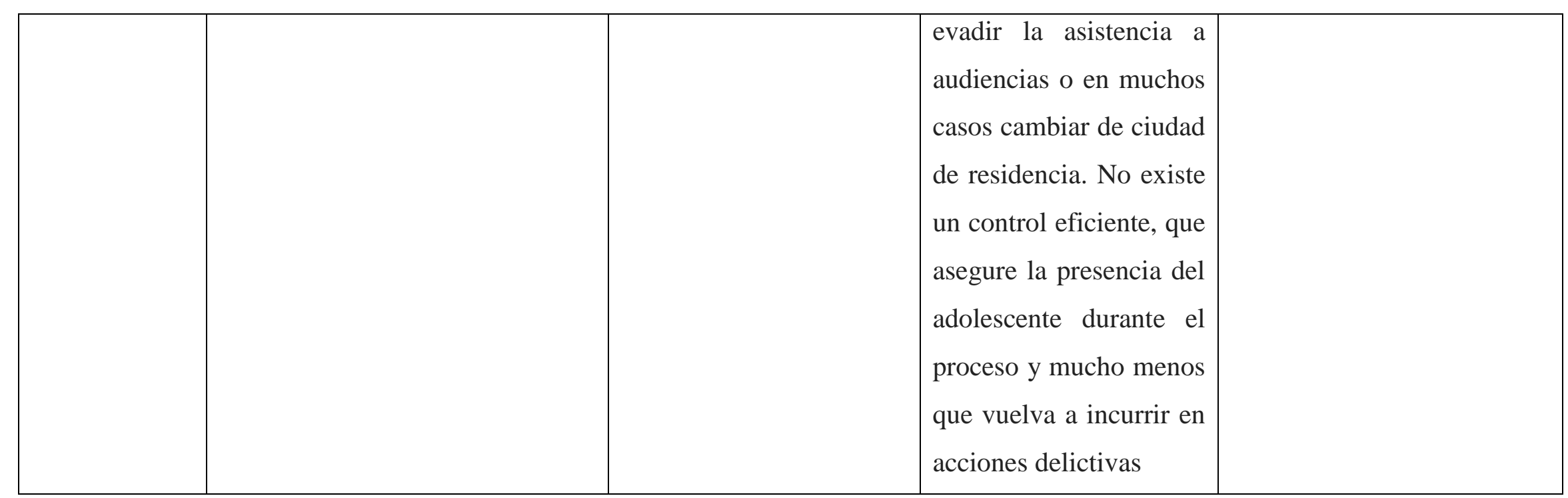


Matriz Garantías de derechos en el Sistema de Responsabilidad Penal para Adolescente

\begin{tabular}{|c|c|c|}
\hline Actores & Estado en la restauración de derechos en el SRPA & $\begin{array}{l}\text { Seguimiento y evaluación de las garantías de derechos en el } \\
\qquad \text { SRPA }\end{array}$ \\
\hline 1 & $\begin{array}{l}\text { E: ¿Cree Ud. que el estado colombiano está respondiendo a } \\
\text { las necesidades del país, en términos de justicia penal para } \\
\text { adolescentes? } \\
\text { R/A: Si, Actualmente se realiza un comité interinstitucional a } \\
\text { fin de corregir las pocas falencias que existen con respecto al } \\
\text { tema. De ofrecer además una buena oferta a los jóvenes que } \\
\text { tienen investigaciones pendientes y que se encuentran } \\
\text { cumpliendo medidas, ya que tienen derecho a la } \\
\text { rehabilitación y a la resocialización mediante planes y } \\
\text { programas que sean garantizados por el estado y que deben } \\
\text { ser implementados por las instituciones que integran el } \\
\text { sistema. } \\
\text { E: ¿Considera que la ubicación en medio familiar, es una } \\
\text { medida de restablecimiento de derechos adecuada? } \\
\text { R/T. Sí puesto que la familia hace parte de la rehabilitación } \\
\text { del joven y solo con ellos se hace el restablecimiento de } \\
\text { derechos de los jóvenes. De igual forma es importante el }\end{array}$ & $\begin{array}{l}\text { E: ¿Cree Ud. que el estado colombiano está respondiendo a las } \\
\text { necesidades del país, en términos de justicia penal para } \\
\text { adolescentes? } \\
\text { R/A: } \mathrm{Si} \text {, Actualmente se realiza un comité interinstitucional a } \\
\text { fin de corregir las pocas falencias que existen con respecto al } \\
\text { tema. }\end{array}$ \\
\hline
\end{tabular}


acompañamiento de la misma durante todo el proceso porque

es allí en el medio en el que el joven se desenvuelve y son

ellos los responsables de su crianza y de su evolución dentro del medio.

E: ¿Cuáles Considera son las causas más relevantes de la reincidencia en la comisión de delitos?

R/A. La educación, Falta de apoyo de la familia, la falta de oportunidades dentro de la sociedad, regresar al mismo grupo o ambiente social de barrios, grupo o pandilla. 
E: ¿Cree Ud. que el estado colombiano está respondiendo a las necesidades del país, en términos de justicia penal para adolescentes?

R/A. El principio y fin último del sistema de responsabilidad penal para adolescentes es pedagógico, preventivo y restaurativo. Sin embargo, si pensamos en los datos estadísticos de incursión de adolescentes al área penal, por motivos de comisión de delitos, podemos considerar que esto no se está cumpliendo a cabalidad. E: ¿La familia asume su rol con suficiente responsabilidad dentro del proceso pedagógico del adolescente?

R/A. Los adolescentes que ingresan al SRPA, proceden de diferentes tipos de familia, en general son familias monoparentales por línea materna, con un subsistema fraterno de varios hijos. En condiciones económicas muy precarias, con niveles educativos muy bajos, con muchas necesidades mínimas no satisfechas. De tal forma que cuando un adolescente ingresa al SRPA, la familia "prefiere" que este quede con medida de privación de libertad, considerando que de esta forma aprenderá la lección y es una forma de liberarse del problema.
E: ¿Qué opina sobre las medidas de protección para adolescentes?

R/A. Las medidas son más restrictivas que restablecedoras o restaurativas.

Una verdadera medida de protección debería estar plagada de elementos y componentes integrales, como trata de establecerlo la norma. Sin embargo, solo se brindan garantías a medias. Debido a que el estado no tiene la capacidad para adelantar acciones eficaces en temas de oportunidades educativas o laborales reales y coherentes a la realidad. Si a un adolescente se otorga libertad asistida, el estado no se encarga de su verdadera reinserción social, consistente en acciones válidas educativas, lúdicas, laborales, familiares, económicas que le permitan desviarse del camino delictivo. De esta forma el adolescente continuó una vida de incursión en hurtos, consumo de spa, sumándose a pares inadecuados que lo conducen a continuar delinquiendo.

E: ¿Qué acciones se toman con la familia?

R/A. Ninguna. Las medidas de amonestación no son funcionales. La familia recibe al adolescente a través del mecanismo de reintegro al medio familiar y no ejercen el control y la supervisión estipulada por el Defensor de Familia 


\section{E: ¿Cómo se involucra la familia en el proceso de los y lo estipulado en la medida de libertad otorgada por la} adolescentes? autoridad competente.

R/A. En realidad, la vinculación de la familia es mínima, esta no responde a los requerimientos de las autoridades y en la mayoría de los casos asume una posición periférica, sin involucrarse directamente en el proceso. Considera que el estado debe asumir el proceso sin participación de estos.
E: ¿Cuáles son los problemas más recurrentes de estos adolescentes? y ¿Qué hacen para tratarlos?

R/A. El principal problema es la reincidencia y el otro problema es la evasión del medio familiar y/o de las instituciones donde es ubicado. 
E: ¿Considera que la ubicación en medio familiar, es una medida de restablecimiento de derechos adecuada? R/A. Bueno la verdad que, en algunos casos, puede que resulte como en otros no resulta en lo absoluto que esta medida brinde las garantías necesarias en que el Adolescente no recaiga de inmediato en volver a la comisión de delitos en su comunidad y con más fuerza y decisión para su comisión. Aquí la Familia como garante del principio de corresponsabilidad debe aportar su efectividad en el control del adolescente que se le ha dado este tipo de ubicación familiar.

E: ¿Con qué frecuencia los adolescentes reinciden en la comisión de delitos?

R/A. Tal como lo anoté arriba son muchas las posibilidades de su reincidencia por cuanto que no se realiza una verdadera prevención y garantía a la no repetición de sus conductas delictivas.

E: ¿Cuáles Considera son las causas más relevantes de la reincidencia en la comisión de delitos?

R/A. La educación, Falta de apoyo de la familia, la falta de oportunidades dentro de la sociedad, que le garantizan nuevamente en reincidir regresando al mismo grupo o
E: ¿Cree Ud. que el estado colombiano está respondiendo a las necesidades del país, en términos de justicia penal para adolescentes?

R/A. Por medio de la Ley 1098 de 2006, se ha tratado de establecer una solución que mediante lo pedagógico, nos han llevado a replantear muchas de las sanciones que hoy en día están establecidas para los Adolescentes, las cuales cada vez se están haciendo más corta frente al proceso de acompañamiento de los jóvenes que las hacen insuficiente, en su efectividad, por cuanto que los Adolescente conocen más ley lo cual hace que el nivel de evasión sea grande y vienen superando las medidas a la que son sometidos. Son insuficientes y muchas veces los traslados por privación de la libertad no se cumple por cuanto que se evaden, estos traslados no se cumplen por la carencia de espacios para ubicarlos, esto hace hacen que el sistema no opere como debe ser y para el cual está diseñado, se necesita un sistema más eficiente para cumplir con las sanciones y realizar el acompañamiento correspondiente y el procedimiento judicial ajustado fallado a la ley.

E: ¿Considera que las medidas de internamiento preventivo, dan resultados pedagógicos? 
ambiente social de barrios, grupos y pesadillas de las pandillas que se constituyen cada día en las formas organizadas de la delincuencia juvenil en nuestro país.
R/A. Esta clase de medidas deben ser revaluadas por el Sistema por cuanto que la pedagogía empleada en esos lugares no despierta la menor atracción y convencimiento como expectativa de vida al adolescente, se debe incentivar a través de nuevos métodos pedagógicos mucho más efectivos y productivos con los adolescentes como escuelas, universidades y programas que le brinden atracción a sus intereses re socializadores y que lo pongan en paz con su familia y comunidad.

E: ¿Una medida privativa de la libertad, da resultados que controlen la participación de los adolescentes en futuros delitos?

R/A. Esta Medida no responde a la prevención, ni garantiza en que el Adolescente puede nuevamente reincidir en la comisión de un nuevo delito o en la repetición del mismo. La experiencia indica que en su mayoría los adolescentes que entran y son sancionados vuelven con mucha más furia a la calle y caen nuevamente en el delito, pero con más audacia en la comisión del

mismo.

E: ¿Las sanciones en medio cerrado, son eficaces? R/A. No son eficaces, por el contrario, sirve como medio de protección al Adolescente para escudarse de sus adversarios o 
víctimas de sus despliegues criminales y al pasar el tiempo y considerar que hay olvido de sus adversarios y víctimas sale con confianza y nuevamente acomete la misma conducta criminal.

E: ¿El adolescente cumple el proceso pedagógico dentro del SRPA?

R/A. Generalmente no lo cumple por cuanto que no le es atractivo y no llena sus expectativas de vida.

E: ¿Considera que la ubicación en medio familiar, es una medida de restablecimiento de derechos adecuada?

R/A. La Familia como estamento indispensable, efectivo y responsable de la corresponsabilidad, viene fallando gravemente en realizar los correctivos necesarios a tiempo, constituyéndose esto en una gran falla y que amerita realizar un reestudio y actualizar o revisar esta responsabilidad que debe tener toda familia con relación al comportamiento de los Adolescente. Cada día se observa como la familia deja de lado la toma de decisión y participación en mecanismos práctico, seguros y en tiempo favorables a sus hijos e hijas y por el contrario lo dejan al Estado para que realice lo que deba realizar en la terminación de la crianza de sus hijos
E: ¿Cómo realizan acciones restaurativas con los adolescentes?

R/A. El ejercicio que se efectúa al cumplimiento de la normatividad vigente al momento de realizar una intervención con los Adolescente involucrados mediante su conducta en situación de Responsabilidad Penal el profesional debe agotar el cumplimiento de sus funciones como tal.

Cuando al adolescente, es merecedor de una sanción amonestatoria al mismo tiempo la misma se le impone a su familia responsable, a quienes se le hace garante de vigilar su accionar con la finalidad que aquel no vuelva a incurrir en el mismo comportamiento.

Otro tipo de sanción es la libertad asistida con servicio social comunitario. 
$\mathrm{Al}$ adolescente se le hace un seguimiento cada seis meses, o se actualiza información básica en caso de tener audiencias en el juzgado.

Son muchos de los casos en los cuales se pierde el contacto con el Adolescente y el de sus familiares, quienes por la situación del caso o de la conducta desplegada que chocó con la norma penal, tienen que huir de la comunidad o vecindad, para protegerse de sus víctimas o adversarios.

E: ¿Considera que la ubicación en medio familiar, es una medida de restablecimiento de derechos adecuada? R/A. No es adecuada por la falta de compromiso necesario y contundente por parte de la familia al momento de recibir al adolescente de nuevo en su seno familiar en la medida en la que la familia no represente su verdadero papel como apoyo necesario a la recuperación de este adolescente en un buen desenvolvimiento de la convivencia en su comunidad no podríamos decir que la familia es garante para ellos, se hace necesario presentar un reestudio en el cual se logre compromisos efectivos del núcleo familiar, en su papel como representante de uno de los estamentos de la corresponsabilidad.

¿El adolescente cumple el proceso pedagógico dentro del
E: ¿Cree Ud. que el estado colombiano está respondiendo a las necesidades del país, en términos de justicia penal para adolescentes?

R/A. Frente a la pregunta es importante tener en cuenta que atreves de la Ley 1098 de 2006, se realizaron esfuerzos bastante grande, para reformular las nuevas sanciones establecidas, a través de un carácter pedagógico y restaurativo, sin embargo la dinámica social, nos han llevado a replantear muchas de las sanciones que hoy en día están establecida de carácter pedagógico y judicial para los Adolescentes, las cuales cada vez se están haciendo más corta frente al proceso de acompañamiento de los jóvenes que las hacen insuficiente, en su efectividad, por cuanto que los Adolescente conocen más ley, con el fin de evitar que les sean 


\section{SRPA?}

R/A. Generalmente no lo cumple por cuanto que no le es atractivo y no llena sus expectativas de vida. E: ¿Con qué frecuencia los adolescentes reinciden en la comisión

de
; lo cual hace que el nivel de evasión sea grande y vienen superando las medidas a la que son sometidos. Son insuficientes y muchas veces los traslados por privación de la libertad no se cumple por cuanto que se evaden, estos traslados no se cumplen por la carencia de espacios para ubicarlos, esto R/A. En su mayoría los Adolescente del que llegan al hace hacen que el sistema no opere como debe ser y para el S.R.P.A. recaen con frecuencia en reincidencia hasta cumplir su Mayoría de edad, quienes saben que la circunstancia procesal y legal cambia al cumplir los 18 años de edad. E: ¿Cuáles Considera son las causas más relevantes de la reincidencia en la comisión de delitos? R/A. La falta de garantías de una verdadera política pública que resuelva esta grave situación de desafíos constantes de los Adolescentes en contra de sus Corresponsales. cual está diseñado, se necesita un sistema más eficiente para cumplir con las sanciones y realizar el acompañamiento correspondiente y el procedimiento judicial ajustado fallado a la ley.

¿El adolescente cumple el proceso pedagógico dentro del SRPA?

R/A. Generalmente no lo cumple por cuanto que no le es atractivo y no llena sus expectativas de vida. E: ¿Considera que las medidas de internamiento preventivo, dan resultados pedagógicos?

R/A. Las medidas pedagógicas en los internamientos preventivos no constituyen ni llenan las expectativas en los adolescentes, es necesario implementar nuevas fórmulas que conquisten el lleno de ese cambio favorable de vida en los Adolescentes.

E: ¿Una medida privativa de la libertad, da resultados que 
controlen la participación de los adolescentes en futuros delitos?

R/A. En principio se vería como necesaria. Pero al tener en cuenta que unos de los dones más preciados es la Libertad y sobre todo en los jóvenes, cuando apenas empiezan a desplegar en sus vidas. Pensamos que no es lo más apropiado para ellos. Esta Medida no responde a la prevención, ni garantiza en que el Adolescente no vuelva a incurrir en conductas delictivas.

E: ¿Cree Ud. que el estado colombiano está respondiendo a las necesidades del país, en términos de justicia penal para adolescentes?

R/T. Al realizar un análisis, que la estructura de la Responsabilidad Penal para Adolescentes tiene como finalidad lo de pedagógico, preventivo y restaurativo. Nos damos cuenta que desafortunadamente y probado por los datos que arroja 1 la comisión de delitos por estos jóvenes, tenemos que decir que no se cumple a su cabalidad los objetivos planteados y perseguidos por esta Ley. E: ¿La familia asume su rol con suficiente responsabilidad dentro del proceso pedagógico del adolescente? R/A. El Adolescente que ingresan al SRPA, proceden de diferentes tipos de familia, la grave situación económica y crecimiento en sus conductas.
E: ¿Qué opina sobre las medidas de protección para adolescentes?

R/A. Las medidas son más restrictivas que restablecedoras o restaurativas.

Una verdadera medida de protección debería ser más integral, tal como lo percibe el espíritu de la norma. Pero desafortunadamente, no se cumple con esto en su debida forma. Por cuanto que existen verdaderas fallas en el cumplimiento del Estado en el seguimiento al centímetro en el accionar conductual de estos jóvenes. Dando o permitiendo de esta manera una libertad al Adolescente de reencontrarse con su problemática delictiva, quien con sus pares negativos en forma conjunta y organizada enfrentan a la norma con mucho 
social de la cual son víctimas estos jóvenes y su familia constituyen un cañón de lanza que asegura su situación de enfrentamiento a la norma penal en virtud de sus problemáticas conductas. E: ¿Cómo se involucra la familia en el proceso de los adolescentes?

R/A. En verdad es muy crítica la vinculación de la familia, cada día este fenómeno social de los Adolescentes que ingresan al Sistema de Responsabilidad Penal, se detecta la falta de una orientación desde su adentro familiar, la cual al no contar con su involucración directamente en el proceso no garantiza una efectividad en la recuperación social de convivencia del Adolescente. E: ¿Qué acciones se toman con la familia? R/A. Totalmente es nula, por cuanto que las medidas de amonestación no funcionan. La familia recibe al adolescente a través del mecanismo de reintegro al medio familiar y no ejercen el control y la supervisión estipulada por el Defensor de Familia y lo estipulado en la medida de libertad otorgada por la autoridad competente. E: ¿Qué aportes considera pueden hacerse desde el rol de la Psicología para que un adolescente no reincida en la comisión 
R/A. Realizar mucho más efusos y responsabilidades, implementando la pedagogía reeducativa, para lo cual se requiere serias disposiciones y disponibilidad de tiempo, sin embargo, la alta cantidad de procesos no lo permiten. Se requiere ampliación de funcionarios en las instituciones de protección y ampliación de planta de personal e las entidades estatales, que permita brindar una atención más eficaz y pertinente.

E: ¿Cree Ud. que el estado colombiano está respondiendo a las necesidades del país, en términos de justicia penal para adolescentes?

R/A. El sistema judicial Colombiano, está respondiendo en 7 términos legales, toda vez que asume la norma, como un entramado judicial restaurativo. Desde lo pedagógico y diferencial. Sin embargo, se requiere mayor atención en el tema de restablecimiento de derechos, toda vez que los adolescentes cuando no son sancionados, regresan a sus familias, sin que las autoridades competentes ejerzan una
E: ¿Qué opina sobre las medidas de protección para adolescentes?

R/A. Considero que se aplican muchas medidas restrictivas, dejando a un lado el verdadero sentido, restaurativo, pedagógico y diferencial. Pero estas medidas restrictivas se aplican como última ration, como última opción, como respuesta a las fallas del mismo SARPA, ya que el juez otorga libertades por delitos menores o cuando el adolescente ha ingresado por primera vez al sistema. Sin embargo, muchas veces se otorga libertad varias veces, tras la reincidencia del 
verdadera vigilancia en el cum0plimiento de la medida de libertad

asistida.

E: ¿La familia asume su rol con suficiente responsabilidad dentro del proceso pedagógico del adolescente? R/A. Nos damos cuenta que desafortunadamente y probado por los datos que arroja 1 la comisión de delitos por estos jóvenes, tenemos que decir que A la familia le hace falta mayor compromiso. Involucrarse más en el proceso de restablecimiento de derechos y el proceso restaurativo. En la mayoría de los casos los padres se niegan a asumir su responsabilidad dentro del proceso o prefieren mantenerse aislados. En numerosas ocasiones solicitan a las autoridades que el adolescente sea privado de la libertad. Argumentando que su hijo "se les ha salido de las manos". En otros casos, cuando se les otorga libertad, la familia solicita al ICBF, representado en el Defensor de Familia, para que el adolescente sea ubicado en medio institucional y se niegan a asumir los cuidados del adolescente. Rechazan la medida de reintegro al medio familiar, o simplemente no asisten al llamado del Defensor de Familia para hacerse cargo del adolescente. adolescente. Y es allí donde radica principalmente la falla del sistema penal de adolescentes, porque al no existir un verdadero proceso pedagógico, que sea productivo para la resocialización del adolescente, este vuelve a incurrir en la comisión de delitos vuelve a ingresar al sistema. De esta forma la justicia se torna restrictiva, porque se incrementan las medidas de internamiento preventivo y de privación de libertad. 


\section{Percepcion profesional y de Autoridades en el proceso S.R.P.A}

\section{Análisis y discusión}

En éste capítulo se presenta el análisis y la discusión de resultados a partir del análisis categorial realizado. De manera esquematica se organizan los resultados a partir del mapa siguientes:

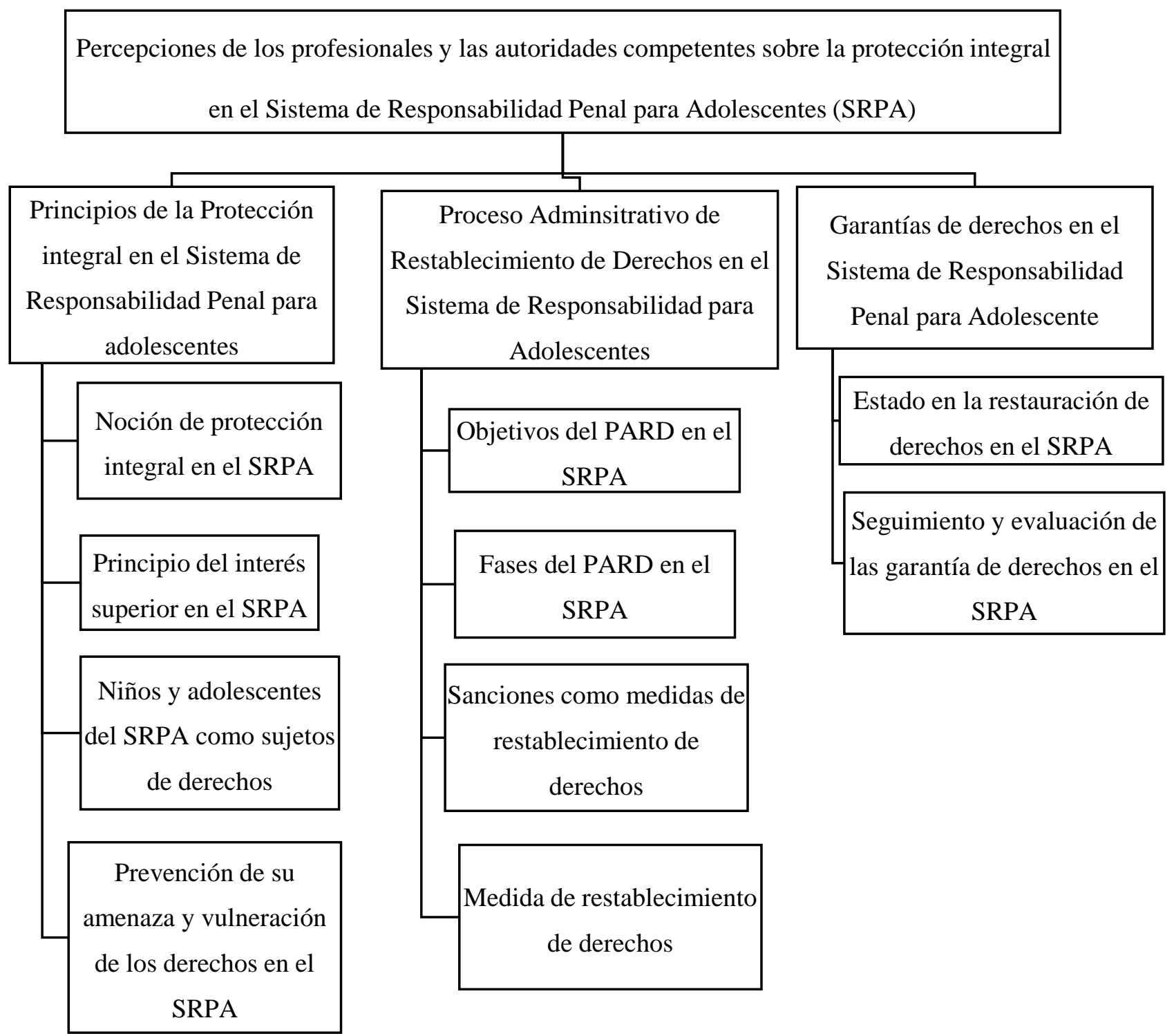

Figura 2. Mapa de análisis de resultados 


\section{Principios de la Protección integral en el Sistema de Responsabilidad Penal para}

\section{adolescentes}

En esta categoría se encontraron resultados sobre la Noción de protección integral en el SRPA, Principio de interés superior en SRPS, Niños y adolescentes como sujetos de derechos y prevención de su amenaza y vulneración de los derechos en el SRPA.

En cuanto a la Noción de protección integral en el SRPA, esté es implícita en los 7 participantes, se refieren más bien a elementos y características que integran la compresión.

Algunos de los elementos que más resaltan los participantes son los procesos pedagógicos, preventivos y restaurativos como se evidencia en las siguientes citas: “Al realizar un análisis, que la estructura de la Responsabilidad Penal para Adolescentes tiene como finalidad lo de pedagógico, preventivo y restaurativo” (Participantes 6), “...por medio de la Ley 1098 de 2006, se ha tratado de establecer una solución que mediante lo pedagógico, nos han llevado a replantear muchas de las sanciones que hoy en día están establecidas para los Adolescentes (Participante 5) y “El sistema judicial Colombiano, está respondiendo en términos legales, toda vez que asume la norma, como un entramado judicial restaurativo, desde lo pedagógico y diferencial” (Participante 7). Estos son componentes fundamentales en la protección porque dan cuenta de la integralidad que la debe caracterizar como lo plantea la Ley 1098 de 2006. Por ejemplo, en el caso español los procesos pedagógicos son fundaméntales para evitar la reincidencia (Ortega-Campos, 2014 y Colás, 2015).

Por otra parte, algunos participantes relacionan la protección con el seguimiento institucional: "Actualmente se realiza un comité interinstitucional a fin de corregir las pocas falencias que existen con respecto al tema" (Participante 1). En este caso se refiere a la importancia del comité interinstitucional como elemento para mejorar el proceso, pues éste favorece los procesos de mejora de la ejecución de la norma. En toda la información suministrada por los 
participantes se trasluce, que el adolescente es sujeto de derechos, “...se busca que el joven que ha infringido la ley penal sea responsable de sus actos y que corrijan sus errores con las personas que los han cometido cambiando su manera de pensar y de actuar.” (Participante 1), “...para prevención de la delincuencia juvenil, debe trabajarse dese la primera infancia, haciendo inversión social en educación, en fortalecimiento de programas productivos familiares, que garanticen el sostenimiento de todos los miembros de la familia..." (Profesional 2), 2...pero al tener en cuenta que unos de los dones más preciados es la Libertad y sobre todo en los jóvenes, cuando apenas empiezan a desplegar en sus vidas..." (Profesional 4). La convención internacional de derechos de los niños establece criterios sobre la administración de justicia para los menores de edad, introduciendo un nuevo paradigma de justicia juvenil diferenciado de los adultos, pero reconociendo la responsabilidad penal que les asiste como sujetos de derechos. Esto significa que bajo ninguna circunstancia, los derechos de los niños, niñas ya adolescentes pueden ser menoscabados, ni siquiera por el hecho de haber infringido la norma penal.

Finalmente, algunos de los participantes relacionan la protección con la garantía de los derechos: "La cual está encaminada a ofrecer una garantía en favor de estos jóvenes" (participante 4), lo cual es preponderante, porque colocan en cabeza del estado, la responsabilidad de garantizar los derechos de estos adolescentes, como en buena hora lo establece la ley 1098 de 2006: “

Proceso Administrativo de Restablecimiento de Derechos en el Sistema de Responsabilidad para Adolescentes

En esta categoría se encontraron resultados sobre los objetivos y sanciones que más se aplican en el SRPA, configurando que el objetivo primordial es la protección integral y el fin pedagógico, específico y diferenciado. Los entrevistados coincidieron en afirmar que “... Los 
adolescentes, tienen derecho a la rehabilitación y a la resocialización mediante planes y programas que sean garantizados por el estado y que deben ser implementados por la instituciones que integra el sistema” (participante 1), “El principio y fin último del sistema de responsabilidad penal para adolescentes es pedagógico, preventivo y restaurativo” (participante 2), “...a través de la Ley 1098 de 2006, se realizaron esfuerzos bastante grande, para reformular las nuevas sanciones establecidas, a través de un carácter pedagógico y restaurativo” (participante 3), “ ...que se encuentran cumpliendo medidas, ya que tienen derecho a su rehabilitación y a la resocialización mediante planes y programas que sean garantizados por el estado y que deben ser implementados por la institución que integra el sistema ...” (participante 4), “...por medio de la Ley 1098 de 2006, se ha tratado de establecer una solución que mediante lo pedagógico, nos han llevado a replantear muchas de las sanciones que hoy en día están establecidas para los Adolescentes..." (participante 5), “... al realizar un análisis, que la estructura de la Responsabilidad Penal para Adolescentes tiene como finalidad lo de pedagógico, preventivo y restaurativo. Se considera que desafortunadamente y probado por los datos que arroja la comisión de delitos por estos jóvenes, tenemos que decir que no se cumple a su cabalidad los objetivos planteados y perseguidos por esta Ley...” (participante 6), “...el sistema judicial Colombiano, está respondiendo en términos legales, toda vez que asume la norma, como un entramado judicial restaurativo. Desde lo pedagógico y diferencial. Sin embargo, se requiere mayor atención en el tema de restablecimiento de derechos, toda vez que los adolescentes cuando no son sancionados, regresan a sus familias, sin que las autoridades competentes ejerzan una verdadera vigilancia en el cumplimiento de la medida de libertad asistida...".

De acuerdo a la investigación realizada sobre la percepción de los funcionarios, que integran el SRPA, es posible detectar que estos asocian el principio pedagógico, específico y 
diferenciado, con el tipo de sanción. Es así como consideran que: “... no se trata de imponer castigos con la medida en lo que tiene que ver con el sistema, sino de presentar su falla desde otra perspectiva y que mire otra forma de actuar y pensar...” (participante 1), “... el adolescente, se sanciona en primera instancia con una amonestacion, la cual impica un compromiso por parte de la familia y del mismo adolescente...” (participante2), “... se debe incentivar a través de nuevos métodos pedagógicos mucho más efectivos y productivos con los adolescentes como escuelas, universidades y programas...”(participante 3), “ ... en verdad cuando el Adolescente es una persona curtida en el crimen y es repetitivo su actuar nos encontramos que dicha medida no corresponde al fin deseado la rehabilitación completa en el Adolescente y es cuando no ponemos a pensar que hay que revisar y actualizar estos modelos pedagógicos impartidos en favor de estos Adolescente cuya finalidad es la de lograr su verdadera restauración en el restablecimiento de sus Derechos ...” (participante 4), “ ... la Amonestación, en la cual la autoridad judicial reconviene al adolescente y de paso a los familiares sobre las consecuencias del hecho en la cual la autoridad le llama la atención y así mismo deberán brindar las garantías necesarias para asegurar un mejor comportamiento de este adolescente en su entorno ...” (participante 5), “ ... cuando al adolescente, es merecedor de una sanción amonestatatoria al mismo tiempo la misma se le impone a su familia responsable, a quienes se le hace garante de vigilar su accionar con la finalidad que aquel no vuelva a incurrir en el mismo comportamiento ...” (participante 6), “.... considero que se aplican muchas medidas restrictivas, dejando a un lado el verdadero sentido, restaurativo, pedagógico y diferencial. Pero estas medidas restrictivas se aplican como ultima ration, como última opción, como respuesta a las fallas del mismo SRPA..." (participante 7). Todos los conceptos emitidos, permiten establecer que son componentes del PARD, (proceso administrativo de restablecimiento de derechos) si se tiene en cuenta que responden a las sanciones con un fin pedagógico como lo 
establece la ley 1098 de 2006 “ Así mismo, el artículo 140, establece que la finalidad del programa de responsabilidad penal es: [...] en materia de responsabilidad penal para adolescentes tanto el proceso como las medidas que se tomen son de carácter pedagógico, específico y diferenciado respecto del sistema de adultos, conforme a la protección integral el proceso deberá garantizar la justicia restaurativa, la verdad y la reparación del daño". De igual forma así lo establecen las políticas públicas en temas de restablecimiento de derechos en casos de adolescentes en conflicto con la ley penal "Conpes 3629 de 2009 establece que el Sistema de Responsabilidad Penal para Adolescentes desarrolla dos procesos; un proceso judicial y otro de restablecimiento de derechos".

\section{Garantías de derechos en el Sistema de Responsabilidad Penal para Adolescente}


En esta categoría, se obtuvieron resultados referentes a la garantía de derechos, en las medidas implementadas por el estado, en los casos de adolescentes que habiendo incurrido en la comisión de delitos, ingresan al SRPA. Ley establece y resalta la obligatoriedad de garantía de la justicia restaurativa. Se encontraron respuestas sobre la obligatoriedad del estado como garante de derechos. “.....ofrecer además una buena oferta a los jóvenes que tienen investigaciones pendientes y que se encuentran cumpliendo medidas, ya que tienen derecho a la rehabilitación y a la resocialización mediante planes y programas que sean garantizados por el estado y que deben ser implementados por la instituciones que integra el sistema.” (Participante 1), “...un adolescente debería recibir por parte del estado, un blindaje que no permitiera su reincidencia en la delincuencia...” (Participante 2), “...se realizaron esfuerzos bastante grande, para reformular las nuevas sanciones establecidas, a través de un carácter pedagógico y restaurativo, sin embargo la dinámica social, nos han llevado a replantear muchas de las sanciones..." (participante 3), “...realizar un verdadero reconocimiento al papel de la corresponsabilidad de la Familia, Sociedad y Estado, con los cuales bajo una adecuada decisión de Políticas Publicas se determine de manera pronta y efectiva una mejor determinación ” (participante 4), “... la falta de garantías de una verdadera política pública que resuelva esta grave situación de desafíos constantes de los Adolescentes...” (participante 5), “... implementando la pedagogía reeducativa, para lo cual se requiere serias disposiciones y disponibilidad de tiempo, sin embargo, la alta cantidad de procesos no lo permiten. Se requiere ampliación de funcionarios en las instituciones de protección y ampliación de planta de personal e las entidades estatales, que permita brindar una atención más eficaz y pertinente...” (Participante 6), “... el estado está dejando a las familias solas en el proceso de crianza de los niños y adolescentes..." (participante 7). Esta categoría de garantías de derechos en el SRPA, está contemplado en la ley 1098, cuando se refiere a promover un sistema de normas 
basadas en la justicia restaurativa, el restablecimiento de derechos y la garantía de los mismos, por parte de los organismos estatales. Como bien plantean Cruz y Cruz (2007)... realizar conductas tipificadas en la legislación penal, las cuales para el caso de los adolescentes no pueden llegarse aplicar desde la perspectiva de la pena, ya que el resultado del acto ilícito no puede justificarse como una conducta antijurídica, implicando que este sea sometido a un sistema de atención especial que garantice sus derechos.

\section{Conclusiones}

En el presente trabajo investigativo, se abordaron componentes desde lo pedagógico, lo preventivo y lo restaurativo, permitiendo a los participantes exponer y explicar su percepción referente a la aplicabilidad del Sistema de Responsabilidad Penal para adolescentes. Acorde a los planteamientos de los funcionarios y autoridades competentes, se evidencian acciones e intervenciones, estatales desde la garantía de derechos, que armonizan con los elementos de la normatividad existente, normas que muy poco se ajustan, a la realidad social, familiar y personal de adolescentes, que en su curso de vida han estado inmersos en un conglomerado de situaciones irregulares.

A la luz de la Ley 1098 de 2006, se instauran medidas especiales para el abordaje de la problemática de la delincuencia de adolescentes. Esta ley se acoge a las directrices internacionales en materia de infancia, como las leyes de Bejíng y las Directrices de Riad, e intenta principalmente, romper con el esquema tradicional de justicia restrictiva, para dar paso a la justicia restaurativa. 
Acorde con Ministerio de justicia (2013) la restauración se fija en el deterioro que la ofensa ocasionó en las relaciones humanas y en los vínculos que afectó y destruyó: "no se centra en el hecho delictivo sino en el conflicto y transformación positiva". Lo que quiere decir que interpreta el problema como un síntoma, como la punta del iceberg y entiende que es fundamental sanar la raíz de éste, que sería la familia o la comunidad. Por ello, el fin no solamente consiste en reparar el objeto, sino en reparar las relaciones, porque nada sacamos con reparar el objeto si no se reparan las relaciones. 24. (Sistema de Responsabilidad Penal para Adolescentes, hacia la Protección Integral y la Justicia Restaurativa).

Para lograr la adopción de la Justicia Restaurativa el Gobierno Nacional da pistas de los asuntos centrales a resolver denominándolos ejes problemáticos:

- Eje problemático 1. Los programas y servicios implementados enfrentan retos de cobertura, calidad y pertinencia, ya que la oferta institucional, Nacional y territorial, no ha sido diseñada e implementada para el cumplimiento de la sanción, a cabalidad. Existen algunas iniciativas locales y programas, sin embargo, la oferta aún es insuficiente y carece de sistemas de seguimiento y monitoreo que garanticen su efectivo cumplimiento.

- Eje problemático 2. Insuficiente recurso humano especializado tanto a nivel Nacional como territorial para operar en el SRPA, debilidad que se podría fortalecer con la vinculación de operadores externos, que centrarán su oferta en el desarrollo de programas restaurativos, ya que en los países en los que mejor operan estos programas, lo hacen en un ambiente distinto al judicial, en coordinación con él, atendiendo remisiones y brindando informes, pero proporcionando los tiempos, la privacidad y el acercamiento que no es posible desde las barras de atención corriente. 
- Eje problemático 3. Limitada articulación y coordinación sectorial, y territorial, de las entidades que hacen parte del SRPA y de éste con otros sistemas, garantes de los derechos de los adolescentes.

- Eje problemático 4. Escasa apropiación de las responsabilidades de las entidades territoriales en el SRPA y ejercicio efectivo del principio de corresponsabilidad. Lo anterior pone en evidencia la necesidad de aumentar la cantidad y calidad de programas restauradores, dentro de ellos los de servicio comunitario, los cuales requieren gestión y obviamente suplirían necesidades de asistencia que siempre tendrá un País en vía de desarrollo. Estos servicios de los transgresores pueden ser un importantísimo recurso para organizaciones gubernamentales y sin fines de lucro (Van Ness, 1986 Restorative Justice 2013). 25

De acuerdo a los datos suministrados por el Instituto Colombiano de Bienestar Familiar, y a el análisis de los planes de desarrollo, diseñados e implementados por las administraciones nacionales, regionales y locales, se puede concluir que la problemática de la delincuencia juvenil, aun no tiene un apropiado diseño, que busque reorientar hacia soluciones estructurales, desde que se dio inicio a la implementación del Sistema de Responsabilidad Penal para Adolescentes en el año 2007, hasta 2016. Lo cual es clara significación que los servicios de prevención instituidos por el estado han resultado escasos, o no han sido eficaces para contrarrestar el acceso de adolescentes a actividades delincuenciales.

En el estudio realizado por el ministerio de justicia en noviembre de 2015. (Sistema de Responsabilidad Penal para Adolescentes, hacia la Protección Integral y la Justicia Restaurativa), se denota que el gobierno desde el orden nacional, tienen claridad de las falencias en el Sistema de Responsabilidad Penal para adolescentes y pretenden hacer una construcción aproximada de políticas públicas, que terminan siendo un conjunto de acciones para intentar minimizar la 
problemática existente. Se quedan cortos al no abordar ni realizar intervenciones profundas, desde la óptica de la integralidad. (Sistema de Responsabilidad Penal para Adolescentes, hacia la Protección Integral y la Justicia Restaurativa, pag. 178.

Para lograr resultados efectivos se requiere construir programas estructurales intersectoriales desde la educación, la salud, la vivienda, la familia y la comunidad como contexto social. Es imprescindible intervenir desde la primera infancia, desde la familia, con articulaciones de programas de todos los sectores.

Las estrategias de intervención han estado diseñadas de una forma descontextualizada social, económica y políticamente. No permitiendo el acceso integral a los derechos fundamentales intrínsecos a los niños y adolescentes como sujetos prevalentes de derechos. Demuestra además que las medidas sancionatorias son ineficaces, teniendo en cuenta que las estadísticas arrojan, la alta reincidencia de adolescentes en la comisión de delitos. Además, es alto el índice de adolescentes que, habiendo sido aprehendidos e ingresados al Sistema de Responsabilidad penal, han sido reintegrados a su medio familiar, sin brindarle a la familia las herramientas sociales para corresponder en la reinserción de esos adolescentes. Muestra de ello es la reincidencia de estos en la comisión de delitos, aquellos adolescentes que son entregados a sus familias, bajo un compromiso de no volver a delinquir, lo cual es lo primero que incumplen y nuevamente caen en los registros policiales, para engrosar las filas de la delincuencia juvenil.

Esto deja en evidencia, que las políticas estatales, estructuradas para contrarrestar esta problemática, se limitan en última instancia a imposición de sanciones, que incluyen hasta una medida privativa de la libertad, las cuales, de acuerdo a los resultados de participación de adolescentes en actividades delincuenciales, continúan siendo carentes de contenido pedagógico integral, que permitan una real y funcional reinserción social. 
Es relevante el esfuerzo de entidades como el Instituto Colombiano de Bienestar Familiar, como entidad regente del cumplimiento y restablecimiento de derechos de los adolescentes en conflicto con la ley penal. Institución que establece los lineamientos de atención en este tema. Sin embargo, se requiere profundizar mucho más en el diseño y construcción de una política pública estatal estructurada que dé una respuesta ontológica a esta problemática social, como es la participación de adolescentes en actividades delincuenciales. Las acciones gubernamentales se han dirigido hacia la atención y al restablecimiento de derechos vulnerados, mas no se ha dedicado a la prevención y garantía de los mismos. De eso se trata un verdadero Sistema de Responsabilidad Penal para Adolescentes, de intervenir una situación problemática, de tal forma que minimicen o en el mejor de los casos neutralice las causas que la generan.

En Colombia, se requiere rediseñar las estrategias de tratamiento y atención a los adolescentes en conflicto con la ley penal, en la búsqueda de mecanismos preventivos que coloquen contención a la participación de estos en eventos delictivos. Esto puede lograrse desde una perspectiva de garantías integrales, que proporcionen desde la primera infancia la satisfacción cabal de sus derechos como sujetos de atención integral, de forma permanente y sostenible, que logren un verdadero impacto social en la comunidad; solo de esta forma se puede desestimular la participación de niños, niñas y adolescentes, en eventos delictivos.

Revisadas las normas existentes y la intervención estatal, en cabeza de los funcionarios y autoridades competentes que conforman el Sistema de Responsabilidad Penal para Adolescentes; se hace necesario, realizar estudios más profundos en la búsqueda de propuestas que respondan acertadamente, para lograr la prevención de la delincuencia juvenil, con un verdadero sentido de justicia social y restaurativa. Es fundamental articular con el sector academico, en la busqueda de investigaciones exhaustivas, que den soluciones estructurales y de esta forma crear escenarios 
sociales y familiares propicios que prevengan la participacion de adolescentes en situaciones delincuenciales. 
Referencias

Abric, J (2001) Prácticas sociales y representaciones. Ediciones Coyoacán S. A. de C. V. México Alarcón, P., Vinet E., y Salvo, S. (2005). Estilos de personalidad y desadaptación social durante la adolescencia. Psykhe, Vol.14 No 001. Santiago de Chile.

Alarcón, P., Vinet E., y Salvo, S. (2009). Características de personalidad de mujeres Adolescentes infractoras de ley: Un estudio Comparativo. Paideia, Vol.19 No 43, 143-152. Santiago de Chile.

Andrews, D.y Bonta, J. (1995). The Level of Service Inventory-Revised. Toronto. Multi-Health Systems.

Andrews, D.y Bonta, J. (2006). The Psychology of Criminal Conduct. Ciciadolescentesti: Anderson

Arboleda, C Baquero, M y Domínguez, M (2010) La inimputabilidad del menor en el sistema penal colombiano. Univ. Estud. Bogotá (Colombia) N 7: 157-174, enero-diciembre de 2010.

Arias, E. (1998). Pasajeros del silencio juventud cultura y voluntad del saber. Medellín: Editorial úrico.

Ballesteros, G. Ordoñez, L y Polo, H (2012). Adolescentes en Conflicto con la Ley. Sistema de Responsabilidad para Adolescentes. Observatorio del Bienestar de la Niñez. Boletín No. 1. Colombia. Editorial: Procesos Digitales Ltda.

Blanco. J y Varela. J (2011) Delincuencia juvenil, violencia y desafíos para los programas de intervención. Revista el Observador. Chile

Bartollas, C. (2000). JuvenileDelinquency, $5^{\mathrm{a}}$ ed. Allyn and Bacon, Needham Heights, MA. 
Bonta. D y Andrews. J. (2010) The psychology of criminal conduct. Lexis nexis group Quinta edición, New York.

Blascos, C. (2012). Descripción y análisis de los factores protectores de Adolescentes en la prevención del delito: El perfil del adolescente resistente y las competencias emocionales asociadas. Centro de estudios jurídicos y Catalunya.

Bravo, M. A. (2015). La responsabilidad penal para adolescentes en Colombia: Un problema de edad o de comprender la ilicitud. Revista Estr@do, 2(3), 1-12. Recuperado de http://venus.unab.edu.co/index.php/estrado/article/view/1504/1403

Cárdenas, D. (2009). Menor infractor y Justicia penal juvenil. (Tesis doctoral, Universidad Católica de Santa María, Arequipa, Perú). Recuperada de http://www.eumed.net/librosgratis/2011a/913/indice.htm

Carrasco, J. (2015). La historia de la Ley de Responsabilidad Penal de menores de edad en Chile: un ejercicio genealógico y una propuesta de análisis. Fractal : Revista de Psicología, 27(3), 272-280. Recuperado de http://dx.doi.org/10.1590/1984-0292/1652

Castillo (1992).Juventud. Reto y promesa. Loma, México DF

Código del menor. Ley 1098 de 2006. República de Colombia.

Colás, A. (2015). Hacia una humanización de la justicia penal: la mediación en la justicia juvenil española. Principios y ámbito aplicativo en la lo 5/2000, reguladora de la responsabilidad penal de los menores. Iuris Tantum Revista Boliviana de Derecho, (20), 142-167. Recuperado de http://www.scielo.org.bo/pdf/rbd/n20/n20_a07.pdf

Comité de Derechos del Niño (2007). Observación General No 10, "Los derechos del niño en la justicia de menores". 
Constitución política de Colombia, (1991)

Cote Menéndez Miguel Consejo Superior de la Judicatura, Sala Administrativa, Dimensión Psicológica y Pedagógica en el SRPA, 2010.

Cruz y Cruz, E (2007). El concepto de menores infractores. Revista del Posgrado en Derecho de la UNAM, Vol. 3, N. 5

Cuervo, K (2011): Menores en riesgo; Perfil y predicción de la reincidencia delictiva. (Tesis de doctorado inédita). Universitat Jaume I. Recuperado de http://www.tdx.cat/bitstream/handle/10803/48511/kcuervo.pdf?sequence=1

DANE. Censo Nacional. 2005

De la fuente. C. (2014); Proyecto Protección - Acciones para Preservar y Restituir el ejercicio Integral de los Derechos de la Niñez y la Familia. Instituto Colombiano de Bienestar Familiar.

Defez. C. (2006) Delincuencia Juvenil, Instituto universitario General Gutiérez Mellado. España

Erazo, M. I. (2016). Reflexiones sobre la política pública dirigida a jóvenes en conflicto con la ley penal, residentes en instituciones cerradas de Colombia. Revista Iberoamericana de Psicología: Ciencia y tecnología, 9(2), 85-94. Recuperado de http://revistas.iberoamericana.edu.co/index.php/ripsicologia/article/view/1050/924

Erikson, E. (1969). Infancia y sociedad. Buenos Aires: Paidós

Escobar, J. y Bonilla, F. (2011). Grupos Focales: Una guía conceptual y metodológica. Universidad del Bosque.

Feldman, P. (1989). Comportamiento Criminal: Un análisis psicológico. México: Fondo de Cultura Económica. 
Garrido, Stangeland y Redondo, 2006. Principios de Criminología. Valencia. Editorial Tirant lo Blanch.

Garrido, V., López, E., Silva, T., López, M. y Molina, P. 2006, El modelo de la competencia social de la ley de menores. Cómo predecir y evaluar para la intervención educativa. Valencia: Tirant "Criminología y Educación Social"

Graña,J. Garrido,V y Gonzáles,L (2008) Reincidencia Delictiva en Menores Infractores de la Comunidad de Madrid: Evaluación, Características Delictivas y Modelos de Predicción. Agencia para la reeducación y reinserción del menor infractor. Madrid, España.

Gómez, A. Bonilla, S (2011) Percepción del menor infractor de su dinámica familiar. ( Tesis para optar por el título de psicología) Caldas, Colombia. Tomado de: http://repository.lasallista.edu.co/dspace/bitstream/10567/657/1/PERCEPCION_MENOR _INFRACTOR_DINÁMICA_FAMILIAR.pdf

Gómez, G. (2007). Delincuencia Juvenil, Reto para la Justicia. Recuperado de http://www.rgs.gov.co/noticias.shtml?x=15728

Hein, A (2000). Factores de riesgo y delincuencia juvenil: revisión de literatura nacional e internacional. Chile

Huertas, O y Morales, I. R. (2013). El sistema de responsabilidad penal para adolescentes: la expansión de la punibilidad en el neopunitivismo colombiano. Revista Guillermo de Ockham, 11(2), 68-78. Recuperado de http://www.redalyc.org/html/1053/105329737005/

Instituto Colombiano de Bienestar Familiar (1993). Autor o participe de una infracción a la ley penal. Colombia.

Jordán, M., Behar, O., Buitrago, S y Castillo, J. (2017). Estrategias educomunicativas para fortalecer procesos de Resocialización de un grupo de adolescentes infractores en Cali. 
Periodismos, medios y agendas, 22, 113-127. Recuperado de http://dx.doi.org/10.18046/recs.i22.2381

Langer, M y Lillo, R. (2014). Reforma a la justicia penal juvenil y adolescentes privados de libertad en Chile: Aportes empíricos para el debate. Política criminal, 9(18), 713-738. Recuperado de http://dx.doi.org/10.4067/S0718-33992014000200013

Lillo,J (2004 ) crecimiento y comportamiento en la adolescencia. Revista de la Asociación Española de Neuropsiquiatría.

Llanos, Á y Marrero, R. (2016). Aplicación de la mediación extrajudicial juvenil en la delincuencia adulta. Gestión y análisis de políticas públicas, (15), 1-14. Recuperado de http://www.redalyc.org/html/2815/281545812005/

López A, Sergio Andrés (2012). El pensamiento humanista; Cesare Beccaria y John Howard respecto de la realidad jurídico penal colombiana

López, L. (2014). Proceso de reflexividad en un contexto de privación de libertad de adolescentes mujeres. Psicología \& Sociedade; 26(3), 603-612. Recuperado de http://www.redalyc.org/html/3093/309332050009/

Lozano, F. Torres y Olivas, M (2010) Factores familiares que inciden en la conducta disruptiva y violenta de niños, Adolescentes .Subsecretaría de Prevención y Participación Ciudadana. Dirección General de Prevención del Delito y Participación Ciudadana. México

Maldonado, F. (2014). Estado y perspectivas de la reforma proyectada en Chile sobre el sistema de protección de menores de edad. Ius et Praxis, 20(2), 209-234. Recuperado de http://dx.doi.org/10.4067/S0718-00122014000200006

Martínez, J. A y Pozo, F. J. (2016). Perspectivas sociológicas, jurídicas y políticas de la justicia juvenil en Colombia. Revista Verba Iuris, 11(35), 107-119. 
Méndez, J. C. (2015). "De la protección constitucional y penal de los menores de edad en Colombia. Un estudio sobre el principio de oportunidad en la Ley 1098 de 2006: un instrumento inocuo [Trabajo de Grado]. . Recuperado de http://repository.ucatolica.edu.co/bitstream/10983/2663/1/Articulo\%20Final\%20Jenny\%2 0Carolina\%20Mendez.pdf

Mettifogo, D., Arévalo, C., Gómez, F., Montedónico, S y Silva, L. (2015). Factores transicionales y narrativas de cambio en jóvenes infractores de ley: Análisis de las narrativas de jóvenes condenados por la Ley de Responsabilidad Penal Adolescente. Psicoperspectivas, 14 (1), 77-88. Recuperado de http://www.scielo.cl/pdf/psicop/v14n1/art08.pdf

Mojica, C y Moreno, J. (2014). Adaptación en adolescentes infractores bajo sistema de responsabilidad penal. Revista Vanguardia Psicológica Clínica Teórica y Práctica, 5(1), 111. Recuperado de https://dialnet.unirioja.es/descarga/articulo/4897624.pdf

Mulde. E, Brand. E, Bullen. R y Van. J (2010) classification of risk factors in serious juvenile offenders and the relation between patterns of risk factors and recidivism. Journal Criminal Behaviour and Mental Health

Muñoz, M. (2000). Adolescencia y Agresividad. (Tesis doctoral, Universidad Complutense, Madrid). Recuperada de http://biblioteca.ucm.es/tesis/19972000/S/4/S4017401.pdf

Organización Mundial de la Salud (2000). La salud de los jóvenes: un desafío para la sociedad. Ginebra (OMS, serie de informes técnicos, $\mathrm{N}^{\circ}$ 731). Recuperada de http://whqlibdoc.who.int/trs/WHO_TRS_731_spa.pdf

OMS (2012). Organización mundial de la salud. Salud de la madre, el recién nacido, del niño y del adolescente. 
Ortega-Campos, E. G.-G.-A. (2014). Meta-análisis de la reincidencia criminal en menores: Estudio de la investigación española. Revista Mexicana de Psicología, 31(2), 111-123. Recuperado de http://www.redalyc.org/html/2430/243033031004/

Peña, M (2010) Conducta antisocial en Adolescentes: Factores de riesgo y de protección. Universidad Complutense de Madrid facultad de psicología. Departamento de Personalidad, evaluación y tratamientos psicológicos.

Ramírez, A y Arroyo, K. (2014). Características neuropsicológicas en adolescentes infractores de la ciudad de Sincelejo-Sucre. http://www.scielo.org.co/pdf/psico/v17n32/v17n32a13.pdf

Redacción Justicia (2012) Cada año, 600 menores son capturados en el país por asesinatos, El Tiempo. Recuperado de http://www.eltiempo.com/archivo/documento/CMS-12178221.

Redondo, S. (2008). Individuos, sociedades y oportunidades en la explicación y prevención del delito: Modelo del Triple Riesgo Delictivo (TRD). Revista Española de Investigación Criminológica Año 2008, Artículo 7, Número 6. ISSN: 1696-9219

Rincón, C. I (2012, 02, 5), “Nos quedó grande educar a nuestro hijos”, El Colombiano. Recuperado dehttp://www.elcolombiano.com/BancoConocimiento/N/nos_quedo_grande_educar_a_lo s_menores_infractores/nos_quedo_grande_educar_a_los_menores_infractores.asp

Rodríguez, F (2009) Violencia ejercida por menores y jóvenes, funcionamiento de la LORPM 5/2000 Anuario de Psicología Jurídica Vol. 19, 2009 - Págs. 15-25 Madrid, España.

Rodríguez, L. A. (2012). Análisis de la Justicia Restaurativa en Materia de Responsabilidad Penal para Adolescentes en Colombia. Anuario de Psicología Jurídica, 22, 25-35. Recuperado de http://www.redalyc.org/html/3150/315024813004/ 
Sanabria, A y Uribe, A (2009) Conductas antisociales y delictivas en Adolescentes infractores y no infractores. Pontificia Universidad Javeriana - Cali (Colombia).

Sanabria. A y Uribe. A (2010) problemáticas en jóvenes infractores y no infractores. Revista diversitas - perspectivas en psicología - Vol. 6, No 2, 2010. Colombia

Sánchez, P. V. (2016). Ordenes discursivos en torno a la reincidencia. Revista Diversitas, 12(2), 2559-273. Recuperado de http://dx.doi.org/10.15332/s1794-9998.2016.0002.07

Sandoval, J. A y Tirado, M. (2013). Fundamentos sociojurídicos en materia penal del adolescente infractor frente al fenómeno del reclutamiento forzado. IUSTA, 1, 38, 81-99. Recuperado de http://dx.doi.org/10.15332/s1900-0448.2013.0038.03

Sanz, A., Moreno, M. A y Pérez, R. L. (2015). Significaciones del proceso de integración social de jóvenes. Psicogente, 19(35), 110-127. Recuperado de http://doi.org/10.17081/psico.19.35.1212

Sección Educación (2013) En lo corrido del año van 18.599 Adolescentes en conflictos con la Ley. El Tiempo. Recuperado de http://www.eltiempo.com/archivo/documento/CMS-13062815. Sepúlveda, E (2011), Denuncian que existe sobre cupo en el CROMI. Vanguardia Liberal. Recuperado de http://www.vanguardia.com/santander/barrancabermeja/135770denuncian-que-existe-sobrecupo-en-el-cromi

Serrato, M y Correa, G (2009) Formulación de política pública para la infancia y la adolescencia en el distrito turístico y cultural de Cartagena de Indias. Cartagena. Versión 2.11. Recuperado $\quad$ de http://www.cartagena.gov.co/Concejo/Documentos/DocumentoInfancia.pdf

Taylor, S.J. Bogdan, R.-Introducción a los métodos cualitativos en investigación. La búsqueda de los significados. Ed. Paidós, España, 1992-Pág-100 -132 
Tendlarz, S. E. (2015). La delincuencia juvenil Desde la perspectiva psicoanalítica. Revista Ajayu, 13(2), 136-146. Recuperado de http://www.scielo.org.bo/pdf/rap/v13n2/v13n2a01.pdf

Trudel, M y Puentes, G (2000) The contemporary concepts of at risk children: theoretical models and approaches in the early years", Pan Canadian Education Research Agenda Symposium, Adolescence.

Vázquez, C. (2003). Delincuencia juvenil. Consideraciones penales y criminologías, Colex, Madrid.

Villaveces y Rendón, 2010. Sistema para la responsabilidad penal para la adolescencia. (Tesis pregrado, Universidad Autónoma de Colombia, Bogotá, Colombia).

Vega, H. (2015). Aspectos dogmáticos y políticos criminales de la estructura general del delito en el sistema penal colombiano. Justicia, 27, 42-72. Recuperado de http://dx.doi.org/10.17081/just.3.27.320

Vega,N (2009) La entrevista como fuente de información: orientaciones para su utilización" de Universidad Nacional del Litoral.

López, F. (2002). El análisis de contenido como método de investigación. Revista de educación, 4, 167-179. Obtenido de https://www.google.com.co/url?sa=t\&rct=j\&q=\&esrc=s\&source=web\&cd=4\&cad=rja\&u act=8\&ved=0ahUKEwjnhtKl6vDWAhUPfiYKHV_7BngQFgg_MAM\&url=http\%3A\%2 F\%2Fwww.uhu.es\%2Fpublicaciones\%2Fojs\%2Findex.php\%2Fxxi\%2Farticle\%2Fdownl oad\%2F610\%2F933\&usg=AOvVaw0eVjdEc5vOkOayFMv

\section{Normatividad}

Congreso de la República. Decreto 2737 de 1989. “Código del Menor”. En: Diario Oficial No 39.080 del 27 de noviembre de 1989.

Congreso de la República. Ley 1098 de 2006. "Por la cual se expide el Código de la Infancia y la Adolescencia”. En: Diario Oficial No 46.446 de 8 de noviembre de 2006. 
Congreso de la República. Ley 12 de 1991. "Por medio de la cual se aprueba la Convención sobre los Derechos del Niño adoptado por la Asamblea General de las Naciones Unidas el 20 de noviembre de 1989”. En: Diario Oficial No 39640 de enero 22 de 1991.

Congreso de la República. Ley 16 de 1972. "Por medio de la cual se aprueba la Convención Americana sobre Derechos Humanos "Pacto de San José de Costa Rica", firmado en san José, Costa Rica, el 22 de noviembre de 1969. 63 Congreso de la República. Ley 75 de 1968. "Por la cual se dictan normas sobre filiación y se crea el Instituto Colombiano de Bienestar Familiar”. En: Diario Oficial No 32.682 del 31 de diciembre de 1968.

Congreso de la República. Ley 83 de 1946. “Orgánica de la defensa del niño”. En: Diario Oficial № 26.363, de 24 de febrero de 1947. Congreso de la República. Ley 95 de 1936. "Código Penal”. En: Diario Oficial No 23.160, del 17 de abril de 1936.

\section{Jurisprudencia}

Corte Constitucional. Sentencia C-684 de 2009. M.P. Humberto Antonio Sierra Porto.

Corte Constitucional. Sentencia C-740 de 2008. M.P. Jaime Araujo Rentería.

Corte Constitucional. Sentencia C-203 de 2005. M.P. Manuel José Cepeda Espinosa. 